UNIVERSIDADE DE SÃO PAULO

INSTITUTO DE FÍSICA DE SÃO CARLOS

DEPARTAMENTO DE FÍSICA E INFORMĀTICA

Implementação Modular da Técnica

de Compressão e Desacompressāo

JPEG para Imagens.

JOÃO DE LUCCA FILHO

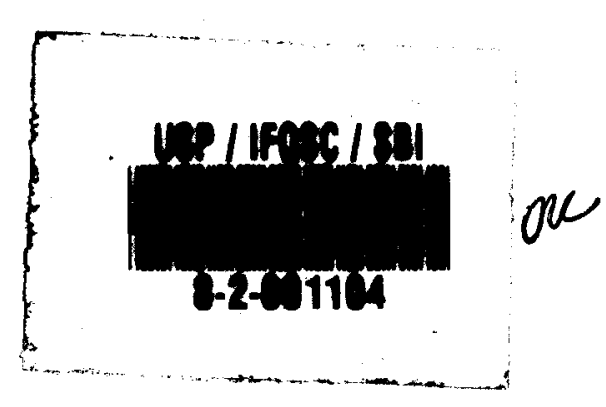

Dissertação apresentada ao Instituto de Física de São Carlos, Universidade de Sāo Paulo para a obtenção do títü 10 de Mestre em Ciências "Física A pl icada-opção Física Computacional.

Orientadora: Profa.Dra.Agma Juci Machado Traina

São Carlos - São Paulo

1994

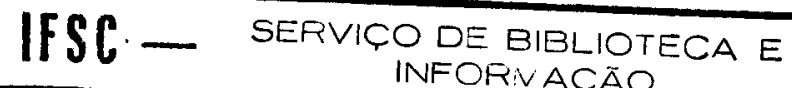




\section{IFSC Universidade de São Paulo}

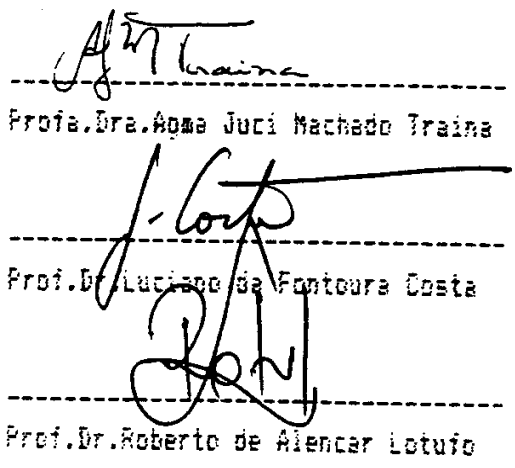




\begin{abstract}
This work presents a review of data compression and decompression techniques. Data compression is aimed at preserving the information while optimizing storage space. The decompression process recovers the original data to a state suitable for presentation or analysis.
\end{abstract}

This work discusses several compression techniques with emphasys on the data loss aspect. Data loss (lossy) is explored by some compression methods to enhance the compression rate, and lossy techniques may be used in applications such as the storage and transmission of images, allowing higher compression rates. In this case, the physical characteristics of the human eye, in addition to phsycological aspect are important factors in the choice of an appropiate technique.

This study was aimed at selecting a suitable compression/decompression tehnique for an imaging Tomographic System, developed for the Tomographic Magnetic Resonance system developed at the IFSC-USP. The choice has fallen on the one proposed by the Joint Photographic Expert Group JPEG. Some standardized compression methods were implemented in a platform independent environment. The availability of a compression engine coupled to such a system is important due to the high number of images thet can be generated in a tomographic session, and also due to the need of preserving many of them. 


\section{Resumo}

O presente trabalho traz uma revisão das técnicas de compressão de dados e a correspondente descompressão. A compressão tem por objetivo preservar as informações de modo que ocupem menos espaço em sistemas de armazenamento de massa de dados. A descompressão é caminho inverso, buscando recuperar os dados para que possam ser reconhecidos.

Neste sentido algumas técnicas são discutidas mostrando como o processo é realizado e em quais métodos encontra-se perda de dados. A perda de dados é uma das características que são exploradas por alguns métodos de compressão de dados principalmente quando trabalha-se com imagens. Características físico-visuais do sistema de visão humano quando da interpretação de imagem, constitui um aspecto importante na escolha do compressor de dados de imagem. Assim, pode-se alcançar uma elevada taxa de compressão para dados de imagem.

A técnica escolhida para tratar a compressão e descompressão de imagens foi a proposta pelo Joint Photographics Expert Group - JPEG, grupo formado pela união de interesses entre International Standard Organazation - ISO e CCITT com o objetivo de constituir uma norma padronizada para compressão de imagens coloridas ou tons de cinza. Assim, implementou-se um sistemas de compressão de dados utilizando alguns módulos do algoritmo proposto por JPEG, sendo implementado em máquinas de uso geral, com o objetivo de colocá-las a disposição do Sistema de Tomografia, desenvolvido pelo grupo de Ressonância Magnética - RM do IFSC, uma vez que em uma sessão de tomografia são geradas muitas imagens, pode-se encontrar dificuldade com a preservação das mesmas. 


\section{Dedicatória}

Dedico o presente o trabalho a pessoas muito importantes e por demais caras para mim:

a LIZETE de LOURDES PEREIRA de LUCCA - Minha Mãe in memoriam a RITA GOMES PEREIRA - Minha Avó Materna - in memoriam a IDA MAZzEI de LUCCA - Minha Avó Paterna - in memoriam a meus Irmãos PAULO ROBERTO, JOSÉ EDUARDO e REGINA MARIA a VTTOR CESAR TAKAI - Meu Afilhado - Little Vitor 


\section{Agradecimentos}

Agradeço em especial a Profa Dra Agma Juci Machado Traina pela oportunidade de realizar o presente trabalho sob sua orientação e pela paciência que devotou.

Agradeço ao Conselho Nacional de Desenvolvimento Científico e Tecnológico CNPq pelo apoio financeiro ao desenvolvimento do presente trabalho.

Agradeço ao CNPq e à Fundação de Amparo à Pesquisa do Estado de São Paulo FAPESP, quando do apoio durante minha formação, pelas bolsas de Iniciação Científica, durante o período de graduação em Engenharia Elétrica pela Escola de Engenharia de São Carlos.

Agradeço aos Instituto de Ciências Matemáticas de São Carlos, ICMSC, e ao Instituto de Física e Química de São Carlos - IFQSC, pela oportunidade oferecida em seus programas de monitoria, durante minha graduação.

Agradeço ao Amigo e Compadre Osvaldo Kotaro Takai pela paciência e dedicação que sempre dispensou nas horas boas e ruíns, durante transcorrer dos anos que compartilhamos, sem desconsiderar o enorme apoio à realização deste trabalho, que sem o qual, esta dissertação não teria o abrilhantamento que vejo após sua conclusão.

Agradeço carinhosamente e com muita saudades à Vânia Aparecida Rocha, que embora esteja distante, neste momento de contemplação para mim, transpôs fronteiras para colaborar e trazer vida a muito do que aqui foi exposto, com o envio de um documento definitivo que me levou à composição de grande parte deste trabalho.

Agradeço a Fred João Valente por artigos que contribuíram com este trabalho.

Agradeço a Rosemeire Aparecida da Silva de Lucca, ROSE, minha esposa, que soube encarar as horas que nos causaram muita tensão e preocupação durante o periodo de composição deste trabalho, carinhosamente - Obrigado!

Agradeço a Maria Aparecida Garcia, $C I D A$, que nunca permitiu que a "peteca" caísse me incentivando e apoiando sempre.

Agradeço a Moacir José Vaz de Souza, FORMIGA, que esteve sempre presente em momento bastante delicado, tanto em minha vida pessoal, bem como durante a finalização deste trabalho.

Agradeço aos amigos e padrinhos Moacir e Rita pelo carinho e forte calor dispensado à nossa amizade que transcende a esta década.

Agradeço aos meus pais que não mediram esforços em incentivar minha formação, às custas de suas próprias necessidades, e sempre colocando a de seus filhos como prioridade. Muito Obrigado, de coração. 
Agradeço a Wladerez pela atenção e por todas informações que levaram à conclusão deste trabalho, em sua forma final.

Agradeço a Mauren Lys pela atenção dispensada, não permitindo que o stress, comum ao final da fase de composição de uma Dissertação, aumentasse.

Agradeço Ali Faez Taha pelo apoio dispensado e confiança cedendo seu equipamento pessoal para composição final de minha dissertação.

Agradeço a Teobaldo Ribas por facilitar e liberar os recursos disponíveis do Laboratório de Informática da Universidade de Ribeirão Preto para impressão do presente trabalho.

Agradeço a Oswaldo Lázaro Mendes por substituir-me, permitindo a finalização deste trabalho.

Agradeço Paulo Francisco Sprovieri pelo apoio na revisão final deste trabalho.

Agradeço aos companheiros de Trabalho Mauro, João Luiz, Fernando Traina, Roseli, Seixas, Celso, pois nada como um dia após outro, para que tudo se encaixe.

Agradeço também as amigas, Adriana e Gizele, pelo apoio e preocupação. 


\section{Índice}

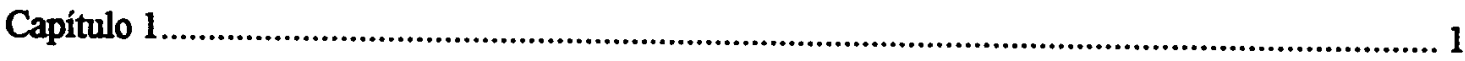

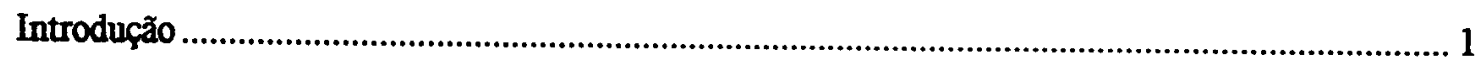

1.1. Consideraçð̃es Iniciais..................................................................................... 1

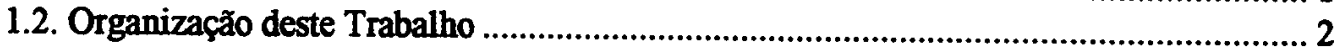

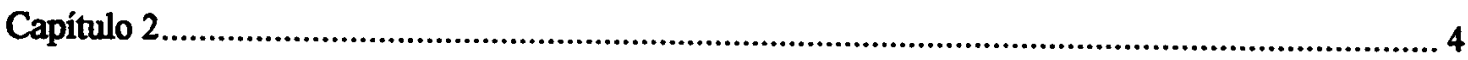

Conceitos sobre Compressão de Dados...................................................................................... 4

2.1. Consideraç̃es Iniciais ...................................................................................... 4

2.2. Introdução à Compressão/Descompressão (CoD) de Dados.......................................... 4

2.2.1. Compressão Lógica .................................................................................... 4

2.2.2. Compressão Física ………………............................................................ 6

2.2.3. Beneficios da compressão ........................................................................ 7

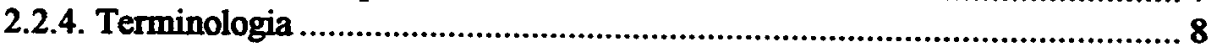

2.3. Técnicas de compressão de dados ........................................................................... 8

2.3.1. Compressão orientada a caractere............................................................... 9

2.3.1.1. Supressão de caracteres nulos .................................................. 9

2.3.1.2. Mapeamento de bits.................................................................. 10

2.3.1.3. Comprimento de fileira ................................................................ 12

2.3.1.4. Compactacão de meio Byte ......................................................... 13

2.3.1.5. Codificaçăo Diatônica.................................................................... 14

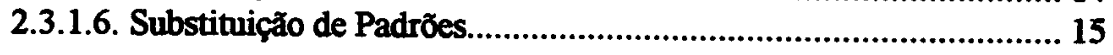

2.4. Outros Métodos de Compressão............................................................................... 15

2.4.1 Compressão por codificação estatística ....................................................... 16

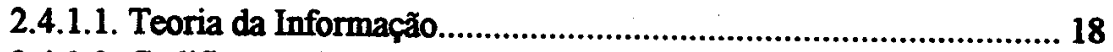

2.4.1.2. Codificação de Huffman ............................................................ 20

2.4.1.3. Codificação Shannon-Fano ........................................................ 23

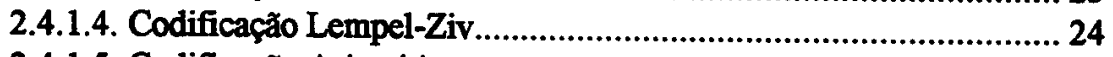

2.4.1.5. Codificação Aritmética ................................................................. 26

2.4.2. Compressão com perda ............................................................................ 27

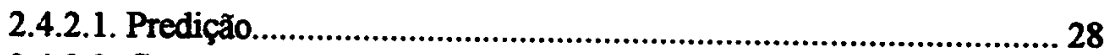

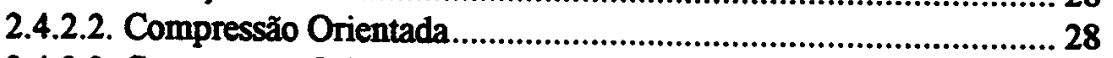

2.4.2.3. Compressão Orientada à Importância .......................................... 28

2.4.2.4. Codificação Hibrida ................................................................. 29

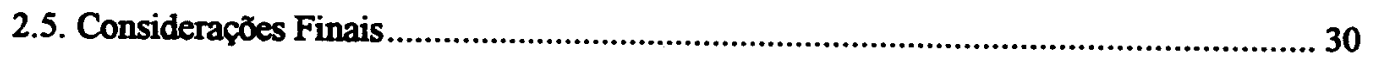


Capítulo 3

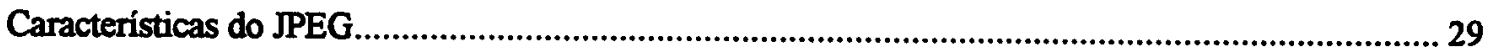

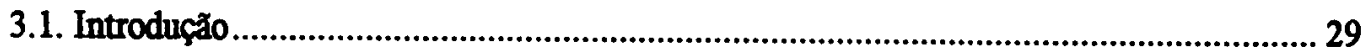

3.2. Elementos de uma codificação e reconstrução de imagens ........................................... 29

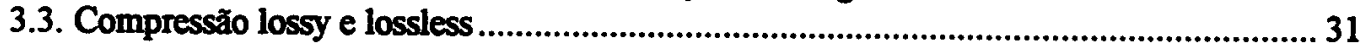

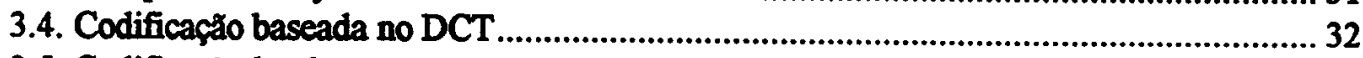

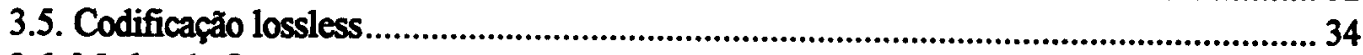

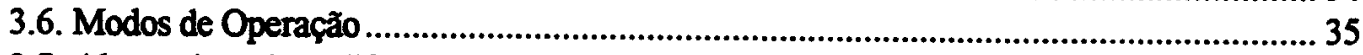

3.7. Alternativas de codificação de entropia.................................................................. 37

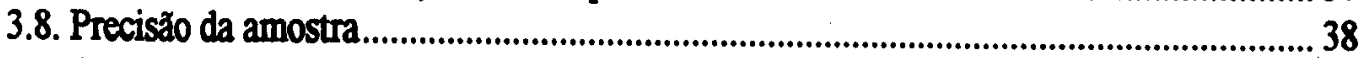

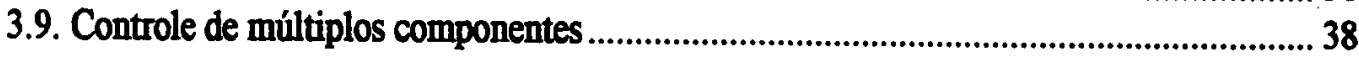

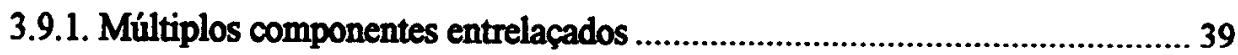

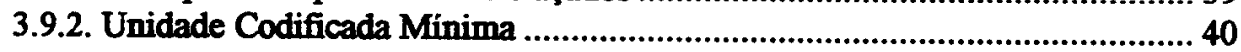

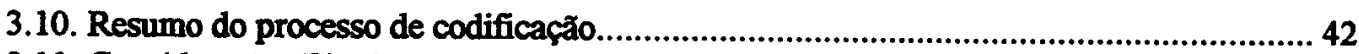

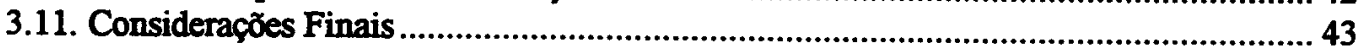

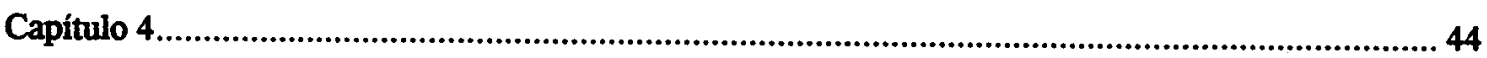

Módulos da Implementação baseado na Técnica JPEG............................................................... 44

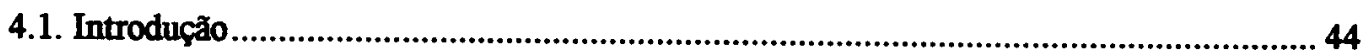

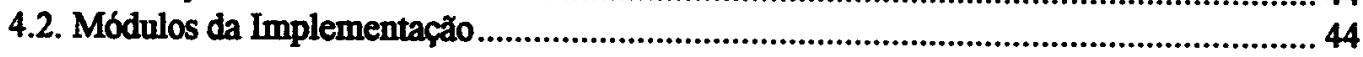

4.2.1. Transferência de dados da imagem fonte................................................. 45

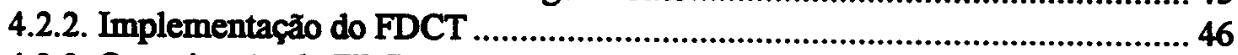

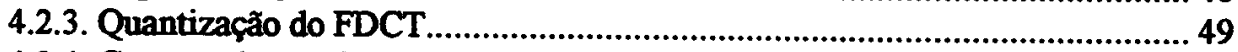

4.2.4. Geração da seqũência ZigZag............................................................ 50

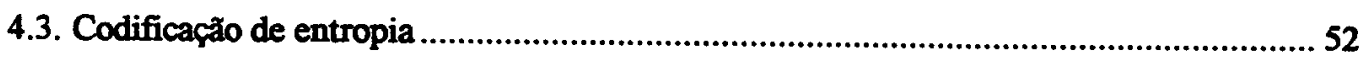

4.3.1. Codificação de entropia para coeficientes DC ............................................55

4.3.2. Codificaça de entropia para coeficientes AC ........................................... 55

4.3.3. Obtenção das tabelas de Huffiman ............................................................ 56

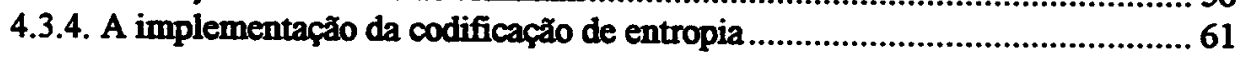

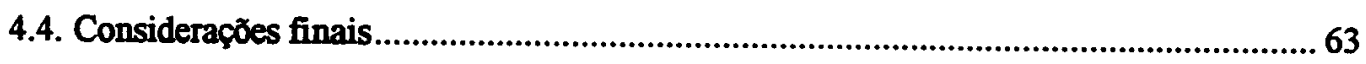

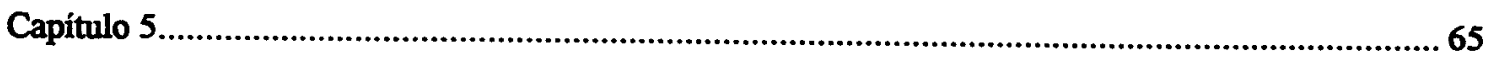

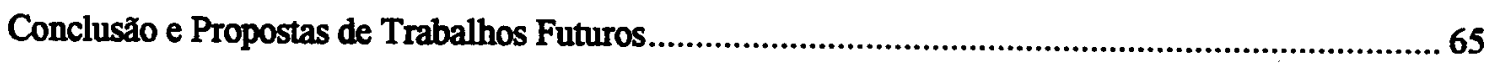

Bibliografia

Anexo I - Informaçōes sobre JPEG

Anexo II - Definiçoes Matemáticas

Anexo III - Sistema Desenvolvido 


\section{Capítulo 1.}

\section{Introdução}

O crescimento na utilização de sistemas computacionais está intimamente ligado ao desenvolvimento da sociedade moderna, a qual necessita de meios cada vez mais eficientes e rápidos a fim de difundir informações dos mais variados tipos. Para tanto, tem-se buscado representar, em sistemas computacionais, o mundo da forma como o homem sente e compreende.

A aplicação de tecnologias, para atender aos anseios do homem, tem trazido beneficios inestimáveis que vão desde a melhoria da qualidade de vida até a racionalização dos processos produtivos.

Embora a tecnologia atual forneça sistemas computacionais com capacidade de armazenamento crescente e tempo de respostas reduzidos, tem-se verificado nos últimos anos, que esta demanda ainda é insuficiente para atender à tendência crescente da complexidade e do volume de informações, despertando-se assim, interesses cada vez maiores na busca de soluções à problemas de armazenamento e recuperação de informações.

Uma das soluções encontradas para este problema, é a adoção de técnicas de Compressão e Descompressão ${ }^{1}$ de dados para minimizar o custo de armazenamento e/ou de transmissão e recepção de tais dados via rede. Diante deste fato, este trabalho procura realizar um estudo a respeito das diversas técnicas de compressão e descompressão existentes e detalhar, mais profundamente, aqueles métodos aplicados à imagens médicas obtidas por Tomografia de Ressonância Magnética (ToRM).

\subsection{Considerações Iniciais}

Desde o desenvolvimento do tomógrafo, que utiliza a técnica de Ressonância Mágnetica (RM), pelo Grupo de Ressonância Mágnetica do Instituto de Física de São Carlos [Pane_85], [Tann_87], têm surgido diversas propostas de trabalho no sentido de dar

\footnotetext{
${ }^{1}$ Descompressão é o processo de reconstrução dos dados comprimidos
} 
suporte à aquisição, armazenamento, processamento e avaliação de imagens, sobretudo àquelas imagens destinadas para a diagnóstico médico [Paiv_90], [Trai_91].

Constatou-se que, para cada sequiência de imagens obtidas pelo tomógrafo, há a necessidade de uma grande capacidade de armazenamento externo, haja vista que, dependendo da resolução adotada, tais imagens podem necessitar de mais de 1 Mbytes de memória secundária.

O problema de armazenamento de informação não é característico apenas desta aplicação. Outras áreas do conhecimento, tal como a Multimídia, freqüentemente se ressentem da falta de mecanismos de armazenamento e recuperação eficientes para um grande volume de informações [Fox_91]. A solução proposta nestes casos, é também a utilização de algoritmos de compressão e descompressão de dados.

Assim, o principal objetivo deste trabalho será o de aplicar os algoritmos existentes para compressão e descompressão de imagens adaptando-os para a realidade das imagens obtidas pelo ToRM.

\subsection{Organização deste Trabalho}

O presente trabalho está dividido em 5 capitulos e 3 Anexos. Os principais assuntos abordados em cada capítulo estão resumidos abaixo:

Capítulo 1. Introdução: São apresentadas as idéias que motivaram o desenvolvimento deste trabalho, bem como a sua organização.

Capítulo 2. Conceitos sobre compressão de dados: Onde são abordados vários métodos de compressão, aqueles que restauram fielmente os dados originais, compressão sem perdas, indicados para aplicações onde não é possível perder nenhum bit de informação, e métodos que trabalham com algumas características contidas nas informações originais, gerando perdas na reconstrução das informações, porém atendendo às várias aplicações, como por exemplo, as que trabalham com características fisico visuais no caso de imagens ou fotografias.

Capítulo 3. A proposta JPEG: A técnica de Compressão/Descompressão de imagens pela proposta do Joint Experts Photographic Group, JPEG, de acordo o padrão internacional 10918, descrevendo os quatro métodos que compõem o padrão. 
Capítulo 4. Módulos da implementação baseados na técnica JPEG: Neste capítulo são descritos todos os algoritmos que compõem o Processo-Baseline, suas características e a forma como foram implementados, usando a Linguagem C. Seguido de exemplos para tornar mais claro a compreensão das etapas descritas no capitulo 3 .

Capítulo 5. Conclusão e proposta de trabalhos futuros. Neste capítulo são feitas as discussões referentes aos resultados encontrados pela execução do Sistema CoD desenvolvido, aplicado às imagens geradas pelo tomógrafo do IFSC da USP, seguido de uma análise dos efeitos causados pelo processo de codificação, "lossy", que gera perdas inserindo ruído na imagem reconstruída, embora atenda aos propósitos de representar a imagem original com reduzido espaço em sistemas de armazenamento de massa. Desta forma, é feita uma discussão levando em conta a taxa de compressão frente ao ruído gerado.

Anexo I - Informações sobre JPEG. Este anexo fornece como é a dependência e como funciona o consórcio ISO/IEC CCITT, que criou o Padrão Internacional 10918 base para 0 desenvolvimento deste trabalho.

Anexo II - Definições Matemáticas. Este anexo mostra como manipular o formalismo matemático necessário, apontados pelo capítulo 3 .

Anexo III - Módulos da Implementação. Neste anexo são colocados de forma completa todos os programas que compõem a implementação: Compressão FDCT e Descompressão IDCT. 


\section{Capítulo 2.}

\section{Conceitos sobre Compressão de Dados}

\subsection{Considerações Iniciais}

O propósito deste capítulo é o de fornecer as principais definições e conceitos existentes na área de Compressão de Dados. Para tanto, as definições e conceitos são apresentadas juntamente com as citações bibliográficas pertinentes.

\subsection{Introdução à Compressão/Descompressão (CoD) de Dados}

A CoD de dados procura fornecer métodos, conceitos e procedimentos para reduzir o número de bits a serem utilizados para armazenar ou transmitir informações. Para esta finalidade, utiliza-se de uma grande variedade de técnicas tanto de software quanto de hardware. Tais técnicas podem adotar os seguintes critérios: Compressão Lógica e Compressão Física [Held_91], codificados como métodos "Lossless" - Compressão sem perdas, e outros métodos apropriados para imagens e vozes que implicam em perdas de informações - métodos "Lossy" [Held_92], [Penn_93].

\subsubsection{Compressão Lógica}

Este critério procura explorar o significado relativo existente entre os dados que necessitam ser comprimidos. Para exemplificar, considere a seguinte aplicação.

Num sistema empresarial existe um banco de dados com 100.000 funcionários. Para cada registro de funcionários há um campo com caracteres alfanuméricos para descrever a função, ocupando 30 bytes, que o funcionário desempenha dentro dessa empresa. Numa avaliação superficial pode-se verificar que são gastos 3.000 .000 de bytes para armazenar apenas este campo. Sabendo-se que existem apenas 8.000 funções distintas nessa empresa, pode-se reduzir este espaço de 30 bytes para apenas 4 bytes criando-se uma relação entre a função ocupada e um número de ordem através de uma tabela (tabela 2.1):

IFSC - SERVICOO DE BIELIOTECA E 


\begin{tabular}{|l|l|}
\hline Ordem & Função Ocupada \\
\hline 1 & Torneiro Mecânico \\
\hline 2 & Secretária \\
\hline 3 & Copeira \\
\hline$\ldots .$. & $\ldots . .$. \\
\hline
\end{tabular}

Tabela 2.1: Tabela que estabelece a relação entre função e número de ordem.

Este espaço pode ser reduzido ainda mais adotando-se dígitos binários conforme 0 mapeamento mostrado na tabela 2.2 :

\begin{tabular}{|l|l|l|l|l|}
\hline Mapeamento & Funções 's & Representação & Ocupando & Taxa \\
\hline 4 digitos decimais & 9999 & 4 bytes & 400.000 bytes & $7,5: 1$ \\
\hline 16 dígitos binários & 65536 & 2 bytes & 200.000 bytes & $15: 1$ \\
\hline
\end{tabular}

Tabela 2.2: Mapeamento alternativo com compressão via consulta à tabela.

Assim, consegue-se uma excelente taxa de compressão, sendo que a descompressão é atingida via consulta do elemento na tabela. Normalmente, este tipo de compressão é freqüentemente levado em consideração na área de modelagem de Bancos de Dados [Elma_94].

\subsubsection{Compressão Física}

A compressão física explora o fato de que, quando os dados são codificados como entidades distintas e separadas, as probabilidades de ocorrências de caracteres e de grupos de caracteres diferem umas das outras, uma vez que os caracteres de ocorrência freqüentemente são codificados em muitos bits, da mesma forma que aqueles caracteres que ocorrem raramente. A redução dos dados torna-se possível codificando os caracteres de maior freqüência em códigos curtos de bits e, de maneira inversa, representando os caracteres de menor ocorrência por códigos mais longos de bits. Outras técnicas substituem cadeias repetitivas de caracteres por um caractere especial, um caractere indicador de compressão e um caractere de quantidade. 


\subsubsection{Benefícios da compressão}

Quando a compressão de dados é usada para reduzir o volume de dados armazenado, o tempo global de execução do programa pode ser reduzido. Isto ocorre porque a redução no armazenamento causará a redução do número de acessos ao disco, enquanto a codificação necessária pela técnica empregada de compressão, resultará em instruções adicionais do programa de execução. Já que o tempo de execução de um conjunto de instruções de programa é, normalmente, e de forma significativa, menor do que o tempo necessário para se acessar e transferir os dados para o dispositivo periférico, o tempo global de execução do programa pode ser reduzido.

Com relação à transmissão de dados, a compressão fornece diversos beneficios ao planejamento e gerenciamento de rede, além de fornecer economia potencial de custo, pois associada a transferência de menos dados na rede, em alguns casos há a dependência do uso da rede telefônica, cujo custo está baseado na duração da chamada.

A compressão pode também reduzir a probabilidade de ocorrência de erros de transmissão, já que a quantidade global de dados transmitidos é reduzida e a quantidade de erros permanece constante. Outro aspecto importante é que a compressão aumenta a eficiência, podendo reduzir ou mesmo eliminar jornadas extras de trabalho, ao mesmo tempo em que o mapeamento gerado pela compressão leva as informações para uma codificação diferente da convencional, garantindo-se assim um maior grau de segurança contra um monitoramento com fins espúrios [Held_91]. A compressão de dados pode ser implementada, na maioria dos hardwares existentes, através de softwares ou do uso de um dispositivo especial que incorpore uma ou mais técnicas de compressão. O diagrama de blocos da figura 2.1 representa, como uma caixa preta, a compressão e a descompressão ocorrendo dentro de um dispositivo, podendo ser um computador pessoal, estação de trabalho ou dispositivos externos ao processador, tais como componentes dedicados em comunicações.

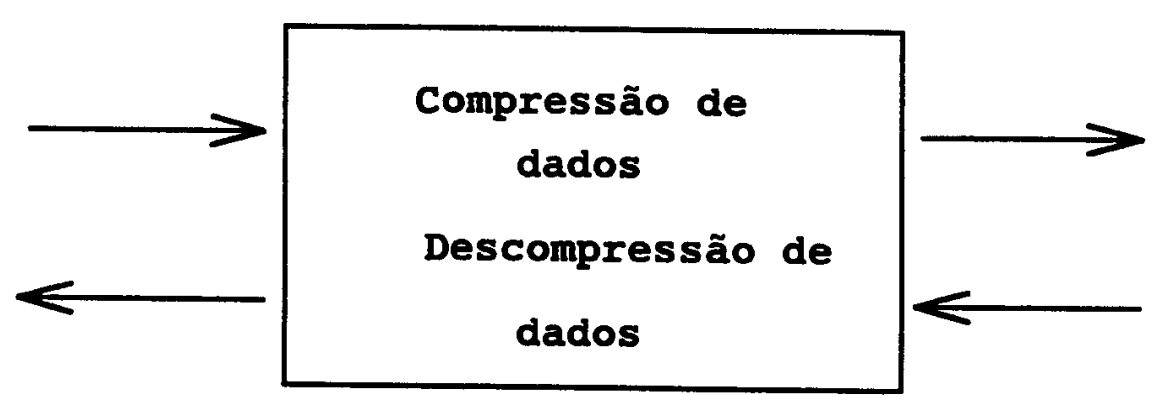

Figura 2.1: Diagrama de blocos básico da Compressão/Descompressão - CoD de Dados. 


\subsubsection{Terminologia}

A figura 2.1 mostra como um fluxo de dados original é manipulado de acordo com um determinado algoritmo para gerar um fluxo de dados comprimidos. Esta compressão pode ser chamada de processo de codificação e, da mesma forma, o fluxo de dados comprimidos é também chamado de fluxo de dados codificado. Ao reverter o processo, o fluxo de dados comprimidos é descomprimido para se reproduzir o fluxo de dados original. 0 grau de redução de dados obtido como o resultado do processo de compressão é conhecido como razão de compressão, equação 2.1 [Held_91].

$$
\text { Razão de Compressão }=\frac{\text { Comprimento da Cadeia de dados original }}{\text { Comprimento da cadeia de dados comprimidos }}
$$

Equação 2.1: Razão de Compressão.

Da equação acima pode-se afirmar que quanto maior a razão de compressão, mais eficaz é a técnica de compressão empregada. Outro termo usado ao se falar de compressão é a Figura de Mérito, equação 2.2, onde:

$$
\text { Figura de mérito }=\frac{\text { Comprimento da cadeia de dados comprimidos }}{\text { Comprimento da Cadeia de dados original }}
$$

\section{Equação 2.2: Figura de Mérito.}

A figura de mérito é a reciproca da razão de comprimento e deve ser sempre menor que 1 para que o processo de compressão seja efetivo. A fração da redução de dados é: um menos a figura de mérito. Assim, uma técnica de compressão, que resulte em um caractere de dado comprimido para cada três caracteres do fluxo de dados originais, teria uma taxa (ou razão) de compressão de 3 , uma figura de mérito é 0,33 e uma fração de redução de dados de 0,66. Em geral pode-se esperar que bons algoritmos alcancem uma taxa de compressão de dados de 1,5, enquanto excelentes algoritmos, baseados em técnicas sofisticadas de processamento, alcançarão uma taxa média de compressão que ultrapassa 2,0 [Held_91].

\subsection{Técnicas de compressão de dados}

Na última década, com a expansão do processamento remoto, aprofundou-se o interesse das equipes de comunicações nas técnicas de compressão de dados. Na década de 60 , técnicos e usuários de processamento de dados estavam interessados em encontrar um 
mecanismo para aumentar a capacidade dos dispositivos de armazenamento de massa. Desde então, houve uma evolução no aumento da capacidade de armazenamento dos dispositivos periféricos além de, uma diversidade de alternativas, evoluindo dos "diskpacks" para rápidos e compactos discos rígidos tipo "winchesters". Hoje, além do emprego de técnicas de compressão para a transferência de dados, onde em periodos menores alcança-se uma taxa maior na transferência, encontram-se dispositivos especializados e dedicados nos sistemas de armazenamento de massa, responsáveis pelo aumento do volume de dados preservados.

Algumas das técnicas de compressão de dados podem ser classificadas como orientadas a caractere, onde é empregado um caractere especial indicando a compressão, um outro indicando a multiplicidade do caractere e as codificações estatísticas que mapeiam os dados com base na freqüência de ocorrência de caracteres.

\subsubsection{Compressão orientada a caractere}

A compressão orientada a caractere oferece o potencial de reduzir, de forma significativa, o volume de armazenamento de dados e, em muitos casos, pode ser o primeiro nível de um esquema de compressão multinivel. Ao se aplicar uma ou mais técnicas de compressão orientadas a caractere, as eficiências operacionais podem ser aumentadas, e se ainda levarse em consideração transações que envolvam comunicação, tem-se reduzidos os custos de comunicação utilizando Supressão de caracteres nulos, Mapeamento de bits, Comprimento da fileira, Compactação de meio byte, Codificação Diatômica, Substituição de padrões e outras. As primeiras técnicas serão descritas a seguir [Held_91].

\subsubsection{Supressão de caracteres nulos}

A supressão de caracteres em branco ou nulos foi uma das primeiras técnicas de compressão de dados desenvolvidas. É uma técnica simples, sendo empregada no protocolo IBM 3780 BISYNC.

A técnica consiste em "varrer" o fluxo de dados a procura de caracteres brancos ou nulos e substituí-los por um par especial de caracteres com o formato descrito na figura 2.2, onde: o primeiro caractere é empregado para indicar que ocorreu a supressão de caracteres nulos, 
e o segundo é usado para indicar a quantidade de caracteres nulos que foram encontrados e substituídos pela seqüência de dois caracteres.

\begin{tabular}{|l|l|}
\hline $\begin{array}{l}\text { Caractere Indicador } \\
\text { de Compressão }\end{array}$ & $\begin{array}{l}\text { Contagem } \\
\text { de Nulos }\end{array}$ \\
\hline
\end{tabular}

Fig. 2.2 - Formato de Compressão.

Exemplo de compressão de dados

Fluxo de dados

Fluxo de dados comprimidos

onde, $S_{c}=$ caractere especial indicador de compressão.
XKWbbbbbbbbTYI

$\mathrm{XKWS}_{\mathrm{c}} 8 \mathrm{TY}$

Há que se considerar que esta técnica está limitada ao máximo de 255 caracteres para cada ocorrência de compressão. Para se ter vantagem com esta técnica, ela deve ser aplicada para no mínimo 3 caracteres de ocorrência de nulos. Esta técnica possui variações de formato com a inclusão de marcadores especiais no início e fim do código de compressão.

\subsubsection{Mapeamento de bits}

Esta técnica de compressão é eficaz quando o fluxo de dados a ser manipulado for composto por uma alta proporção de tipos de dados específicos, tais como números e espaços em branco. Um mapa de bits é empregado para indicar a presença ou ausência de caracteres de dados (figura 2.3), ou o fato de que certos caracteres de dados foram manipulados novamente, para que os dados voltem ao formato original. 

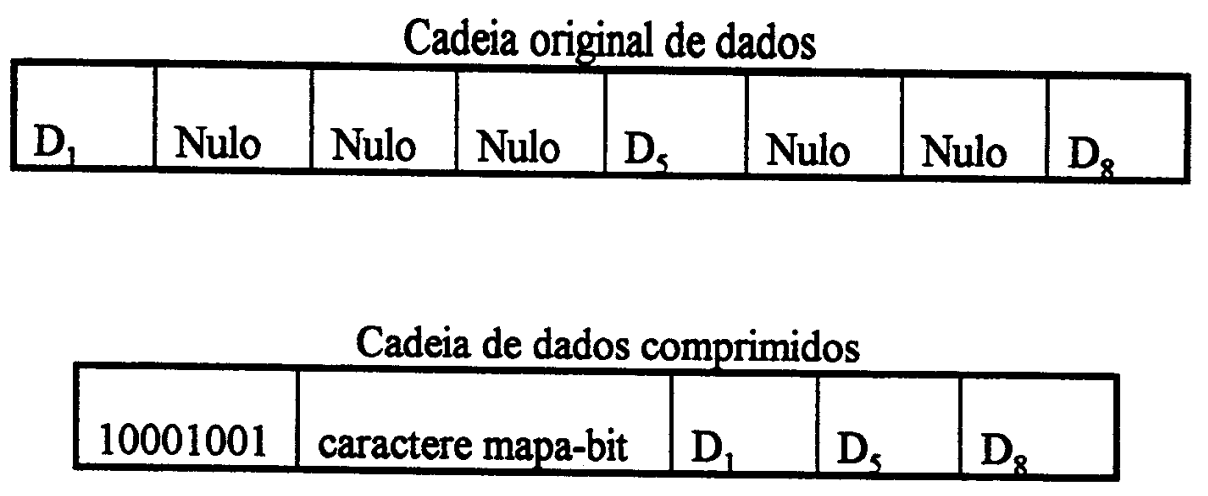

Figura 2.3: 0 processo de mapa de bits.

Através do uso de um mapa de bit anexado na frente da cadeia pode-se indicar a presença ou a ausência de nulos ou brancos e assim reduzir o tamanho da cadeia de dados. A supressão de caracteres nulos é efetiva quando há 3 ou mais caracteres encontrados para compressão.

\subsubsection{Comprimento de fileira}

A codificação de comprimento de fileira é um método de compressão de dados que reduzirá, fisicamente, qualquer tipo de sequeência de caracteres repetidos, desde que a seqüência de caracteres alcance um nivel pré-definido de ocorrência. Para a situação especial onde o caractere nulo é o caractere repetido, a compressão de comprimento de fileira pode ser vista como um processo avançado de supressão. Semelhante à supressão de nulos, o emprego de codificação de comprimento de fileira, normalmente, requer o uso de um caractere especial para indicar que ocorreu este tipo de compressão, seguido de um caractere de contagem, que indicará o número de vezes que o caractere repetido apareceu na seqüência. 
Fluxo de dados

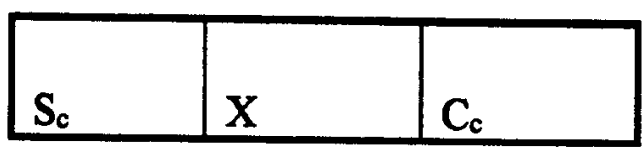

Figura 2.4: Codificação de comprimento de fileira, formato geral de compressão, $\mathrm{S}_{\mathrm{c}}$ : Caractere especial indicando a existência de compressão; $\mathrm{X}$ : Caractere repetido; $\mathrm{C}_{\mathrm{c}}$ : Contagem de caracteres.

Exemplo de Comprimento de Dados:

$\begin{array}{ll}\text { Cadeia original de Dados } & \text { Cadeia } \\ \mathbf{R} \$ * * * * * * 32.73 & \mathbf{R S S}^{*} 732.73 \\ +H++++++ & \mathrm{S}_{\mathrm{c}}+11 \\ \text { LonabbbbbbbbbbbbbBranca } & \text { LonaS } \mathrm{c} \text { 13Branca }\end{array}$

Este método é limitado a uma contagem de 255 caracteres, usado no protocolo BISYNC do IBM 3780. Uma variação desta técnica é encontrada na compressão Classe 5 Microcom Network Protocol (MNP), e usado em Sistemas Honeywell como uma versão de compressão para seus terminais remotos (GRTS) e sistemas autônomos fita-a-fita (SATTS) [Held_91].

\subsubsection{Compactação de meio Byte}

A técnica de compressão de dados, compactação de meio byte, pode ser vista como uma derivação do processo de mapeamento de bits. Esta técnica se beneficia da estrutura de certos caracteres em um conjunto de caracteres.

A compactação de meio byte é feita quando uma parte do padrão de bits usado para representar aqueles caracteres, se torna repetitiva. Como exemplo, os 4 bits de mais alta ordem na representação EBCDIC para representar caracteres numéricos, são todos bits 1 , podendo-se assim tirar vantagens, principalmente em aplicações financeiras; de forma semelhante ocorre no código ASCII mesmo quando adicionado o bit de paridade, conforme tabela 2.3. 


\begin{tabular}{cll} 
Caractere Numérico & \multicolumn{2}{c}{ Estrutura de Bits } \\
& EBCDIC & ASCII \\
0 & 11110000 & 0110000 \\
1 & 11110001 & 0110001 \\
2 & 11110010 & 0110010 \\
3 & 11110011 & 0110011 \\
4 & 11110100 & 0110100 \\
5 & 11110101 & 0110101 \\
6 & 11110110 & 0110110 \\
7 & 11110111 & 0110111 \\
8 & 11111000 & 0111000 \\
9 & 11111001 & 0111001
\end{tabular}

Tabela 2.3: Representação Numérica EBCDIC e ASCII da Caracteres Financeiros.

$\begin{array}{ccccccccc}\text { Numérico } & 2 & 1 & 0 & 9 & 1 & 9 & 9 & 3 \\ \text { Binário } & 11110010 & 11110001 & 11110000 & 11111001 & 11110001 & 11111001 & 11111001 & 1110011\end{array}$

Figura 2.5: Compactação de Meio Byte.

Na figura 2.5 tem-se a demonstração da técnica de compactação de meio byte tomando como exemplo a representação numérica de caracteres financeiros EBCDIC.

\subsubsection{Codificação Diatônica}

A codificação diatônica é um processo de compressão de dados, onde um par de caracteres é substituído por um caractere especial. A estrutura binária do caractere especial representa o par codificado de caracteres permitindo a redução de dados. O número de caracteres especiais que pode ser empregado para representar diferentes tipos de compressão é limitado, logo o potencial teórico de se obter uma redução de 50 por cento não é possível ser atingido [Held_91].

Uma vez conhecida a freqüência esperada de ocorrência de pares de caracteres, pode-se escolher os pares mais freqüentes para serem os indicados para a codificação Diatônica. $O$ número de indicados está limitado ao número de caracteres especiais disponíveis. Assim, o 
principal problema da codificação Diatônica é determinar que pares devem ser representadas por caracteres especiais.

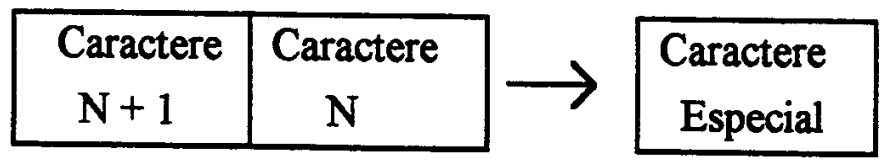

Figura 2.6: Processo de Codificação Diatômica.

\subsubsection{Substituição de Padrões}

A técnica de Substituição de Padrões representa uma técnica de compressão sofisticada de codificação Diatônica, pois um código especial de caractere é substituído por um padrão de caractere pré-definido. Esta técnica de compressão por substituição de padrões pode ser altamente interessante, quando se trata de listagem de programas e outros tipos de arquivos de dados, contendo padrões de repetição conhecidos. Em linguagens de programação aparecem várias palavras chaves que constituem instruções ou cláusulas que podem ser substituídas com vantagens, e pode-se encontrar, em textos, vocábulos tais como: 'como', 'também', 'outros', 'que', 'porque'; que a exemplo de instruções de linguagens de programação encabeçariam a lista de indicados à substituição.

\subsection{Outros métodos de Compressão}

Buscando representar os dados com elevadas taxas de compressão, a figura 2.7 mostra uma classificação dos métodos de compressão. No esquema "Lossless" a representação original pode ser perfeitamente recuperada e no esquema "Lossy", a recuperação aproxima-se da original havendo uma quantidade de ruído controlada no sinal recuperado.

No esquema "Lossless" é usual em textos, e imagens Bi-nível. Imagens em Bí-nível são tratadas por JBIG ("Joint Bi-level Image Experts Group") um grupo de especialistas pertencente a ISO/IEC CCITT. Estes esquemas são chamados "noiseless" dado que não adicionam ruído ao sinal, ou de codificação de entropia por reduzirem a redundância estatística ou técnicas de decomposição, classificados como métodos sem perda (Lossless), uma vez que não há presença de ruído ou mudança na característica da informação quando do processo de restauração do sinal original. 
Têm-se ainda, processos que tratam de freqüências espaciais do sinal (imagem) e persistência temporal (som), métodos com perda (Lossy), neste caso, pode-se controlar a quantidade de perda de informação e o ruído inserido no sinal restaurado, pois atua-se com características físicas do sistema de visão e audição do homem e o cérebro faz o reconhecimento da informação baseado em objetos conhecidos, a exemplo de como ocorre com o sistema telefônico que não transmite todo o sinal presente na voz.

Assim, a figura 2.7 representa o grafo para a escolha dos métodos com taxas mais elevadas de compressão

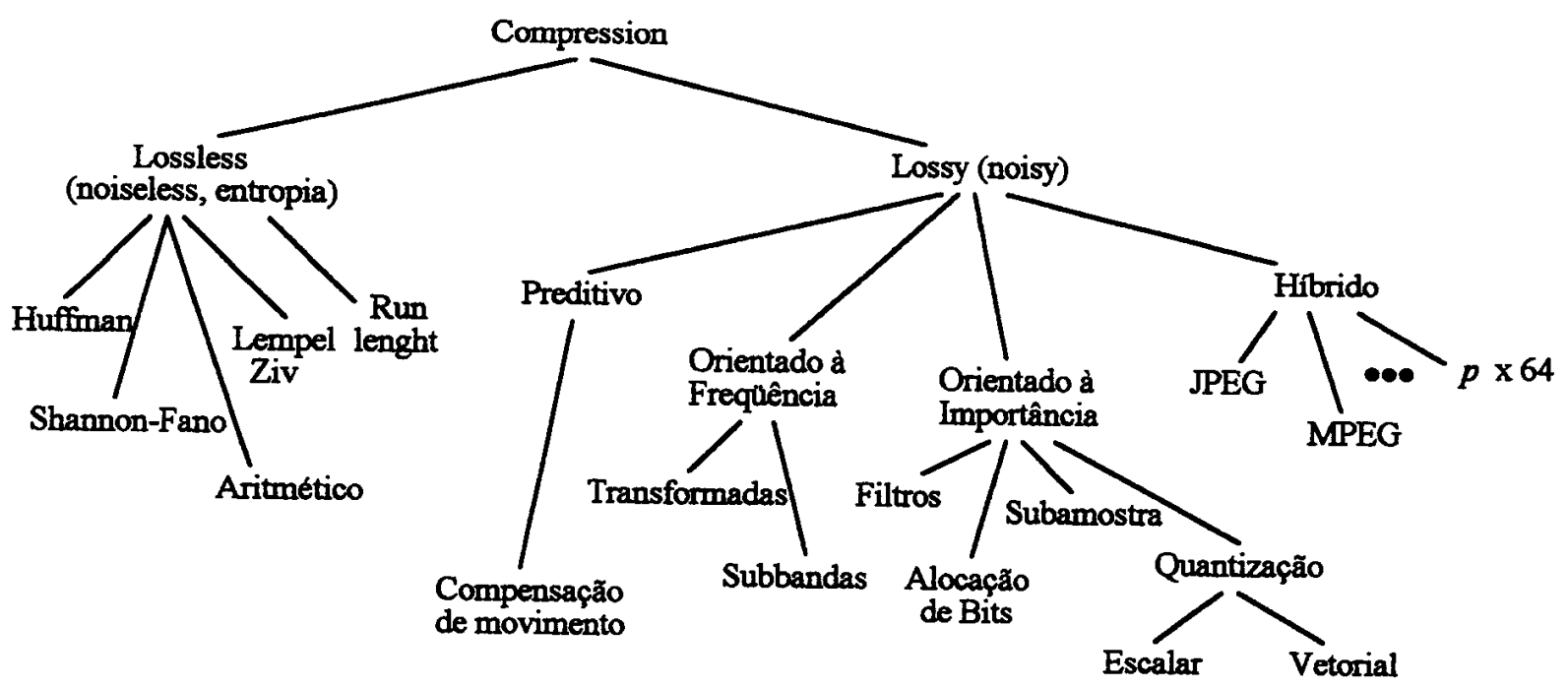

Figura 2.7: Árvore de Seleção dos Métodos de Compressão

\subsubsection{Compressão por codificação estatística}

A codificação estatística trabalha com as probabilidades de ocorrência de caracteres únicos e grupos de caracteres, de maneira que códigos menores podem ser usados para representar caracteres freqüentemente usados ou grupos de caracteres, ao passo que códigos maiores são usados para representar caracteres encontrados com menos freqüência e grupos de caracteres. Assim, pode-se citar a técnica de codificação Huffman, a codificação ShannonFano e o método de codificação em cadeia Lempel-Ziv, entre outros [Nels_92]. O fundamento teórico para este tipo de codificação baseia-se na teoria da Informação que será descrita a seguir. 


\subsubsection{Teoria da Informação}

Para um sistema capaz de transmitir em $n$ niveis discretos e em intervalos de $\lambda$ segundos, o número de diferentes combinações de sinais em $T$ segundos é $n^{T / \lambda}$. Já que as informações são proporcionais ao tempo de transmissão, pode-se utilizar logaritmo de $n^{T / \lambda}$, para obter as informações transmitidas em $T \mathrm{~s}$, sendo proporcionais ao $(T / \lambda) \log n$. O fator de proporcionalidade dependerá da base do logaritmo usado. Fazendo-se a escolha da base 2 , tem-se :

$$
H=\frac{T}{\lambda} \log _{2} n \text { ou, } H=-\frac{T}{\lambda} \log _{2} n \text { (bits em } T \mathrm{~s} \text { ) }
$$

considerando que $n$ possiveis eventos ocorrem num intervalo de tempo $T$ com probabilidade de $1 / n$.

Decorre deste fato que, em se tratando de 2 níveis, 0 e 1 , tem-se $P$ e $Q$ probabilidades de ocorrência de 0's e 1's, respectivamente.

O conteúdo das informações de uma mensagem longa composta por O's e 1's é, depende de:

$$
P * \log _{2} P+Q * \log _{2} Q,
$$

ou seja, a informação em bits por ocorrência de um 0 ou 1 , vezes a freqüência relativa do valor de bit. A freqüência de ocorrência de cada nível de sinal possível é representada como $P_{i}$. Assim, cada intervalo carrega $-\log _{2} P_{i}$ bits de informação. Em $t$ períodos de tempo, $i$ aparecerá de $t^{*} P_{i}$ vezes a média, somando as informações dos bits, fornecidos na média por cada símbolo, obtêm-se:

$$
H=-t * \sum_{i=1}^{n} P_{i} \log _{2} P_{i} \text { bits em } t \text { períodos. }
$$

Para o intervalo $T$, obtemos então:

$$
H=-\frac{T}{\lambda} * \sum_{i=1}^{n} P_{i} \log _{2} P_{i} \text { bits em T s. }
$$

Para uma mensagem com $n$ simbolos ou níveis possíveis com probabilidade de ocorrência $P_{i}$ a $P_{n}$, a informação média por intervalo de símbolo $\lambda$ é:

$$
H_{\text {avg }}=-\sum_{i=1}^{n} P_{i} \log _{2} P_{i} \text { bits/intervalo de símbolo. }
$$

Esta equação representa a definição matemática de entropia, termo usado em teoria da informação para indicar o número médio de bits, exigidos para representar cada símbolo de um alfabeto fonte. Assim, com base no que foi visto anteriormente, podemos calcular a redundância contida na informação, pois $\log _{2} n$ representa a unidade de informação para um

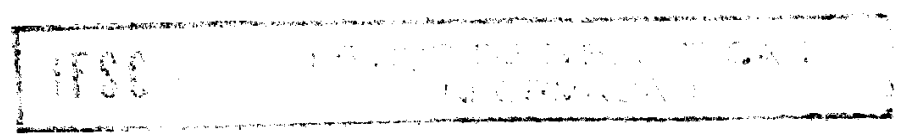


sistema capaz de transmitir $n$ niveis discretos, e sua redundância se torna $R=\log _{2} n-H_{\text {arg }}$. Assim, quando há redundância zero, $H_{\text {avg }}=\log _{2} n$.

Uma vez que a entropia representa o número médio de bits necessários para representar cada símbolo de um alfabeto fonte, será exemplificado como isso pode ser aplicado nas técnicas de compressão de dados [Held_91].

Baseados numa experiência como no lançamento de uma moeda não viciada, onde se representa a probabilidade de cara $(\mathrm{K})$ igual a probabilidade de coroa $(S)$, então: $P(K)=$ $P(S)=0,5$. A partir da definição anterior de entropia,

$$
H_{\text {arg }}=-\left[\frac{1}{2} \log _{2} \frac{1}{2}+\frac{1}{2} \log _{2} \frac{1}{2}\right]=1
$$

Assim, pelo cálculo da entropia, tem-se que um bit seria necessário para codificar os resultados de um jogo de cara ou coroa. Estendendo-se a experiência para duas moedas tem-se: $H_{\text {avg }}=-\sum_{i=1}^{4} P_{i} \log _{2}=-4 \cdot \frac{1}{4} \log _{2} \frac{1}{4}=2$. Pelo resultado, são necessários dois símbolos binários para codificar cada símbolo do alfabeto. A tabela 2.2 ilustra este fato:

\begin{tabular}{|c|c|c|c|}
\hline Resultado & Símbolo do alfabeto & Probabilidade & Código \\
\hline $\mathrm{KK}$ & $\mathrm{X}_{1}$ & $1 / 4$ & 00 \\
\hline $\mathrm{KS}$ & $\mathrm{X}_{2}$ & $1 / 4$ & 01 \\
\hline $\mathrm{SK}$ & $\mathrm{X}_{3}$ & $1 / 4$ & 10 \\
\hline $\mathrm{SS}$ & $\mathrm{X}_{4}$ & $1 / 4$ & 11 \\
\hline
\end{tabular}

Tabela 2.3: Resultado para o lançamento 2 moedas, $P(K)=P(S)$.

Considerando a experiência do jogo de cara ou coroa com dois lançamentos, onde a probabilidade da ocorrência de coroa (S) seja igual a 0,25 , e a probabilidade de cara $(\mathrm{K})$ é igual a 0,75 , a tabela terá o seguinte aspecto (tabela 2.4):

\begin{tabular}{|c|c|c|c|}
\hline Resultado & Símbolo do alfabeto & Probabilidade & Código \\
\hline KK & $\mathrm{X}_{1}$ & 0,5625 & 00 \\
\hline KS & $\mathrm{X}_{2}$ & 0,1875 & 01 \\
\hline SK & $\mathrm{X}_{3}$ & 0,1875 & 10 \\
\hline SS & $\mathrm{X}_{4}$ & 0,0625 & 11 \\
\hline
\end{tabular}

Tabela 2.4: Resultados para lançamentos de 2 moedas, $P(S) !=P(K)$. 
Assim, a redundância da experiência acima fica: $R=\log _{2} 4-H_{\text {avg }}=2-1,62=0,38$.

Em comparação com a primeira experiência do jogo de cara ou coroa, com dois lançamentos, o número médio de bits necessários para representar um símbolo do alfabeto de quatro símbolos foi reduzido de 0,38 . Isto indica que usando-se outro tipo de esquema de codificação, consegue-se uma redução em relação aos dois símbolos usados anteriormente. Para obter-se essa redução, deve-se atribuir códigos pequenos para os símbolos do alfabeto de maior ocorrência, e códigos maiores para os símbolos de menor ocorrência. Este método resultará em uma longa cadeia de símbolos de dados tendo, em média, menos bits por símbolo e, assim, constitui a base para a codificação Huffman [Huff_52].

\subsubsection{Codificação de Huffman}

É uma técnica de compressão de dados estatística, cujo emprego reduzirá o tamanho médio do código usado para representar os símbolos de um alfabeto. $O$ alfabeto pode ser a língua portuguesa ou um alfabeto de dados codificado (por exemplo, o código ASCII).

O código de Huffamn possui propriedade de prefixo, estabelecendo que nenhum grupo pequeno de código seja duplicado no início de um grupo maior. Exemplificando, se um caractere for representado pela combinação de bits, 110, então, 11000 não pode ser código para outro caractere já que, ao examinar-se seu fluxo de bits da esquerda para a direita, o algoritmo de descodificação interpretaria os cinco bits como o caracteres de codificação de bits 110 seguido de um caractere de codificação de bits 00 .

A propriedade de prefixo do código de Huffman assegura que o código seja descodificável de forma única. Considere-se o alfabeto de quatro símbolos, conforme tabela 2.5:

$$
\begin{aligned}
& X_{1}=0 \\
& X_{2}=01 \\
& X_{3}=11 \\
& X_{4}=00
\end{aligned}
$$

Tabela 2.5: Representação do alfabeto de 4 símbolos não descodificável de forma única.

Se a mensagem recebida for "0001", a esta seqüência se poderia representar $X_{1} X_{1} X_{2}$ ou $\mathrm{X}_{4} \mathrm{X}_{2}$. Sendo assim, o código não é de descodificação única. A figura abaixo ilustra a 
árvore de decisão que corresponde à atribuição de valores ao alfabeto de quatro símbolos, proposta na tabela 2.5 .

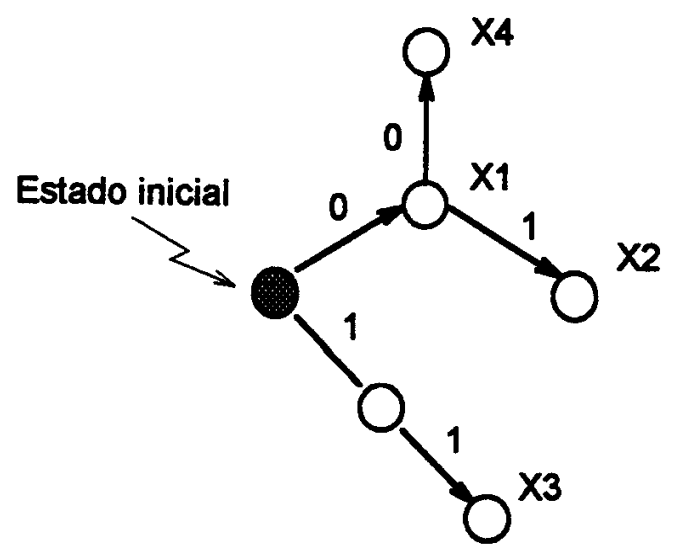

Figura 2.8: A árvore de decisão para formar o alfabeto de quatro simbolos $X_{1}, X_{2}, X_{3}, X_{4}$; onde $X_{1}=0, X_{2}=01, X_{3}=11$ e $X_{4}=00$.

Ao examinar a árvore de decisão da figura 2.8, observa-se que o caminho ao nó $\mathrm{X}_{3}$ é feito através de um nó intermediário que não é necessário, uma vez que não há nenhuma rota do nó intermediário para outro nó, que não seja o nó $X_{3}$. Observa-se também que o nó $X_{1}$ é realmente um nó intermediário e o caminho para $\mathrm{X}_{1}$ não representa uma combinação única de bits.

Para resolver o problema de ramificação, acrescentam-se regras apontando para o fato de que cada ramificação termine com um nó como um estado terminal, ou funções como ponto de decisão que permita uma rota para um estado terminal. Seguindo as regras, redesenhando a árvore de decisão e atribuindo valores binários para cada ramificação temse (figura 2.9):

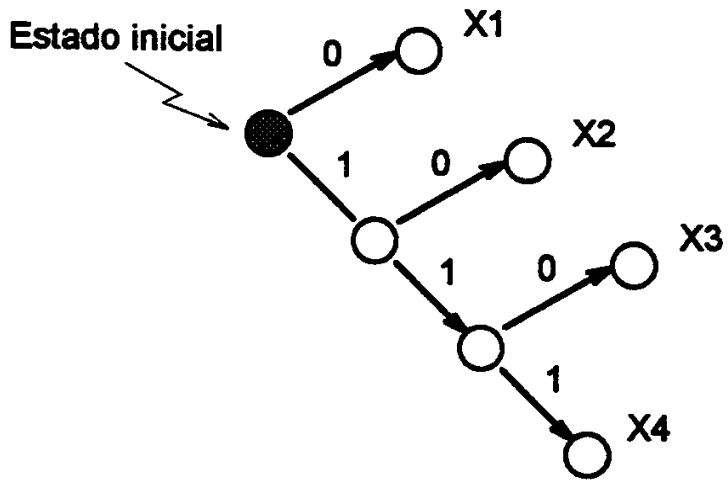

Figura 2.9: Árvore de decisão revisada de acordo com as regras de ramificação. 
Observa-se na figura 2.9, que $\mathrm{X}_{1}$ ainda tem o valor binário 0 , mas foram atribuídos os valores 10, 110 e 111 para $X_{2}, X_{3}$ e $X_{4}$, respectivamente. Cada palavra do alfabeto fonte é examinado somente uma vez, e cada caminho representa uma combinação única de bits.

O código de Huffiman pode ser desenvolvido através de uma estrutura de árvores como ilustra a figura 2.10 abaixo.

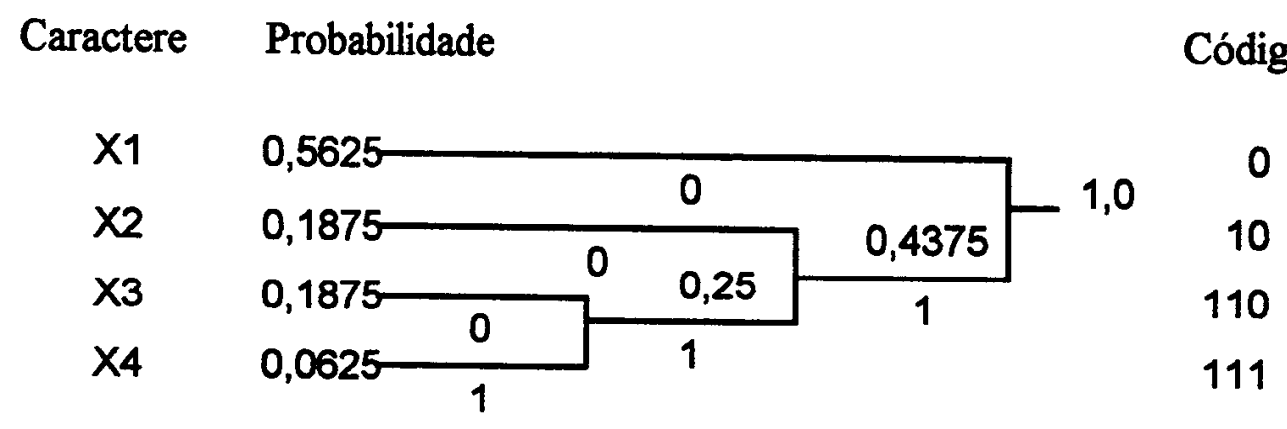

Figura 2.10: O desenvolvimento do código Huffman, empregando a estrutura de árvore.

Aqui os símbolos são primeiramente listados em ordem decrescente, de acordo com a freqüência de ocorrência (figura 2.10). Os grupos com as freqüências menores $\left(\mathrm{X}_{3}\right.$ e $\left.\mathrm{X}_{4}\right)$ são combinados em um nó com a probabilidade conjunta de ocorrência de 0,25 . A seguir, esse nó é fundido com a menor probabilidade de ocorrência de símbolo ou par de símbolos mais próximo. Nesta ilustração, o par $\mathrm{X}_{3}$ e $\mathrm{X}_{4}$ é fundido com $\mathrm{X}_{2}$ para gerar um nó cuja probabilidade desta junção seja 0,4375 . Finalmente, o nó representando as probabilidades de ocorrência de $X_{2}, X_{3}$ e $X_{4}$ é fundido com $X_{1}$, resultando em um nó cuja probabilidade de ocorrência é unitária. Este nó mestre representa a probabilidade de ocorrência de todos os quatro caracteres no conjunto de caracteres.

Ao atribuir 0's e 1's binários para cada segmento originário de cada nó, pode-se gerar o código de Huffman para cada caractere. $O$ código é obtido ao rastrear o nó de probabilidade 1,0 até cada símbolo de caractere, observando os 1's e 0's encontrados.

O número médio de bits (L) [Penn_93] pode ser calculado pelo somatório das multiplicações do comprimento do código de Huffman pela sua probabilidade de ocorrência. Sendo assim, o código usa:

$$
\begin{gathered}
\mathrm{L}=1 * 0,5625+2 * 0,1875+3 * 0,1875+3 * 0,0625 \\
\text { ou } \\
\mathrm{L}=1,63 \text { bits por símbolo. }
\end{gathered}
$$


O resultado acima, de 1,63 bits para o código de Huffman, aproxima-se da entropia de 1,62 bits por símbolo, calculada no final da seção 2.3.2.1, para alfabetos de símbolos de igual probabilidade.

Como explicado anteriormente, a propriedade chave da codificação de Huffman é o fato de poder ser descodificado instantaneamente, a medida que os bits codificados no fluxo de dados comprimidos são encontrados. Um exemplo da propriedade de descodificação instantânea encontra-se na figura 2.11, abaixo.

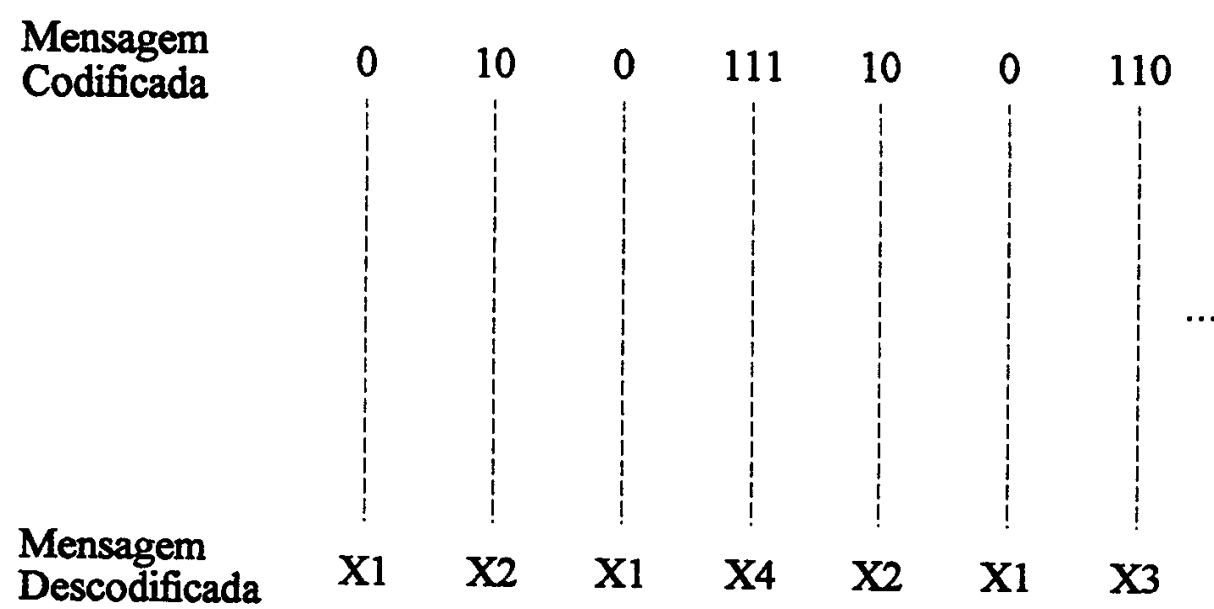

Figura 2.11: Propriedade de descodificação instantânea.

Aqui, o fluxo de dados comprimido pode ser descodificado instantaneamente ao ser lido da esquerda para a direita, sem esperar que ocorra o fim do bloco de dados.

A substituição de um número de bits o qual representa um caractere de dados, ou um grupo de caracteres particulares, é um processo razoavelmente simples quando o número de substituições for limitada. A medida que o número de substituições aumenta, a complexidade do processo de substituição também aumenta [Huff_52].

\subsubsection{Codificação Shannon-Fano}

A codificação Shannon-Fano resulta em um código de comprimento variável que é codificável instantaneamente, cujo desenvolvimento é semelhante ao código Huffinan. Antes de desenvolver o código Shannon-Fano para cada caractere, deve-se determinar a probabilidade de ocorrência de cada caractere, então, rearranjar o conjunto de caracteres em ordem decrescente com base na probabilidade de ocorrência de cada caractere. 
Uma vez que o conjunto de caracteres esteja disposto em ordem decrescente pela probabilidade de ocorrência, o conjunto deve ser dividido em dois subconjuntos iguais ou quase iguais, com base na probabilidade de ocorrência dos caracteres em cada subconjunto.

O primeiro dígito em subconjunto que representa um grupo de frequêencias de ocorrência é atribuído com o valor binário 0 , enquanto um binário 1 é atribuido ao primeiro dígito no segundo subconjunto. $O$ segundo subconjunto representa todas as freqüências restantes de ocorrência. Este processo de formar subconjuntos é repetido até que o conjunto de caracteres esteja completamente subdividido. Então, um bit de sufixo é adicionado em todos os caracteres de um subconjunto de dois caracteres, como requisito para distinguir uma composição binária de caracteres de um outro caractere no subconjunto.

Assim, o processo de codificação Shannon-Fano pode ser ilustrado abaixo, na tabela 2.6.

\begin{tabular}{|l|l|l|l|l|}
\hline Caracter & Probabilidades & Ordenando & Código & Passos \\
\hline $\mathrm{X} 1$ & $1 / 4$ & $\mathrm{X} 2$ & 0 & $1^{\circ}$ \\
\hline $\mathrm{X} 2$ & $1 / 2$ & $\mathrm{X} 1$ & 10 & $2^{\circ}$ \\
\hline $\mathrm{X} 3$ & $1 / 16$ & $\mathrm{X} 5$ & 110 & $3^{\circ}$ \\
\hline $\mathrm{X} 4$ & $1 / 32$ & $\mathrm{X} 3$ & 1110 & $4^{\circ}$ \\
\hline $\mathrm{X} 5$ & $1 / 8$ & $\mathrm{X} 4$ & 11110 & $5^{\circ}$ \\
\hline $\mathrm{X} 6$ & $1 / 32$ & $\mathrm{X} 6$ & 11111 & \\
\hline
\end{tabular}

Tabela 2.6: Exemplo das etapas da codificação Shannon-Fano.

Na tabela acima é mostrada a aplicação do método para a particular distribuição de probabilidades. $O$ tamanho de cada palavra do alfabeto codificado é igual a $-\log p\left(a_{i}\right)$, pois é possivel subdividir o grupo em subgrupos de iguais probabilidades. Quando isto não for possível, as palavras do alfabeto podem ser $-\log p\left(\mathbf{a}_{\mathbf{i}}\right)+1$ [Lele_87], [Nels_91].

\subsubsection{Codificação Lempel-Ziv}

A codificação Lempel-Ziv representa uma saida da visão clássica de um mapeamento de um conjunto fixo de mensagens - letras, símbolos ou palavras - para um conjunto fixo de palavras do alfabeto codificado.

Em 1977 e 1978, Jacob Ziv e Abraham Lempel descrevem um par de métodos de compressão usando um dicionário adaptativo. Estes dois algoritmos clareiam um fluxo de novas técnicas que usam técnicas baseadas em dicionário para alcançar novas razões de compressão [Nels_92], [Nels_89].

$$
\begin{gathered}
\text { If Sl - SEFVICO DE BIELIOTECA E } \\
\text { INFORNACÁ }
\end{gathered}
$$


O algoritmo Lempel-Ziv consiste de uma regra descrita de forma que cordões ou cadeias de símbolos de um alfabeto finito, dentro de subcadeias ou palavras do qual o tamanho não excede um inteiro $\mathrm{L}_{1}$ e uma codificação de esquemas que mapeia estas subcadeias seqüencialmente dentro das palavras do alfabeto unicamente decifrável, de tamanho fixo $\mathrm{L}_{2}$. As cadeias são selecionadas tal que tenham probabilidade de ocorrência muito próxima. Como resultado, freqüentemente ocorre que símbolos são agrupados em cadeias mais longas. Entretanto, não freqüentemente, aparecem símbolos em cadeias mais curtas. Esta estratégia é efetiva ao explorar a redundância para símbolos freqüentes, caracteres repetidos e alto uso de padrões [Lele_87].

O primeiro algoritmo de compressão descrito por Lempel-Ziv, sendo referenciado por LZ77, onde o dicionário, que consiste de todas as cadeias de caracteres, lidas previamente em um canal de entrada como, por exemplo, 4 Kbytes de uma janela. Enquanto novos grupos de símbolos são inicialmente lidos, o algoritmo procura adequá-los com as cadeias encontradas nos 4 Kbytes de dados lidos anteriormente. Quaisquer adequações são codificadas como ponteiros enviados para o canal de saída.

A tabela 2.7 mostra um pouco da tabela de códigos Lempel-Ziv. Letras com pouca freqüência, como $\mathbf{Z}$, aparecem individualmente associadas com uma palavra do alfabeto de códigos com tamanho fixo (neste caso, representada com 12 bits de código). Freqüentemente ocorrem símbolos, tais como brancos b e zeros, aparecendo em cadeias longas. A compressão efetivamente é encontrada quando uma cadeia longa é trocada por código simples de 12 bits.

\begin{tabular}{|l|l|}
\hline Cadeia de Símbolos & Código \\
\hline A & 1 \\
\hline T & 2 \\
\hline AN & 3 \\
\hline TH & 4 \\
\hline THE & 5 \\
\hline AND & 6 \\
\hline AD & 7 \\
\hline b & 8 \\
\hline bb & 9 \\
\hline bbb & 10 \\
\hline 0 & 11 \\
\hline $\mathbf{C O}$ & 12 \\
\hline $\mathbf{C O 0}$ & 13 \\
\hline $\mathbf{C O 0 0}$ & 14 \\
\hline$Z$ & 15 \\
\hline & \\
\hline & 4096 \\
\hline
\end{tabular}

Tabela 2.7: Uma Tabela de Códigos Lempel-Ziv 
O programa conhecido por LZ78 pega um acesso diferente para construir e manter o dicionário, ao invés de possuir uma janela delimitada, o LZ78 constrói seu dicionário saída de todos os símbolos previamente vistos no texto de entrada. Ao invés de possuir um mecanismo de acesso para todas as cadeias de símbolos no texto precedente, um dicionário de cadeias é construido com um único caractere por vez. Por exemplo, a primeira vez que a cadeia "João" é vista, a cadeia "Jo" é adicionada ao dicionário, na próxima vez, "João" é adicionada, se "João" for vista novamente, a cadeia é adicionada ao dicionário.

\subsubsection{Codificação Aritmética}

Na codificação Aritmética um alfabeto fonte é representado por um intervalo entre 0 e 1 sobre um conjunto de números reais, onde cada símbolo do alfabeto é ajustado neste intervalo. Como o intervalo torna-se muito pequeno, o número de bits necessários para especificá-lo cresce. $O$ código Aritmético assume um modelo de probabilidade explícito do alfabeto fonte, sendo definido um esquema de palavras, que usa a probabilidade do alfabeto fonte de mensagens, para sucessivamente estreitar o intervalo usado para representar o conjunto. Uma mensagem de grande probabilidade estreita o intervalo menos que as de baixa probabilidade, tanto que mensagens com alta probabilidade contribuem com poucos bits para 0 alfabeto de mensagens codificada [Lang_84].

O método inicia com uma lista de mensagens fontes não ordenadas e suas probabilidades. $O$ número de linhas é particionado em subintervalos sobre bases de probabilidades acumuladas.

O exemplo da tabela 2.8 é usado para ilustrar a idéia da codificação aritmética, mostrando o alfabeto de mensagens fonte $e$ as respectivas probabilidades. É demonstrado na figura o particionamento inicial. Quando a codificação se inicia, o conjunto fonte é representado por todo intervalo $[0.0,1.0)$

\begin{tabular}{|c|c|c|c|}
\hline Mensagem Fonte & Probabilidade & Probabil. Acumulada & Variação \\
\hline A & 0.2 & 0.2 & {$[0.0,0.2)$} \\
\hline B & 0.4 & 0.6 & {$[0.2,0.6)$} \\
\hline C & 0.1 & 0.7 & {$[0.6,0.7)$} \\
\hline D & 0.2 & 0.9 & {$[0.7,0.9)$} \\
\hline$\#$ & 0.1 & 1.0 & {$[0.9,1.0)$} \\
\hline
\end{tabular}

Tabela 2.8: Modelo de Codificação Aritmética. 
Para o conjunto "AADB\#", o primeiro "A" reduz o intervalo a $[0,0.2)$, o segundo " $\mathrm{A}$ " ao intervalo $[0,0.04)$, seguido pelo " $D$ " que promove um estreitamento do intervalo para $[0.028,0.36)$. Com a codificação de "B" o intervalo fica $[0.0296,0.0328)$, e o "\#" mostra o final do intervalo de $[0.03248,0.0328)$. Qualquer número de elementos $i$ dentro do intervalo, pode ser usado para representar o intervalo do alfabeto de mensagens fonte.

O tamanho do subintervalo final do alfabeto fonte determina o número de bits necessários para especificar um número no limite. $O$ número de bits necessários para especificar um subintervalo de $[0,1)$ de tamanho $s$ é - $\log s$, dado que o tamanho do subintervalo final é produto das probabilidades das mensagens fontes no conjunto, isto é:

$s=\prod_{i=1}^{N} p$ (fonte de mensagens $i$ ), $N$ é o tamanho de cada conjunto

tem-se que:

$$
\left.-\log s=-\sum_{i=1}^{N} \log p \text { (fontes de imagens } i\right)=\sum_{i=1}^{n} p\left(a_{i}\right) \log p\left(a_{i}\right),
$$

onde $n$ é o número de mensagens fontes únicas $\mathrm{a}_{1}, \mathrm{a}_{2}, \ldots, \mathrm{a}_{\mathrm{n}}$. Assim, o número de bits gerado pela codificação Aritmética é exatamente igual ao gerado pela entropia H. Está demonstrado o fato de que a codificação Aritmética atinge uma compressão que é muito próxima do que prediz a entropia do alfabeto fonte de mensagens.

A descodificação consiste de uma série de comparações dos números $i$ para a extensão representada pelas mensagens fontes. Para 0 exemplo da figura 2.8, $i$ pode ser 0.0325 $(0.03248,0.0326$, ou 0.0327 se ajustaria muito bem). $O$ descodificador usa $i$ para simular as ações do codificador, desde que $i$ fica entre 0 e 0.2 , o descodificador deduz que a primeira letra foi " $\mathrm{A}$ " (desde que a extensão $[0,0.2)$ corresponde a mensagem fonte " $A$ "). $O$ descodificador pode agora deduzir que a próxima mensagem leva ao estreitamento dos caminhos: para $[0,0.04)$ para "A", [0.04, 0.12) para "B", $[0.12,0.14)$ para "C", $[014,0.18)$ para " $\mathrm{D}$ " ou $[0.18,0.2)$ para "\#". Desde que $i$ caia dentro do intervalo $[0,0.04)$, o descodificador sabe que a segunda mensagem é de novo "A". Este processo continua até que o conjunto de mensagens seja totalmente recuperado.

\subsubsection{Compressão com perda}

Encontra-se na figura 2.9 também o esquema de compressão "Lossy" ou "Noisy" que adicionam características e ruídos que podem ser notados no sinal recuperado. Estudos cuidadosos dos sistema visual do homem têm chamado a atenção sobre uma aproximação que cause pouca perda na qualidade das informações após o processo de reconstrução, porém obtendo altas taxas de compressão. Estes processos de compressão são interessantes 
quando se busca facilidades no acesso interativo a sistemas de informações de multimídia digitais [Fox_91]. A seguir são apresentados alguns dos processos que trabalham com essa características.

\subsubsection{Predição}

Aproximações preditivas tipo "Adaptive Differential Pulse-Code Modulation", ADPCM, envolvendo predição de valores subseqüentes pela observação prévia de alguns, e transmitindo somente pequenas diferenças entre o dado atual e o dado predito. Um exemplo envolve a compensação de movimentos, onde sucessivos "frames" em uma seqüência de vídeo são completamente similares ou possuem blocos de elementos de imagem deslocados de 1 "frame" do próximo.

\subsubsection{Compressão Orientada}

A codificação de sub-bandas podem explorar o fato de que o homem tem sensibilidade diferente para a combinação espacial e temporal. Separando as diferentes combinações de freqüências (com o uso de filtros) e então codificar com grande fidelidade as freqüências para as quais o homem é mais sensível. Esta técnica proporciona alta qualidade com um total de poucos bits. Sem a codificação de sub-bandas, todas as combinações de freqüência seriam codificadas identicamente. Uma aproximação que envolve freqüência espacial, como em uma fotografia, é obtida pelo uso de DCT (Discrete Cosine Transform), realizando a codificação por transformação, $\operatorname{Re}\{F F T\}$, componente real da transformação de Fourier [Wall_91].

\subsubsection{Compressão Orientada à Importância}

Outras características da imagem, além de freqüência, são usadas como base de compressão, onde o princípio está em se considerar as partes de uma imagem sobre as quais o homem melhor se atem. Um exemplo desta aproximação está em filtrar as imagens, liberando os detalhes que não são percebidos, como em um filtro passa-baixa feito para vídeo em tempo real nos sistemas DVI (Digital Video Interactive). Uma outra técnica poderia alocar mais bits para codificar partes importantes da imagem, onde aparecem contornos, e menos bits para regiões homogêneas, facilmente preenchidas, pois há grande redundância. 
Sub-amostragem, também baseada sobre características da visão humana, envolve o uso de menos bits para Crominância (UV) que para Luminância (Y). A interpolação, gerada na saída, resulta em uma reconstrução completa, mas aproximada, da imagem original. A interpolação de valores nas horizontais, nas verticais e nas diagonais de uma matriz pode gerar matrizes 4 ou 16 vezes maiores, princípio este usado em muitos sistemas DVI para sair de 256 linhas da compressão de vídeo e chegar nas 512 linhas.

Para ressaltar padrões contidos em uma imagem, descrições de niveis mais altos, onde os símbolos referem-se a estruturas muito grandes, podem receber mais espaço que formas compostas de várias linhas paralelas em conjunto ("raster forms"). A teoria da codificação exprime o fato de que o vetor de quantização pode induzir maior compressão que a quantização escalar, muitas vezes chamada de quantização. É possivel que o vetor possa estar representado sob a forma de um arranjo 2-D.

\subsubsection{Codificação Híbrida}

Vários métodos de compressão podem ser combinados como, por exemplo, DCT e DPCM ("Diferencial Pulse Code Modulation"), Codificação Sub-bandas e DCT, DPCM e Vetor de Quantização. Sistemas e padrões para compressão de vídeo freqüentemente aplicam compensação de movimento para compressão temporal, codificação por transformadas para compressão espacial, e codificação de Huffman ou Aritmética para compressão estatística.

A Codificação DCT faz a transformação da amostra na dimensão do espaço para a dimensão de freqüências. A informação é reagrupada em blocos de dimensões $2^{n} \times 2^{n}$, geralmente com $n=3$, quando se trata de imagens. Sobre cada bloco é realizado o DCT, gerando um espalhamento das informações concentrada na parte superior da matriz triangular secundária, isto é os elementos de maior freqüência, o restante da matriz praticamente é composto por elementos nulos de frequência. Isto é atingido após aplicação de uma matriz ou vetor de quantização, que tem por função reduzir a magnitude da amostra. A compressão é atingida quando se despresa os elementos de frequeência próximos de zero feito através de processo de varredura na matriz descrito por Tescher [Penn_93], levando assim a perda de informações na recomposição do sinal, tratando-se de um processo "lossy", a perda está vinculada a aspectos fisicos-visuais, podendo ser maior ou menor em função da aplicação. 
Neste sentido, surgiram vários grupos voltados para o desenvolvimento de técnicas que incorporem dois ou mais métodos de compressão agindo em cascata. Cada método empregado trata as informações com o objetivo de antingir, ao final de todos os estágios, uma maior taxa de compressão.

Existem vários grupos com este objetivo: JPEG, que trata da CoD de fotografias em tonscontínuos, H.261 ("Specialist Group on Coding for Visual Telephony"), grupo que estuda CoD de vídeo para serviços aúdio-visuais sob canais $p$ x 64, MPEG ("Moving Picture Experts Group") [Gall_92], para CoD de cenas (imagens em movimento) associadas com som, MHEG ("Multimedia and Hypermedia Information Coding Expert Group"), desenvolvendo $\mathrm{COD}$ da representação de informações de Multimídia e Hipermídia, HyTime ("Standard Music Representation Work Group"), que trabalham com Hipermídia com Linguagem Estruturada Baseada no Tempo [Wall_91], [Fox_91]. Todos os grupos aqui citados fazem parte de um consórcio entre ISO/IEC e CCITT, na busca por um padrão de uso internacional.

No próximo capítulo serão mencionados os principais aspectos que envolvem a CoD proposta por JPEG. A técnica JPEG manter-se-á, pelos próximos dez anos, como um Sistema CoD de dados de fotografias em tons-contínuos [Wall_92]. Desta forma, torna-se extremamente interessante aplicá-lo em compressão e descompressão de imagens geradas a partir de Tomografia por Ressonância Magnética, ToRM.

\subsection{Considerações Finais}

Neste capítulo foram apresentados muitos processos de CoD de dados, separados em métodos com perdas e sem perdas, em função da forma como tratam a codificação dos dados originais e, ao mesmo tempo, apontando para que tipo de informações tais métodos são mais indicados. Muitos destes processos constituem algoritmos patenteados, sendo necessário obter licença de uso. Além disso, encontramos em alguns métodos o uso de tabelas proprietárias empregadas pelos processos de $\mathrm{CoD}$, isto é, de uso exclusivo pelo seu distribuidor.

Alguns algoritmos discutidos aqui possuem várias implementações comercias bastantes difundidas, como é o caso do COMPRESS, utilizado em sistemas UNIX, em que a implementação é baseada no algoritmo LZW, que é uma variação do algoritmo LZ78 desenvolvido por Lempel-Ziv, com refinamentos introduzidos por T. Welch. Da mesma forma, o PKZIP da PKWARE (Glendale Wisc.) e o ARC da System Enhanced Associate 
(Wayne, N.J.) para sistemas baseados em MS-DOS, baseado no LZ78 com tabelas proprietárias [Nels_89]. Estes sistemas, por tratarem apenas a entropia do código fonte, não trazem grandes vantagens quando aplicados a imagens ou fotografias.

Existem várias implementações para Codificação Aritmética, geralmente constituídas por patentes o que, neste caso, torna obrigatória a obtenção de licenças de uso. $O$ próprio JPEG se vale desta codificação, uma vez que atinge compressões de 5 a10 por cento melhores que aquelas obtidas através da codificação de Huffman, porém levando a cálculos bastantes complexos e de dificil convergência, [Wall_91], o que torna bastante atraente o uso da Codificação de Huffinan em sistemas de compressão, principalmente quando a Codificação de Huffman compõe um dos estágios de compressão.

Para dados provenientes de imagens ou fotografias mostra-se bastante interessante o uso de transformadas ou mesmo filtros, fato este explorado pelo JPEG, que sendo um Sistema Híbrido de CoD, faz uso de vetor de quantização e posterior Codificação de Entropia como o último estágio de codificação, propiciando elevadas taxas de compressão.

Desta forma, pode-se concluir que para se atingir elevadas taxas de compressão é necessário um Sistema CoD composto por vários estágios em cascata, onde cada estágio atua sobre $o$ aspecto para o qual foi desenvolvido, constituindo assim um Sistema Hibrido de Compressão. Neste caso, pode ou não haver perdas de algumas das características das informações, isto é, o Sistema de CoD inserir ou não ruído na reconstrução dos dados no processo de descompressão. 


\section{Capítulo 3.}

\section{Características do JPEG}

\subsection{Introdução}

A recomendação da International Telegraph and Telephone Consultative Committee CCITT propõe em sua recomendação T-81 que o Padrão Internacional, relatado pelo número 10918, juntamente com o International Electrotechnical Commission, IEC, e a International Standards Organization, ISO, que criam o Joint Technical Committee 1 JTC1, é aplicável a dados de imagens digitais coloridas e em tons-de-cinza, não sendo aplicável a dados de imagens em Bi-level. Essa recomendação proposta é conhecida como JPEG, Joint Photographic Expert Group, dado o esforço dispendido pelo grupo para atingir este padrão. Todas as figuras e o próprio texto deste capítulo foram adaptados a partir do Padrão Internacional 10918, Information Technology: Requirements and Guidelines [Draf_91].

\subsection{Elementos de uma codificação e reconstrução de imagens}

Existem três elementos especificados:

Um codificador é o modelo que realiza o processo de codificação. Como mostrado na figura 3.1, um codificador recebe como entrada dados digitalizados da imagemfonte, uma tabela de especificação e um conjunto de procedimentos que geram dados de imagem comprimidas.

Um descodificador é o modelo que realiza o processo de descodificação. Como mostrado na figura 3.2, um descodificador toma como entrada dados da imagem comprimida, a tabela de especificação e um conjunto de procedimentos que geram dados digitais da imagem reconstruída.

O formato de intercâmbio, mostrado na figura 3.3, é uma representação dos dados da imagem comprimida que inclui todas as tabelas de especificação usadas no processo de codificação. O formato para intercâmbio é útil para troca entre ambientes da aplicação. 


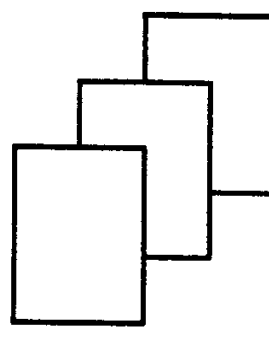

Imagem Fonte

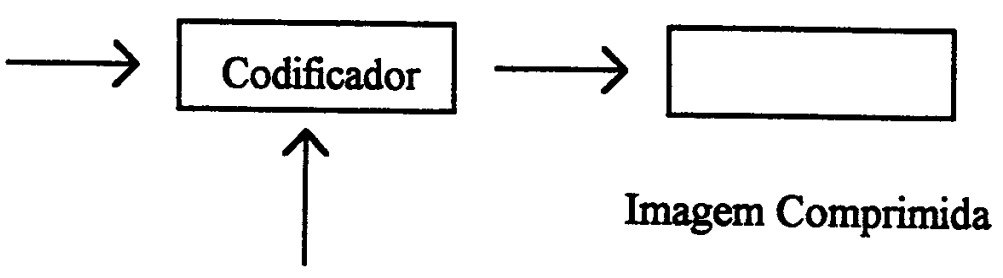

Tabela Especif

Figura 3.1: Diagrama de Codificação da Imagem Fonte.

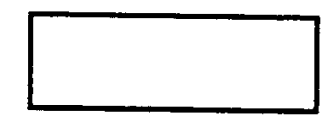

Imagem Comprimida

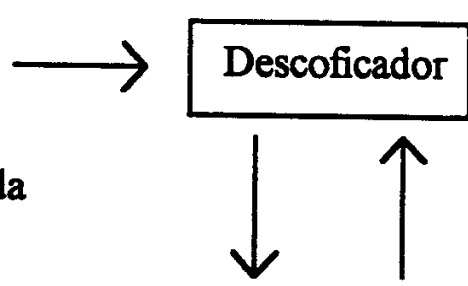

Tabela Especif.

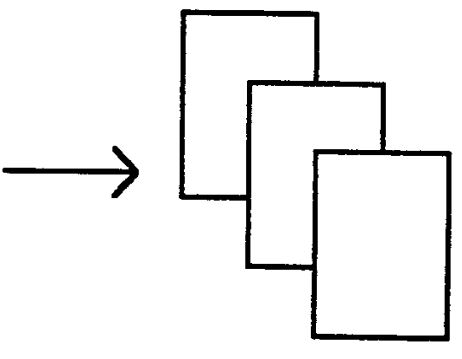

Imagem Reconstruída

Figura 3.2: Diagrama de Reconstrução da Imagem Codificada.

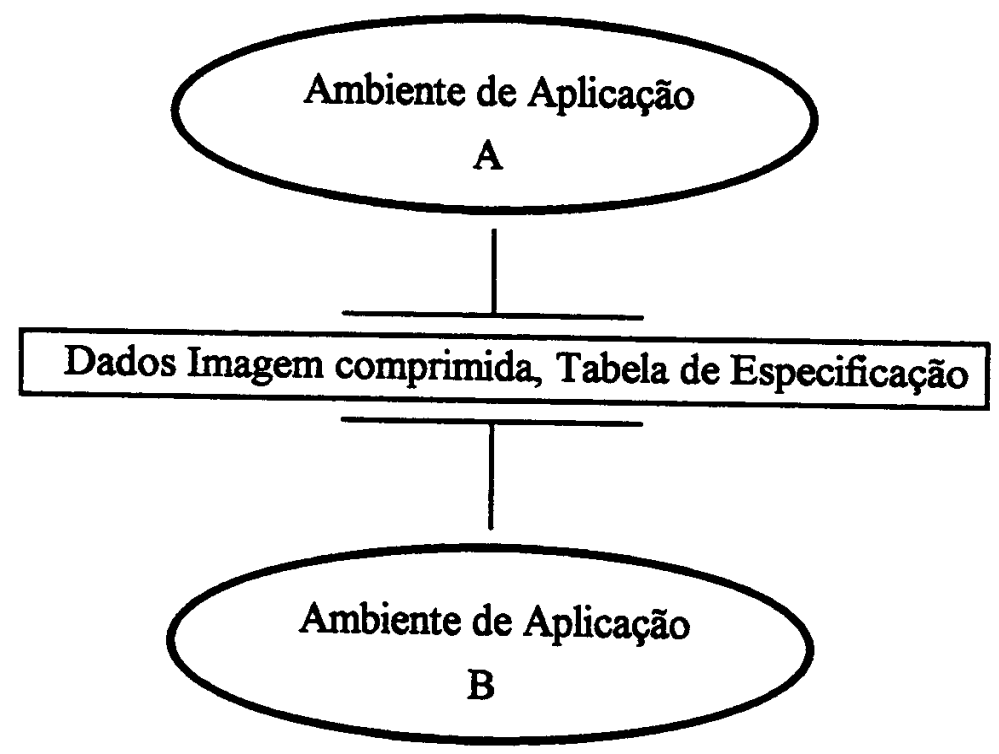

Figura 3.3: Formato de Intercâmbio para Dados de Imagem Comprimida. 
As figuras 3.1 e 3.2 ilustram o caso geral para o qual dados da imagem de tons-contínuos e reconstruídos consistem de múltiplos componentes (uma imagem colorida consiste de múltiplos componentes; uma imagem em escala-de-cinza consiste de apenas um componente). Estas figuras procuram mostrar que as mesmas tabelas especificadas para um codificador, devem ser fornecidas para o descodificador reconstruir a mesma imagem.

O formato de intercâmbio, na figura 3.3, mostra as tabelas que são incluídas dentro da imagem comprimida. Uma imagem comprimida por um processo de codificação específico, dentro de um ambiente da aplicação $A$, é passada para um ambiente diferente $B$, que conhece $O$ formato de intercâmbio. $O$ formato de intercâmbio não especifica uma representação da imagem codificada completa.

\subsection{Compressão lossy e lossless}

A especificação JPEG define duas classes de processos de codificação e descodificação: processo "lossy", também conhecido por Compressão Com Perdas, e "lossless" denominado, de mesma forma, por Compressão Sem Perdas. Métodos de compressão baseados na transformação discreta do cosseno (DCT) são "lossy" permitindo assim compressão substancial, ao mesmo tempo em que produz a reconstrução de imagens com alta fidelidade visual.

O processo de codificação baseado no DCT é chamado processo seqüencial Baseline. Ele possui atributos que são suficientes para muitas aplicações. Além disso, existem processos baseados no DCT que estendem o processo seqüencial baseline para uma grande quantidade de aplicações. Em qualquer descodificador, que use o processo de descodificação baseado no DCT estendido, é obrigatória a presença do processo de descodificação baseline a fim de fornecer a capacidade de descodificação.

A segunda classe de processos de codificação não é baseado no DCT e supre as necessidades de aplicações que requerem compressão com pouca perda ("lossless"). Este processo de codificação e descodificação são utilizados independentemente de quaisquer processos baseados no DCT.

A quantidade de compressão fornecida por quaisquer processos é dependente das características da imagem que está sendo comprimida, bem como da qualidade visual desejada pela aplicação e da velocidade desejada para compressão e descompressão. 


\subsection{Codificação baseada no DCT}

A figura 3.4 mostra os procedimentos principais para todo o processo de codificação baseado no DCT (Anexo I - Equação I e Figura I.5). Ela ilustra um caso especial de uma imagem com uma única componente; assim, é uma simplificação apropriada para propósito de revisão, devido aos processos especificados operarem sobre cada componente da imagem independentemente.

No processo de codificação as entradas de amostras de componentes são agrupadas em uma matriz 8x8 (blocos), e cada bloco é transformado pelo DCT implementado através de uma DCT rápida (FDCT) e um conjunto de 64 valores referenciados como coeficientes DCT. Um dos valores é referenciado como coeficiente DC e os outros 63 como coeficientes AC.

Cada um dos 64 coeficientes é então quantizado usando um dos 64 valores correspondentes na tabela de quantização (determinada por uma das tabelas de especificação mostrada na figura 3.4). Fica em aberto para aplicações poderem especificar valores que personalizem a qualidade visual para sua particular característica da imagem, periférico de visualização e condições de visualização.

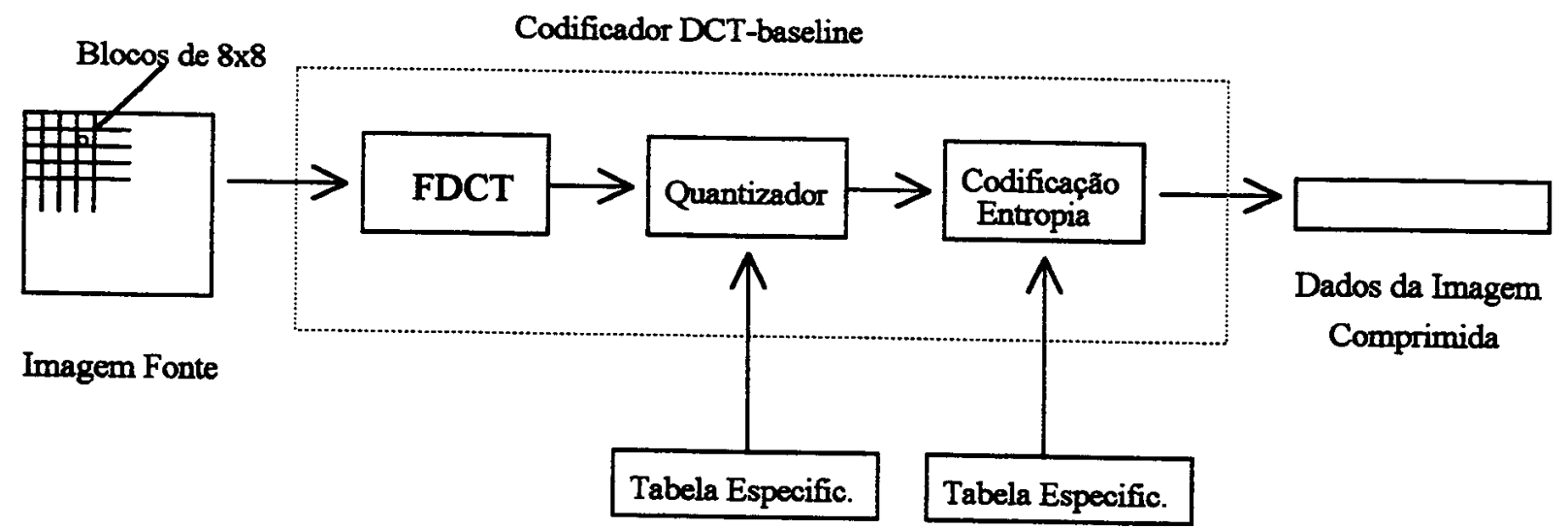

Figura 3.4: Diagrama Básico do Codificador DCT-Baseline.

Após a quantização, o coeficiente DC e os 63 coeficientes AC são preparados para codificação de entropia. $\mathrm{O}$ coeficiente $\mathrm{DC}$ quantizado anteriormente é usado para predizer o coeficiente DC quantizado correntemente, e a diferença é codificada. Os 63 coeficientes AC quantizados não seguem a codificação diferencial, uma vez que são convertidos numa seqüência zig-zag unidimensional, como mostra a figura 3.5. 


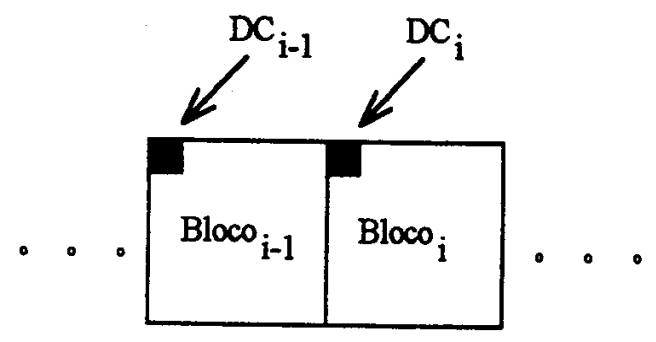

$\mathrm{DIFF}=D C_{i}-D C_{i-1}$

Codificąão DC Diferencial

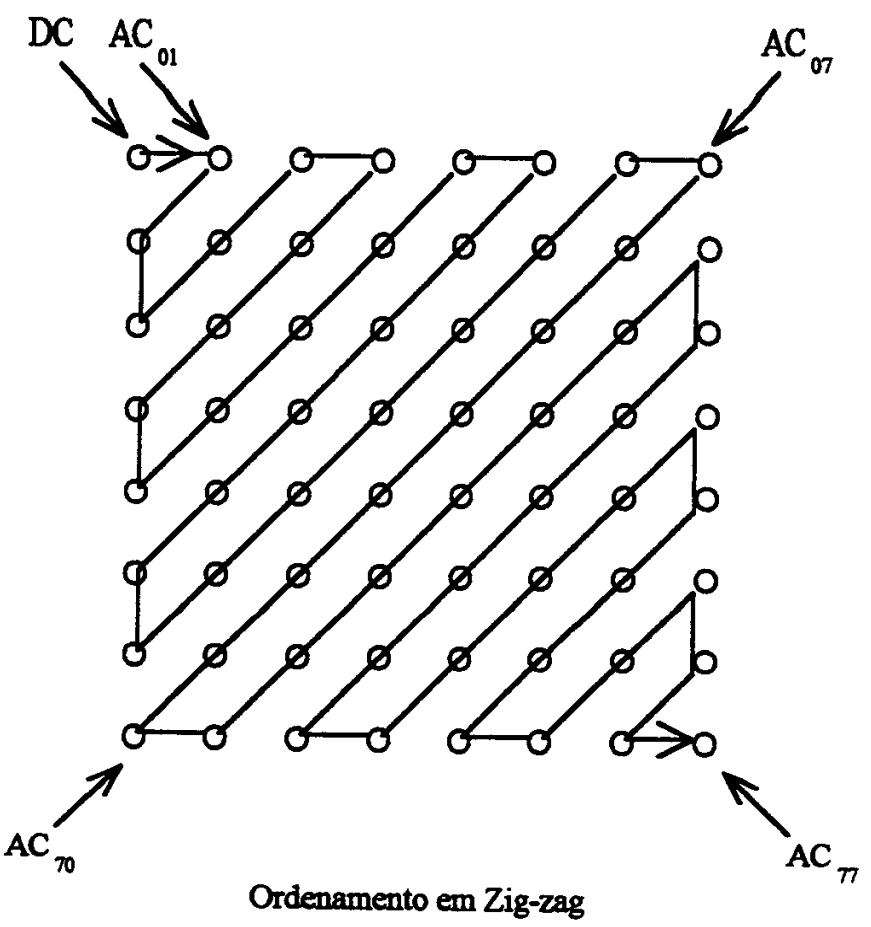

Figura 3.5: Preparação do coeficiente quantizado para codificação de Entropia.

Os coeficientes quantizados são então passados para o procedimento de codificação de entropia que comprime os dados. Um dos dois procedimentos de codificação de entropia podem ser usados, como descrito na seção 3.7. Se a codificação de Huffman é usada, as especificações da tabela de Huffman devem ser fornecidas para o codificador. Pode-se aqui utilizar-se da codificação aritmética e, neste caso, as especificações da tabela de condicionamento da codificação aritmética devem ser fornecidas.

A figura 3.6 mostra os principais procedimentos para o processo completo de descodificação baseado no DCT. Cada passo mostrado desempenha essencialmente o inverso do processo correspondente no codificador. $O$ descodificador de entropia descodifica a seqüência zig-zag dos coeficientes quantizados. Após a desquantização os coeficientes DCT são tranformados em blocos de $8 \times 8$ pela inversa-DCT (IDCT), detalhados no Anexo II - Equação II.3 e Figura II.5. 


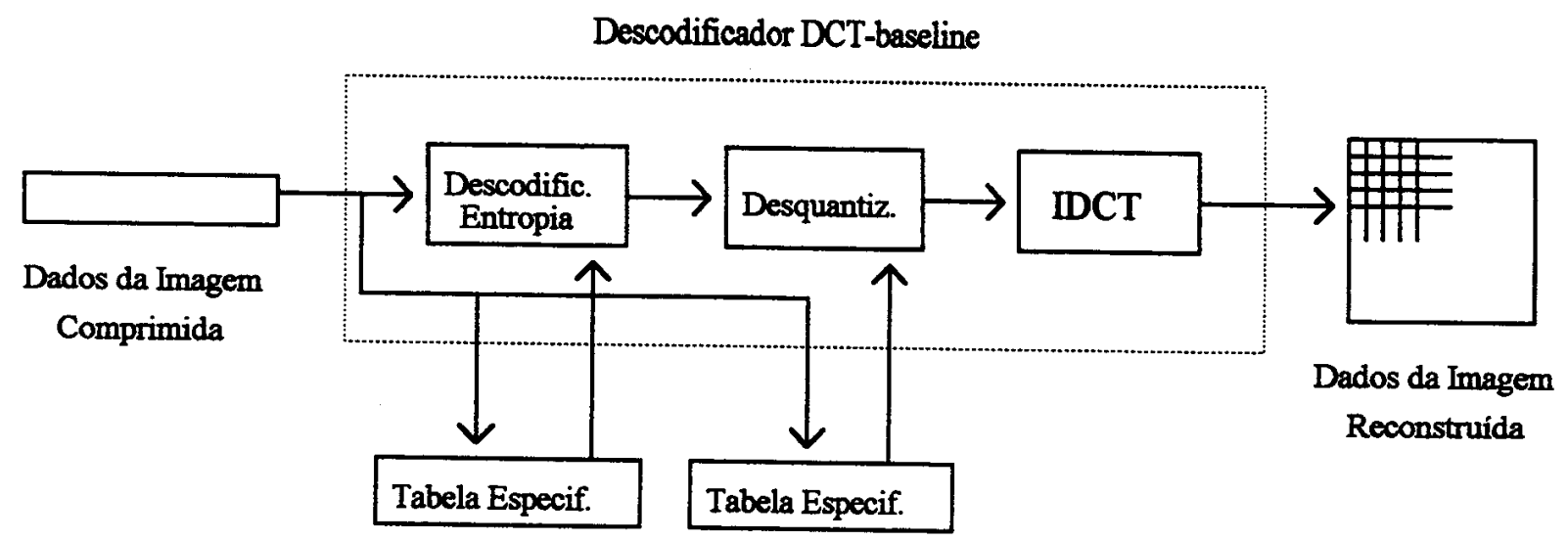

Figura 3.6: Diagrama Básico do Descodificador DCT-Baseline.

\subsection{Codificação lossless}

A figura 3.7 mostra os principais procedimentos para o processo de codificação "lossless". Um previsor combina os valores reconstruídos dos três vizinhos superiores nas posições a, b e c para formar uma previsão da posição x, como mostra a figura 3.8. Esta previsão é então subtraída do valor atual da posição x, e a diferença pode ser codificada, ou pela codificação Huffman ou pela Aritmética.

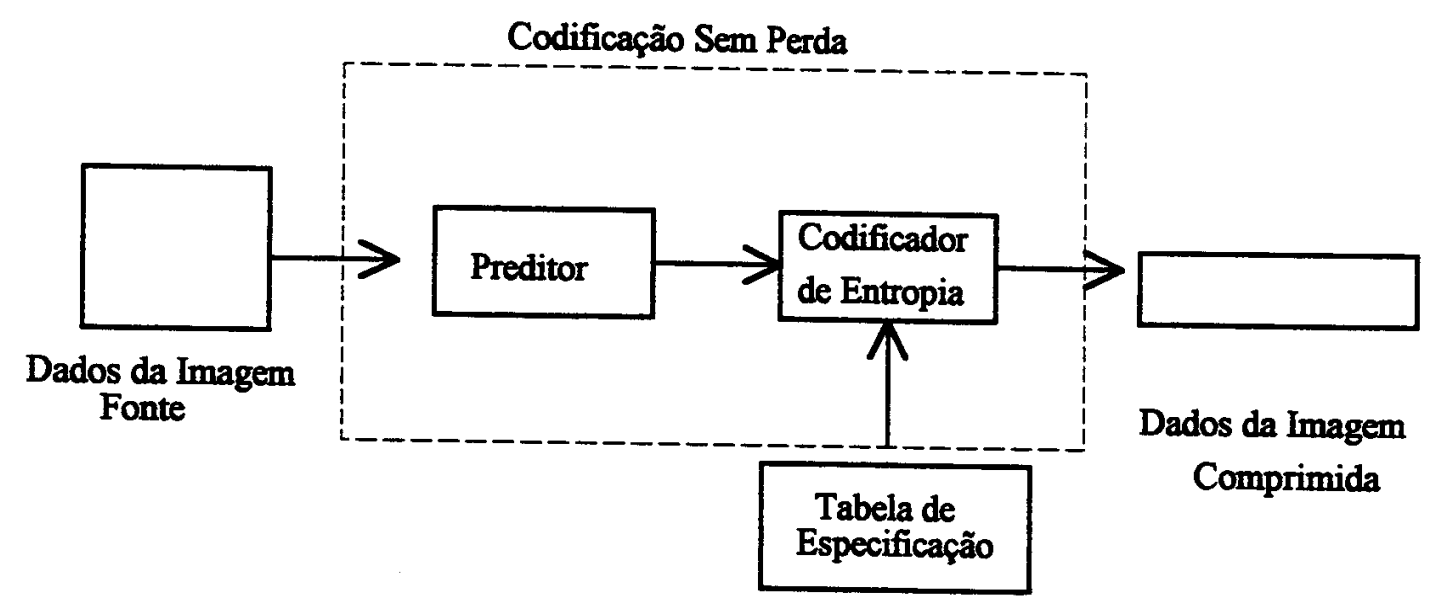

Figura 3.7: Diagrama simplificado da Codificação Sem Perdas.

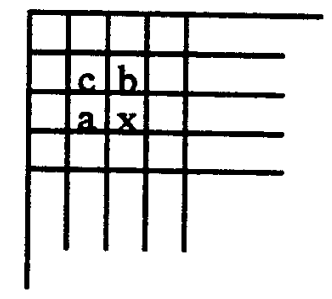

Figura 3.8: Região de Predição da Amostra. 


\subsection{Modos de Operação}

Existem quatro modos de operação distintos sob os quais os vários processos de codificação são definidos: seqüencial DCT, progressivo DCT, "lossless" e hierárquico. O modo "lossless" de operação foi descrita em 3.5. Os outros modos de operação são comparados a seguir.

Para o modo seqüencial DCT, blocos $8 \times 8$ são enviados, bloco-a-bloco, da esquerda para a direita. Após um bloco ter sido quantizado e preparado para entropia, todos os seus 64 coeficientes DCT quantizados podem ser imediatamente codificados para entropia $\mathrm{e}$ retornar dados da imagem comprimida (como descrito em 3.4), minimizando assim o recurso de armazenamento.

Para o modo progressivo DCT, blocos $8 \times 8$ são também codificados na mesma ordem, mas em múltiplas varreduras na imagem. Isto é obtido adicionando-se buffers de memória de coeficientes do tamanho da imagem entre o quantizador e o codificador de entropia. Cada bloco é quantizado, seus componentes são armazenados em buffer, os coeficientes DCT no buffer são então parcialmente codificados em cada uma das múltiplas varreduras. A seqüência normal da apresentação da imagem do descodificador nos modos de operação seqüencial versus progressivo é mostrada na figura 3.9.
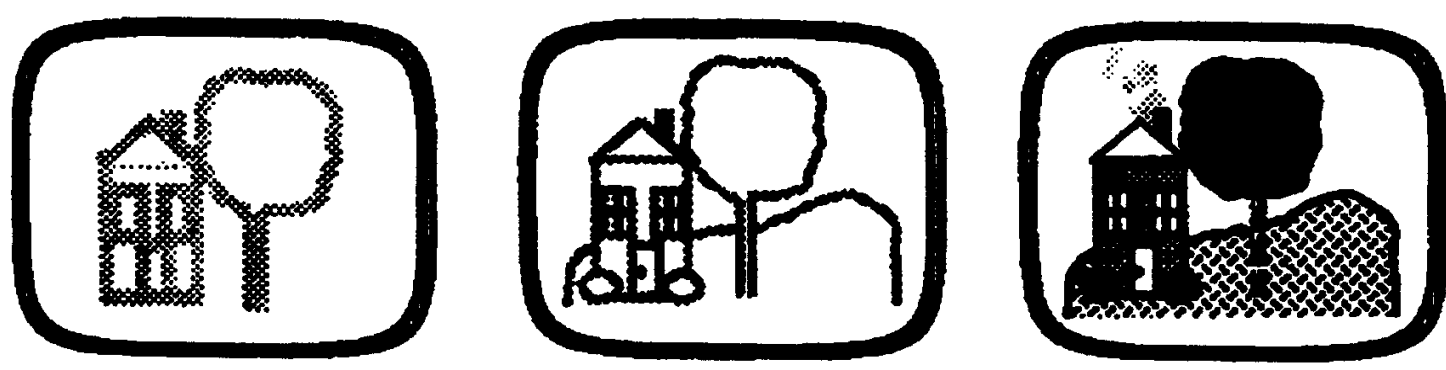

Progressivo
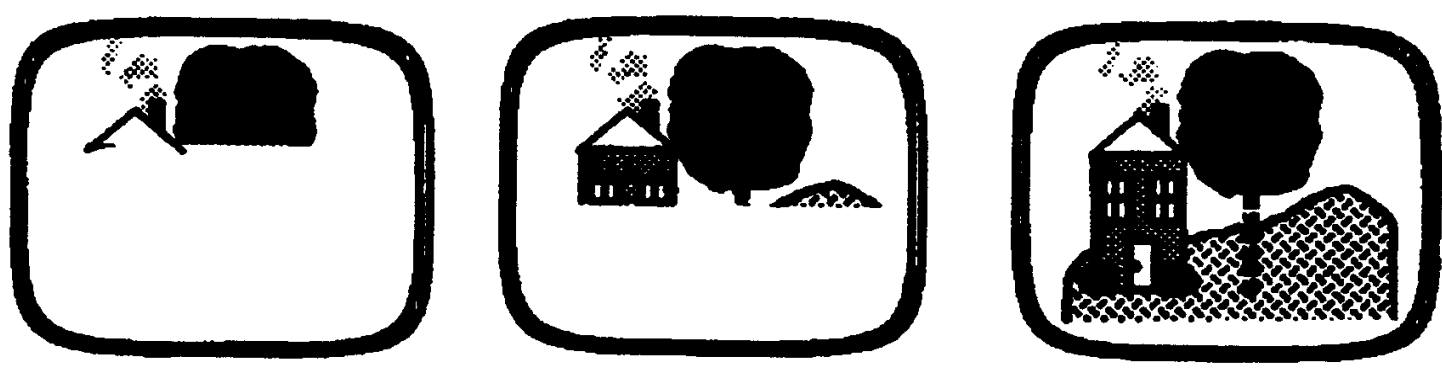

Sequencial

Figura 3.9: Apresentação do modo Progressivo x Seqüencial. 
Existem dois procedimentos pelos quais os coeficientes quantizados no buffer podem ser parcialmente codificados na varredura. Primeiro, apenas uma banda específica de coeficientes da seqüência zig-zag necessita ser codificada, seleção espectral, porque cada banda contém tipicamente coeficientes que ocupam menor ou maior parte do espectro de freqüência de cada bloco. Segundo, os coeficientes da banda corrente não precisam ser codificados na sua totalidade (quantizados) em cada varredura. Na codificação do primeiro coeficiente, um número especificado dos bits mais significativos é inicialmente codificado. Nas varreduras subseqüentes, os bits menos significativos são então codificados. Este procedimento é chamado de aproximação sucessiva. Os procedimentos podem ser usados separadamente ou combinados.

No modo hierárquico, uma imagem é codificada como uma seqüência de frames. Estes frames fornecem componentes de reconstrução referencial que são normalmente necessários para predição nos frames subseqüentes. Exceto para o primeiro frame de uma dada componente, frames diferenciais codificam a diferença entre componentes-fontes e componentes de reconstrução de referência. A codificação das diferenças pode ser feita usando-se apenas o processo baseado em DCT, apenas o processo "lossless" ou processo baseado em DCT com um processo "lossless" final para cada componente. Filtros passa-alta e passa-baixa podem ser usados para fornecer uma pirâmide de resoluções espaciais como mostra a figura 3.10. Alternativamente, o modo hierárquico pode ser usado para promover a qualidade das componentes reconstruídas numa dada resolução espacial.

O modo hierárquico oferece uma apresentação progressiva similar ao modo progressivo baseado em DCT, mas é útil em ambientes que têm necessidades de multi-resolução, ou ainda, onde haja necessidade de transmissão progressiva para um estágio "lossless" final. 

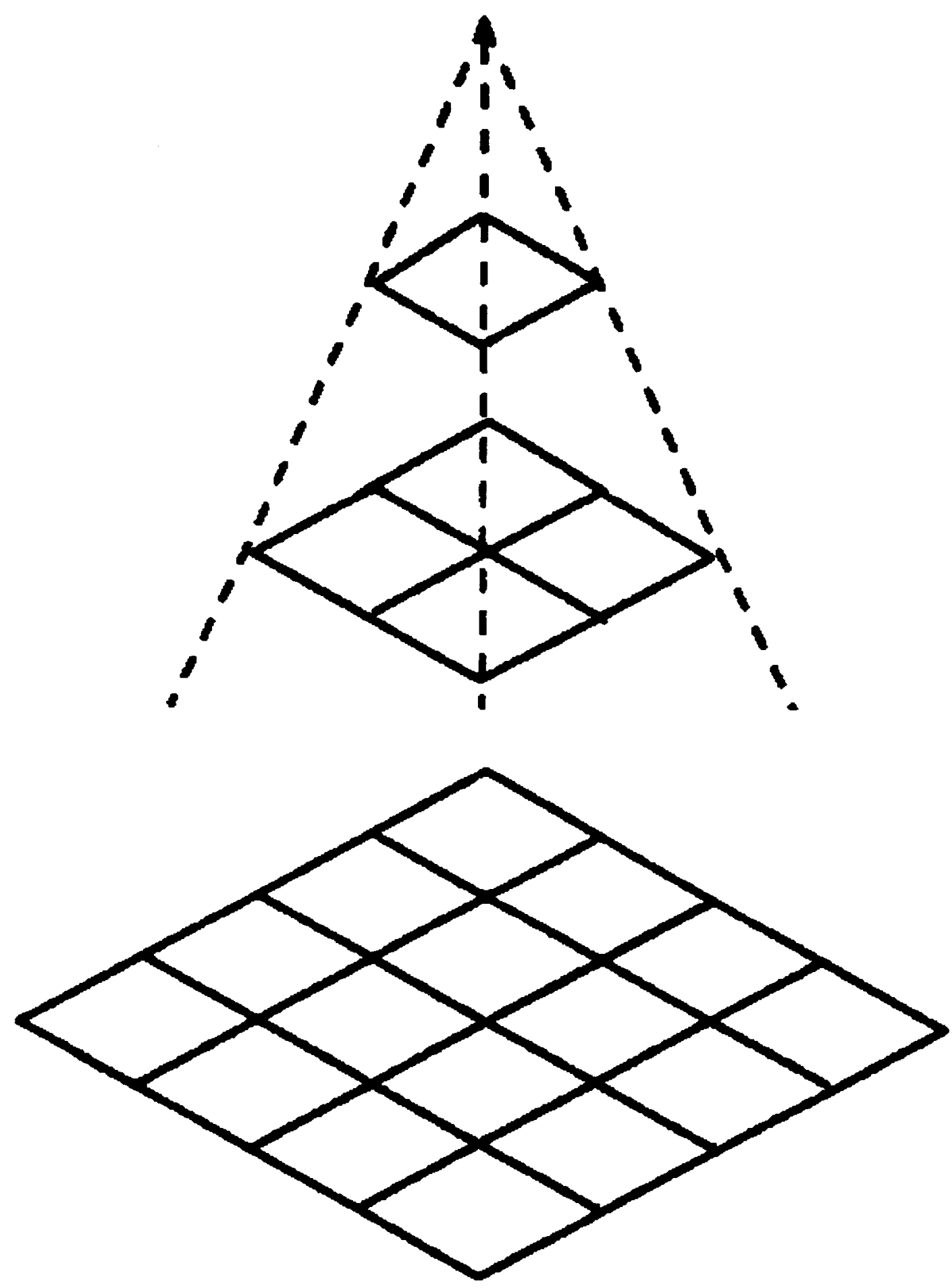

Figura 3.10: Codificação com Multi-Resolução Hierárquica.

\subsection{Alternativas de codificação de entropia}

Duas alternativas de procedimentos de codificação de entropia podem ser aplicadas Codificação Huffman e Aritmética. $O$ procedimento de codificação Huffiman utiliza tabelas 
de Huffman, sendo determinado por uma das tabelas de especificação mostradas nas figuras 3.1 e 3.2. Procedimentos de Codificação Aritmética utilizam tabelas de condicionamento de codificação aritmética, e podem ser também determinados por uma tabela de especificação. Nenhum valor para tabela de Huffman é especificado, de tal modo que as aplicações podem escolher tabelas apropriadas para o seu próprio ambiente. Tabelas default são definidas para o condicionamento da Codificação Aritmética.

O processo de codificação baseline usa codificação Huffiman, enquanto os processos baseados em DCT estendido e "lossless" podem usar tanto codificação Huffman como Aritmética.

\subsection{Precisão da amostra}

Para o processo baseado em DCT, duas alternativas de precisão da amostra são especificadas: ou 8 ou 12 bits por amostra. Aplicações que usam amostra com outras precisões podem utilizar 8 ou 12 bits de precisão pelo deslocamento apropriado da amostra da imagem-fonte (Anexo II seção A.I.5.1). O processo baseline usa apenas 8 bits de precisão. Implementações baseadas em DCT, que manipulam amostras da imagem-fonte de 12 bits, necessitam de recursos computacionais maiores do que aquelas que manipulam imagens-fontes de apenas 8 bits. Para processos "lossless" a precisão da amostra é especificada de 2 a 16 bits.

\subsection{Controle de múltiplos componentes}

Controle de múltiplos componentes são os procedimentos que controlam a ordem em que os dados da imagem-fonte entram para o processo de codificação, assegurando que o conjunto apropriado da tabela de dados seja aplicado para cada unidade-dado apropriada na imagem. Uma unidade-dado é uma amostra para o processo "lossless" e um bloco 8x8 de amostra para o processo baseado em DCT. 


\subsubsection{Múltiplos componentes entrelaçados}

A figura 3.11 mostra um exemplo de como um processo de codificação seleciona múltiplos componentes da imagem-fonte, e conjuntos múltiplos da tabela de dados, para o procedimento de codificação. A imagem-fonte, neste exemplo, consiste de três componentes: A, B e C, e existem dois conjuntos da tabela de especificação.

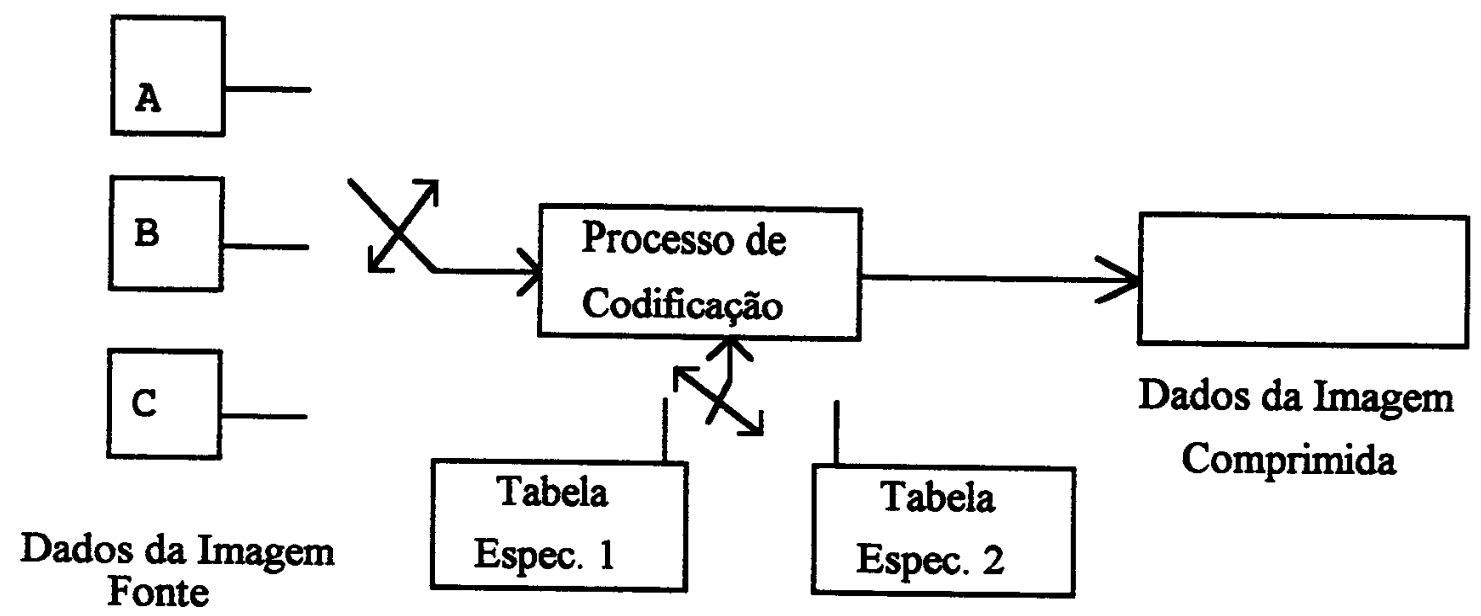

Figura 11: Controle dos componentes - Entrelaçados e tabelas.

No modo seqüencial, a codificação é não-entrelaçada se o codificador comprime todas as unidade-dados da imagem na componente $\mathrm{A}$, antes de iniciar a componente $\mathrm{B}$, e então fazer toda a componente $B$ antes de $C$, enquanto que na codificação entrelaçada o codificador comprime uma unidade-dados de $\mathrm{A}$, uma unidade-dados de $\mathrm{B}$, uma unidade-dados de $\mathrm{C}$, de modo cíclico, ilustradas na figura 3.12 que mostra um caso em que todas as três componentes da imagem têm dimensões idênticas: $X$ colunas por $Y$ linhas, para um total de $\mathrm{n}$ unidades-dados cada. 

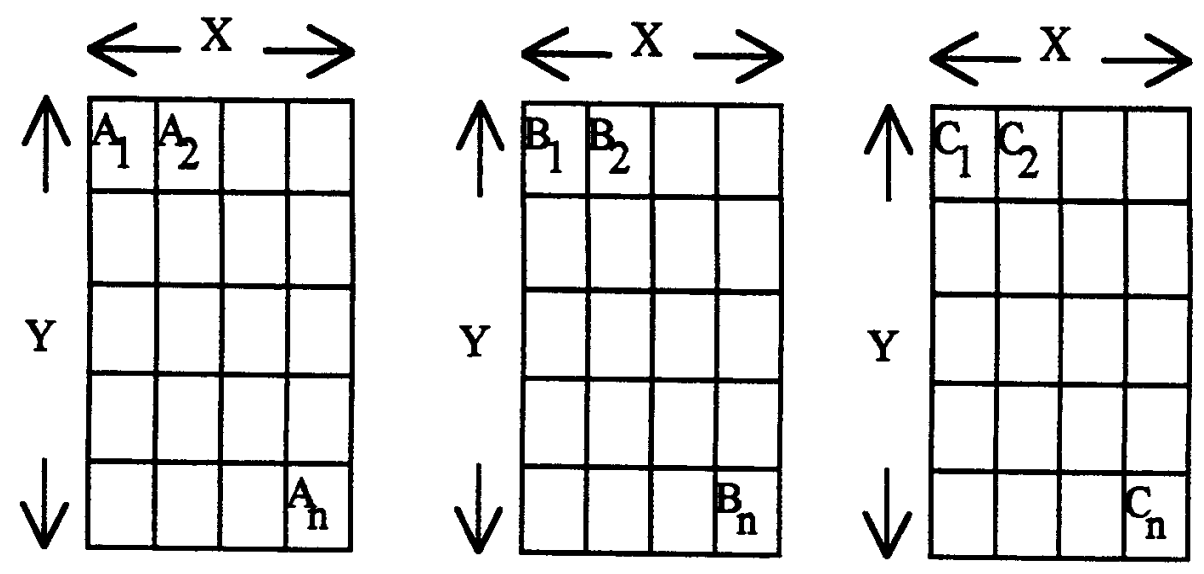

$$
A_{1}, A_{2}, \ldots A_{n}
$$

$\mathrm{B}_{1}, \mathrm{~B}_{2}, \ldots \mathrm{B}_{\mathrm{n}}$

Varredura 1

Varredura 2

$C_{1}, C_{2}, \ldots C_{n}$

Varredura 3

Modo Não-Entrelaçado - Ordem da Codificação da Unidade de Dados

$$
\begin{gathered}
A_{1}, B_{1}, C_{1}, A_{2}, B_{2}, C_{2}, \ldots A_{n}, B_{n}, C_{n} \\
\text { Varredura } 1 \\
\text { Modo Entrelaçado - Ordem da Codificação da Unidade de Dados }
\end{gathered}
$$

Figura 3.12: Ordem da Codificação Modo Entrelaçado x Não-Entrelaçado.

A figura 3.13 mostra um caso em que duas das componentes, B e C, têm a metade do número de amostras horizontais relativas à componente $\mathrm{A}$. Neste caso, duas unidades-dados de A são entrelaçadas com uma de cada em B e C.

\subsubsection{Unidade Codificada Mínima}

Relacionado ao conceito de entrelaçamento de múltiplos componentes está a unidade codifida mínima (MCU). Se os dados da imagem comprimida estão não-entrelaçados, o MCU é definido como uma unidade de dados. Por exemplo, na figura 3.12 o MCU para o caso não-entrelaçado é uma unidade de dados unitária. Se o dado comprimido é entrelaçado, o MCU contém uma ou mais unidades de dados para cada componente. Para o caso entrelaçado da figura 3.12, o MCU (inicial) consiste de 3 unidades de dados entrelaçados Al, B1, C1. No exemplo da figura 3.13, o MCU (inicial) consiste de 4 unidades de dados A1, A2, B1, C1. 

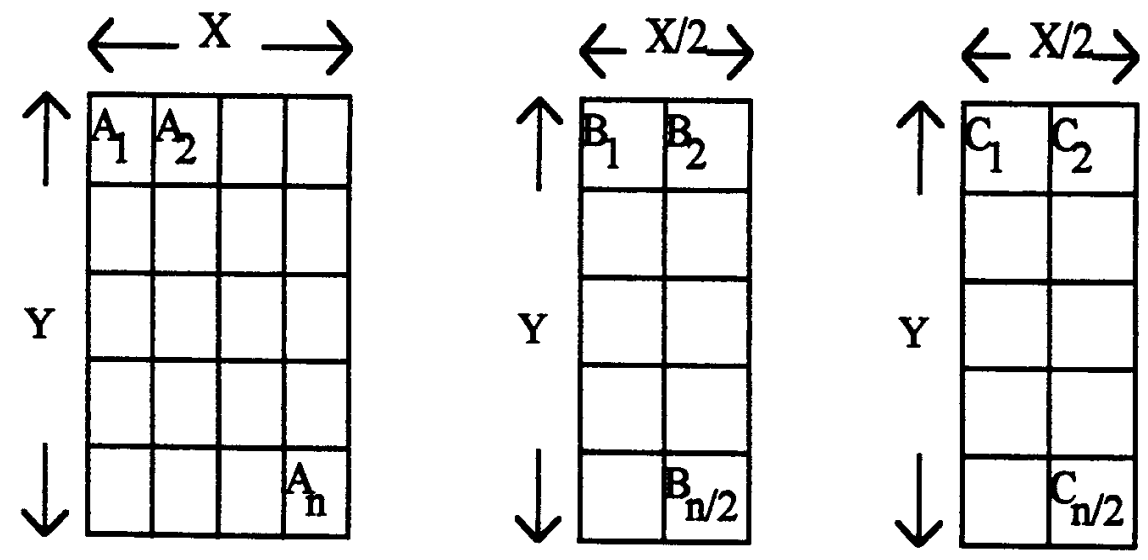

$$
A_{1}, A_{2}, B_{1}, C_{1}, A_{3}, A_{4}, B_{2}, C_{2}, \ldots A_{n-1}, A_{n}, B_{n / 2}, C_{n / 2}
$$

Varredura 1

Modo Entrelaçado - Ordenamento da Codificação da Unidade de Dados

Figura 3.13: Componentes para Ordenamento Entrelaçado com dimensões diferentes. 


\subsection{Resumo do processo de codificação}

A tabela 1 fornece um resumo das características essenciais dos distintos processos de codificação.

Processos Baseline (Necessários para todos os descoficadores baseados DCT)

Processo baseado em DCT

Imagem-fonte: amostras de 8 bits em cada componente

Seqüencial

Codificação Huffman: Tabelas 2 AC e 2 DC

Descodificadores podem processar varreduras com 1, 2, 3 e 4 componentes

Varreduras entrelaçadas e não-entrelaçadas.

\section{Processos Baseados em DCT Estendido}

Processo baseado em DCT

Imagem-fonte: amostras de 8 bits ou 12 bits

Seqüencial ou progressivo

Codificação Huffman ou Aritmética: Tabelas 4 AC e 4 DC

Descodificadores podem processar varreduras com 1, 2, 3 e 4 componentes

Varreduras entrelaçadas e não-entrelaçadas.

\section{Processos "Lossless"}

Processo preditivo (não baseado no DCT)

Imagem-fonte: amostras de $\mathrm{N}$ bits $(2<=\mathrm{N}<=16)$

Seqüencial

Codificação Huffman ou Aritmética: Tabelas 4 DC

Descodificadores podem processar varreduras com 1, 2, 3 e 4 componentes

Varreduras entrelaçadas e não-entrelaçadas.

\section{Processos Hierárquicos}

Múltiplos Frames (não-diferencial e diferencial)

Usa processos Baseados em DCT Estendido ou "Lossless"

Descodificadores podem processar varreduras com 1, 2, 3 e 4 componentes

Varreduras entrelaçadas e não-entrelaçadas. 


\subsection{Consideraçð̃es Finais}

Este capítulo mostrou como o processo de compressão de dados baseado em DCT pode ser realizado de acordo com o que está especificado pelo Padrão Intemacional 10918 da ISO/IEC - CCITT de acordo com [Draf_91] no Anexo II que trata das Informações Tecnológicas, de forma clara e objetiva, para atender a necessidade de comprimir e reconstruir imagens, com o objetivo de preservar e transmitir dados de imagens em contínuos tons-de-cinza e coloridas, contendo no máximo quatro componentes por amostra. 


\section{Capítulo 4.}

\section{Módulos da Implementação baseado na Técnica JPEG}

\subsection{Introdução}

Neste Capítulo são descritos os principais módulos implementados para a CoD baseados na técnica proposta por JPEG. A implementação segue o algoritmo descrito no Capítulo 3 para a CoD com base no Processo Baseline. Neste processo de codificação com perdas, as imagens 'são tratadas por um conjunto de módulos e fases que procuram atender as características atuais do grupo de RM do IFSC. $O$ grupo ainda não adotou um formato padrão para $O$ armazenamento de imagens, sendo estas geradas em múltiplos tons-de-cinza com 8 bits de resolução para cada elemento de imagem. Um dos formatos, atualmente adotados, adiciona no início do arquivo 4 bytes os quais representam a quantidade de linhas e colunas, geradas pela varredura, seguidos dos dados da imagem.

\subsection{Módulos da Implementação}

A implementação dos módulos do sistema de Compressão seguiu a ordem indicada pela figura 3.4, dividida em três módulos que tratam primeiramente do cálculo do DCT, da Quantização e, posteriormente, da Codificação de Entropia do código gerado. Inversamente, no processo de descompressão, é efetuada a reconstrução da Imagem, conforme já ilustrado na figura 3.6.

Antes que o processo de compressão se inicie, os dados da Imagem Fonte são segmentados na memória em blocos de 8x8 para se dar início ao cálculo da transformada discreta do cosseno. Uma vez que um bloco tenha sido processado pelo módulo FDCT, ele é quantizado, isto é, cada elemento da matriz resultante é dividido por um fator correspondente, denominado fator de quantização, com o objetivo de reduzir a precisão com que os coeficientes DCT são representados, convertendo-se tais coeficientes para a suas respectivas representações inteiras. A seguir, tem-se a geração da seqüência ZigZag, para a codificação DC e AC (figura 3.5) e, então, são montadas as tabelas que compõem a Codificação da Entropia baseada na Codificação de Huffman para composição final das tabelas modificadas pela codificação JPEG. 
A Descompressão trata da reconstrução da Imagem, conforme demonstra a figura 3.6. Inicía-se a Descodificação fazendo-se a carga das tabelas em memória, tanto a tabela de Quantização quanto as tabelas de Huffman modificadas por JPEG, para então fazer a reconstrução da Imagem. A partir deste ponto os dados da imagem são reconstruídos pela descodificação do código comprimido pelo módulo de descodificação de entropia de Huffman. $O$ módulo seguinte trata da montagem da seqüência ZigZag seguido da reconstrução dos blocos de $8 \times 8$ para proceder à Desquantização e, então, iniciar o cálculo da IDCT (transformada inversa do cosseno discreto). Ao final destes passos, a imagem terá sido reconstruída. Cabe ressaltar que a imagem reconstruída não é idêntica à imagem fonte, uma vez que a CoD da proposta JPEG implica em perdas "lossy". Isto ocorre devido ao processo de quantização que subestima ou superestima coeficientes DCT quantizados quando aproximados para o inteiro mais próximo.

\subsubsection{Transferência de dados da imagem fonte}

$O$ arquivo contendo os dados da imagem fonte é transferido byte-a-byte para montar um vetor de blocos de $8 \times 8$ bytes. Este processo pode ser verificado no seguinte fragmento de código:

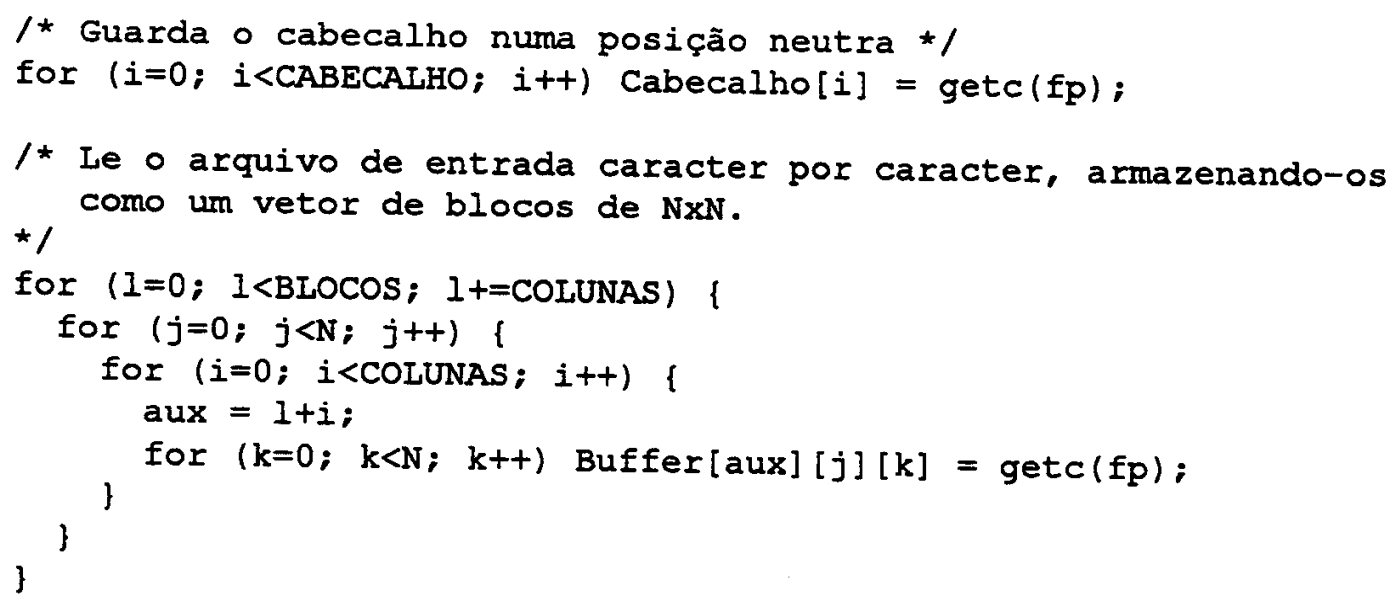

Normalmente, um arquivo de imagem possui um descritor para indicar algumas características, tais como o número de LINHAS e COLUNAS dos bytes que compõe a imagem, tons-de-cinza e "frames". Essas informações não podem sofrer alterações devido às perdas decorrentes do processo de compressão "lossy". Sendo assim, é interessante aplicar um algoritmo de compressão "lossless", caso ela ocupe muitos bytes. No caso específico desta implementação, devido ao formato do arquivo de imagem tomográfica possuir apenas 4 bytes, para indicar a quantidade de linhas e colunas de bytes ocupadas pela imagem, nenhum tratamento de compressão foi aplicado. 
A quantidade de BLOCOS existentes em uma imagem varia de acordo com a quantidade de IINHAS e COLUNAS de bytes existentes. Para exemplificar, uma imagem que tenha 256 linhas por 256 colunas, tem 1024 blocos de 8x8. Este valor é obtido segundo a fórmula:

$$
\text { BLOCOS }=\frac{\text { LINHAS * COLUNAS }}{\mathrm{N}^{2}}
$$

Dependendo da disponibilidade de memória, pode ser que seja necessário particionar o processo de carga em vários passos, onde cada passo realiza a transferência de um conjunto determinado de blocos $8 \times 8$ (BLOCOS), desde a codificação DCT até a entropia.

\subsubsection{Implementação do FDCT}

Um dos parâmetros considerados para se avaliar um método de compressão é a velocidade com o qual ele desempenha sua tarefa. Sendo assim, têm sido propostos diversos algoritmos para se calcular a Transformada Discreta do Cosseno, a fim de minimizar a quantidade de operações aritméticas [Loef_89][Ahme_74].

A fórmula DCT para gerar um conjunto de 8 pontos $\left\{y_{n}, n=0,1,2, \ldots, N-1\right\}$ dado $\left\{x_{n}, n=0,1,2, \ldots, N-1\right\}$ é descrita abaixo :

\[ y(k)=C \cdot a_{k} \cdot \sum_{n=0}^{N-1} x(n) \cdot \cos \left(\frac{2 \pi \cdot(2 n+1) \cdot k}{4 N}\right) \]
onde $a_{0}=\cos \left(\frac{\pi}{4}\right) ; \quad a_{k}=1$ para $k=0, \ldots, N-1$.

A codificação imediata desta fórmula pode resultar em um algoritmo extremamente lento, uma vez que são calculados, a cada iteração, valores de cosseno multiplicados com o vetor de entrada.

A classe de algoritmos que procuram reduzir a quantidade de operações necessárias para o cálculo do DCT é conhecida como "Fast DCT" (FDCT).

Neste trabalho, a implementação do FDCT foi realizada com base no algoritmo descrito na figura 4.1. Este algoritmo realiza o DCT sobre um mesmo conjunto de pontos 
$\left\{x_{n}, n=0,1,2, \ldots, N-1\right\}$, requerendo apenas 11 multiplicações e 29 adições [Loef_89]. Os símbolos encontrados no algoritmo são descritos na figura 4.2 .

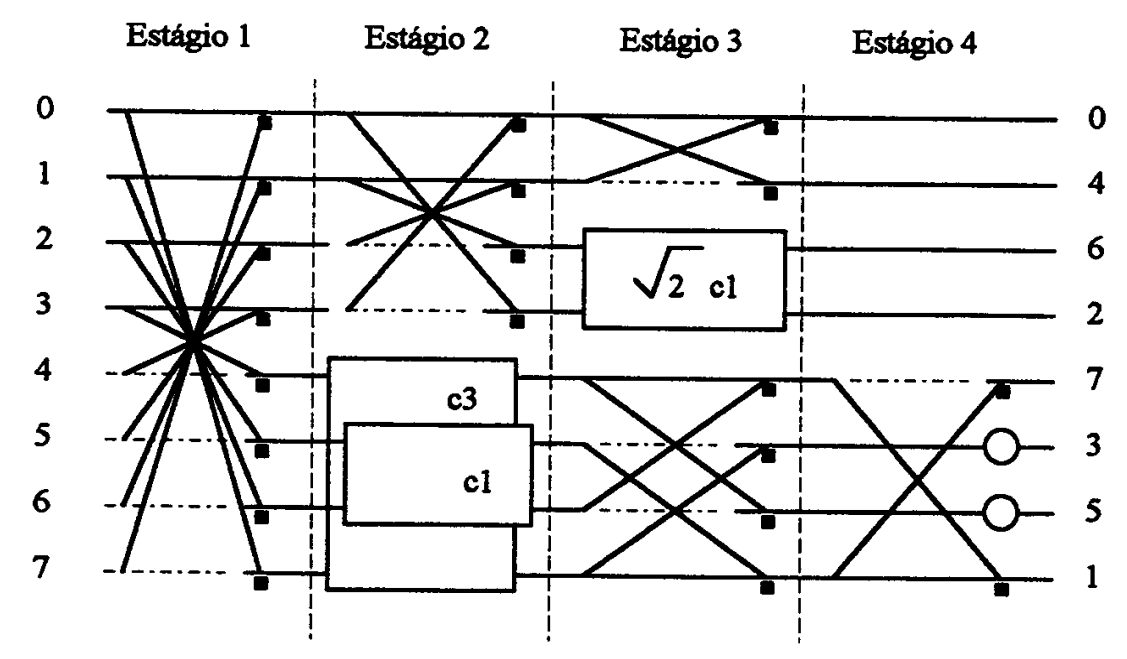

Figura 4.1: Algoritmo DCT para 8 pontos com 11 multiplicação 29 adições

Este algoritmo, composto por quatro estágios seqüenciais, é rapidamente implementado considerando que a saída de cada estágio constitui a entrada para o próximo. A figura 4.2 descreve os blocos construtores deste algoritmo.

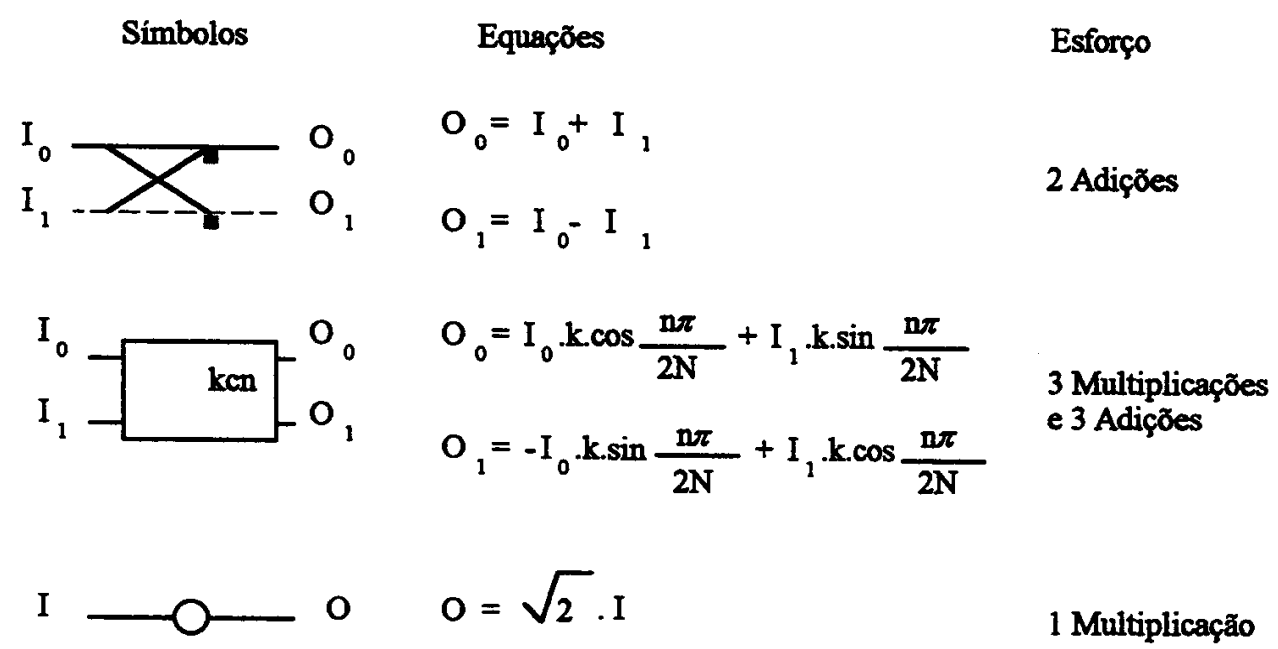

Figura 4.2: Símbolos Usados no Algoritmo DCT

No segundo bloco construtor, a rotação pode ser calculada usando apenas 3 multiplicações e 3 adições ao invés de 4 multiplicações e duas adições, usando a seguinte relação: 


$$
\begin{aligned}
& y_{0}=a \cdot x_{0}+b \cdot x_{1}=(b-a) \cdot x_{1}+a \cdot\left(x_{0}+x_{1}\right) \\
& y_{1}=-b \cdot x_{0}+a \cdot x_{1}=-(b+a) \cdot x_{0}+a \cdot\left(x_{0}+x_{1}\right)
\end{aligned}
$$

Para exemplificar, considere o seguinte fragmento de código que mostra a maneira como o estágio 3 foi implementado:

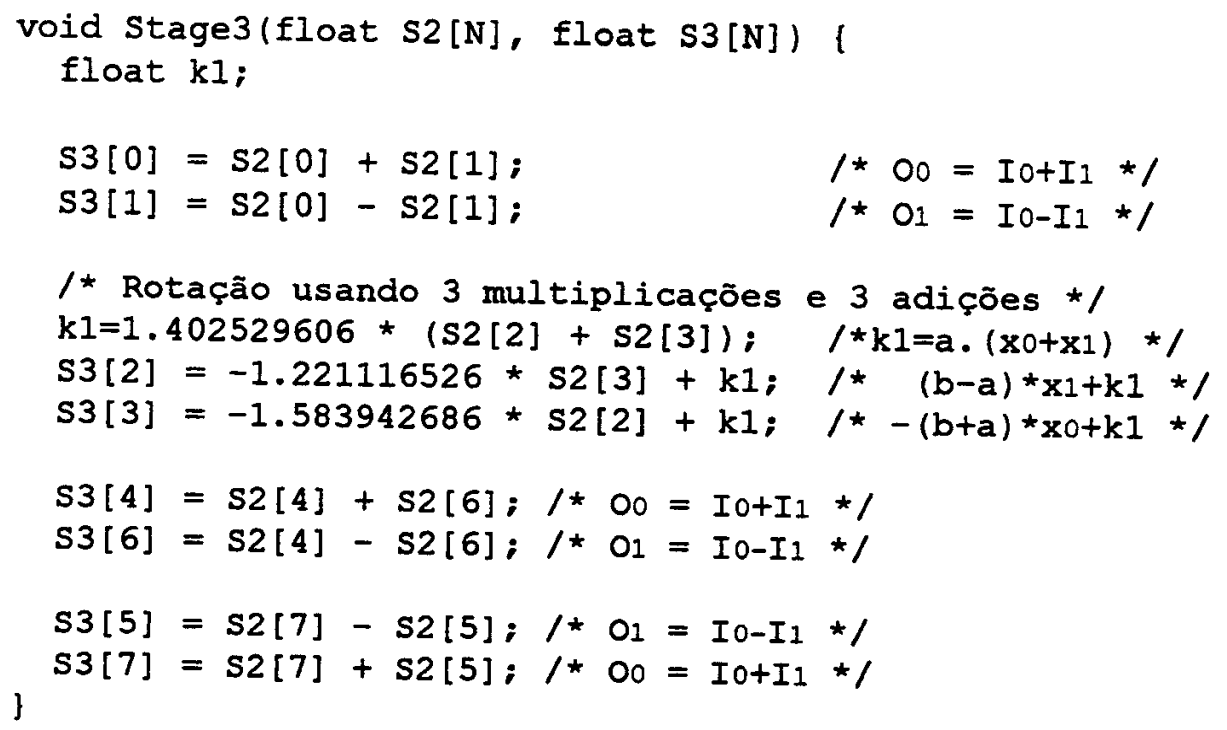

Para a realização da 2D-DCT é necessário que o conjunto de quatro estágios, 1D-DCT, seja aplicado inicialmente a todas as linhas seguido da aplicação para todas as colunas, conforme o código abaixo:

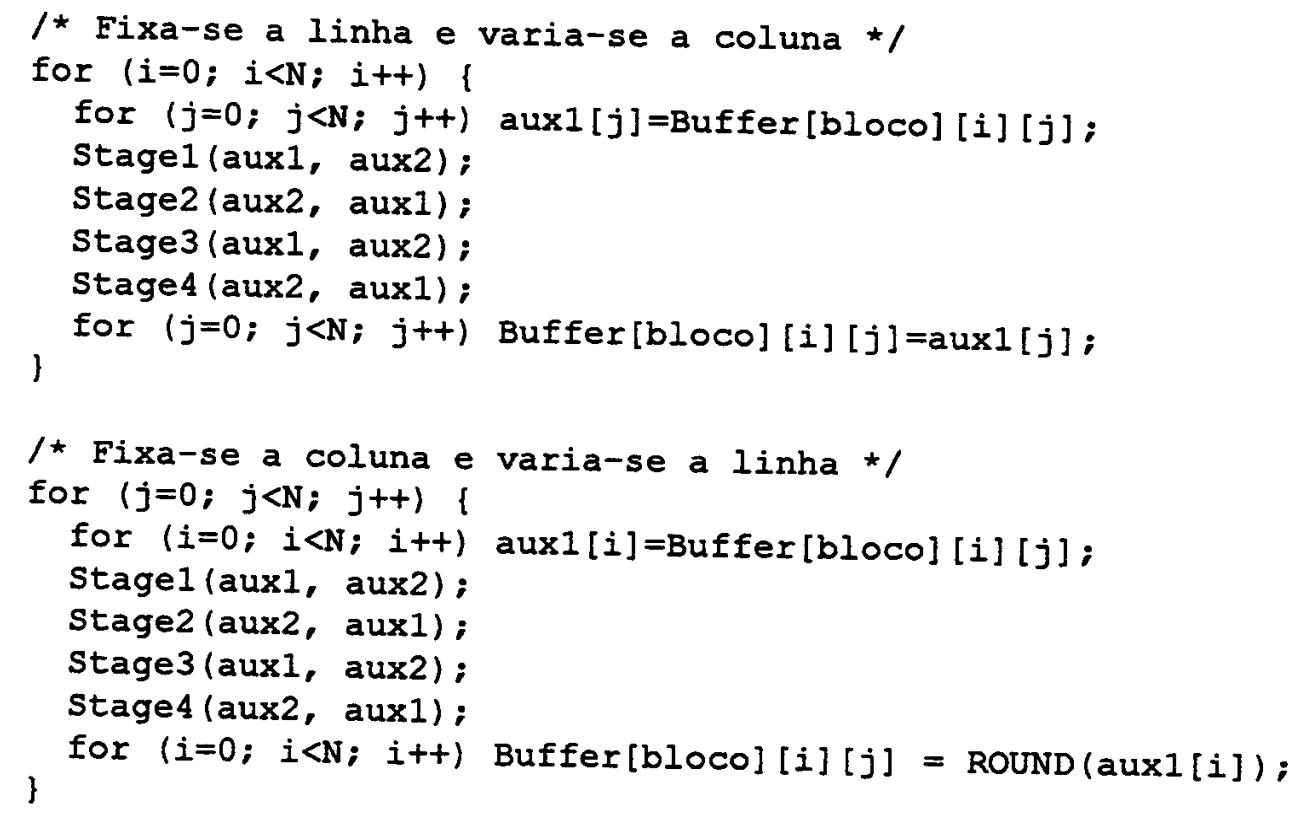

Este processo deve ser repetido para todos os blocos de 8x8 que compõem a imagem. 


\subsubsection{Quantização do FDCT}

Como discutido anteriormente, a quantização é um processo que provoca perdas devido à necessidade de converter os coeficientes DCT, gerados anteriormente na representação inteira.

Os fatores de quantização correspondentes aos elementos do bloco são representados em uma matriz 8x8. O padrão JPEG não determina nenhuma matriz de quantização, tornando flexível a utilização de matrizes de quantização especificas para uma determinada aplicação.

Sendo assim, esta implementação utilizou-se do seguinte método para gerar a matriz de quantização [Nels_92]:

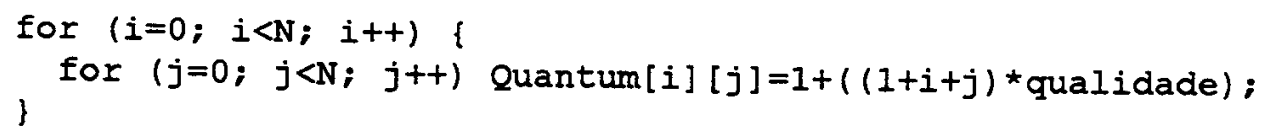

A variável qualidade, utilizada acima, permite parametrizar a geração da matriz, aumentando ou reduzindo os fatores homogeneamente. $O$ aspecto desta matriz utilizando o valor de qualidade $=2$ é o seguinte:

\begin{tabular}{|r|r|r|r|r|r|r|r|}
\hline 3 & 5 & 7 & 9 & 11 & 13 & 15 & 17 \\
\hline 5 & 7 & 9 & 11 & 13 & 15 & 17 & 19 \\
\hline 7 & 9 & 11 & 13 & 15 & 17 & 19 & 21 \\
\hline 9 & 11 & 13 & 15 & 17 & 19 & 21 & 23 \\
\hline 11 & 13 & 15 & 17 & 19 & 21 & 23 & 25 \\
\hline 13 & 15 & 17 & 19 & 21 & 23 & 25 & 27 \\
\hline 15 & 17 & 19 & 21 & 23 & 25 & 27 & 29 \\
\hline 17 & 19 & 21 & 23 & 25 & 27 & 29 & 31 \\
\hline
\end{tabular}

Note-se que os fatores de quantização crescem da esquerda para a direita na direção da diagonal principal.

A quantização, propriamente dita, é realizada da seguinte maneira:

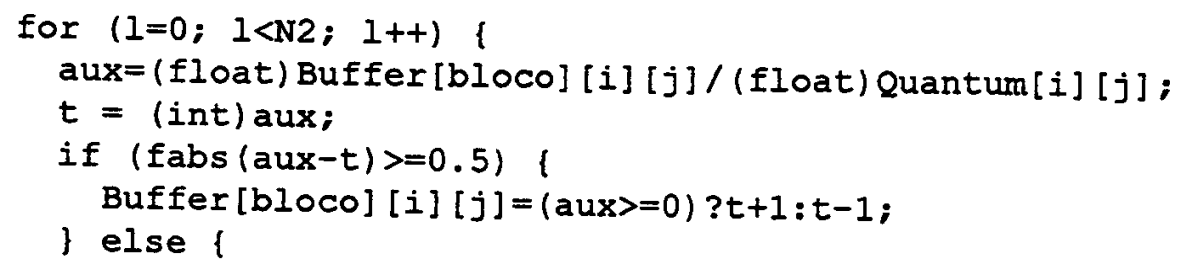


O código assume que todos os blocos de $8 \times 8$, com os coeficientes gerados pelo DCT estão armazenados no vetor Buffer. Cada elemento do bloco é dividido pelo seu correspondente fator de quantização. $O$ resultado é então arredondado para o inteiro mais próximo e armazenado novamente no bloco.

Uma vez que os fatores de quantização crescem da esquerda para a direita na direção da diagonal principal, os valores quantizados do bloco tenderão a diminuir neste mesmo sentido e direção, aumentando a probabilidade de ocorrências de zeros na matriz triangular inferior do bloco.

\subsubsection{Geração da seqüência ZigZag}

Devido a alta probabilidade de se encontrar zeros na matriz triangular inferior de um bloco, após a quantização, o padrão JPEG determina a reorganização dos valores quantizados, de tal forma a provocar um maior agrupamento de zeros. Isto é feito linearizando-se a matriz e seguindo a ordem especificada na figura abaixo:

\begin{tabular}{|r|r|r|r|r|r|r|r|}
\hline 0 & 1 & 5 & 6 & 14 & 15 & 27 & 28 \\
\hline 2 & 4 & 7 & 13 & 16 & 26 & 29 & 42 \\
\hline 3 & 8 & 12 & 17 & 25 & 30 & 41 & 43 \\
\hline 9 & 11 & 18 & 24 & 31 & 40 & 44 & 53 \\
\hline 10 & 19 & 23 & 32 & 39 & 45 & 52 & 54 \\
\hline 20 & 22 & 33 & 38 & 46 & 51 & 55 & 60 \\
\hline 21 & 34 & 37 & 47 & 50 & 56 & 59 & 61 \\
\hline 35 & 36 & 48 & 49 & 57 & 58 & 62 & 63 \\
\hline
\end{tabular}

Para se percorrer a matriz nesta ordem, foi criado um vetor que realiza o mapeamento das coordenadas na seqüência especificada na figura acima. A rotina abaixo ilustra uma maneira de inicializar este vetor:

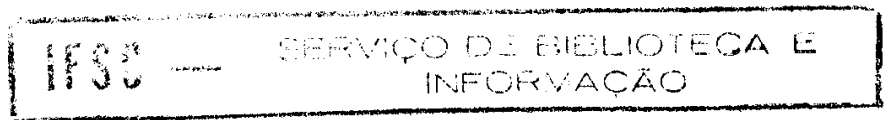




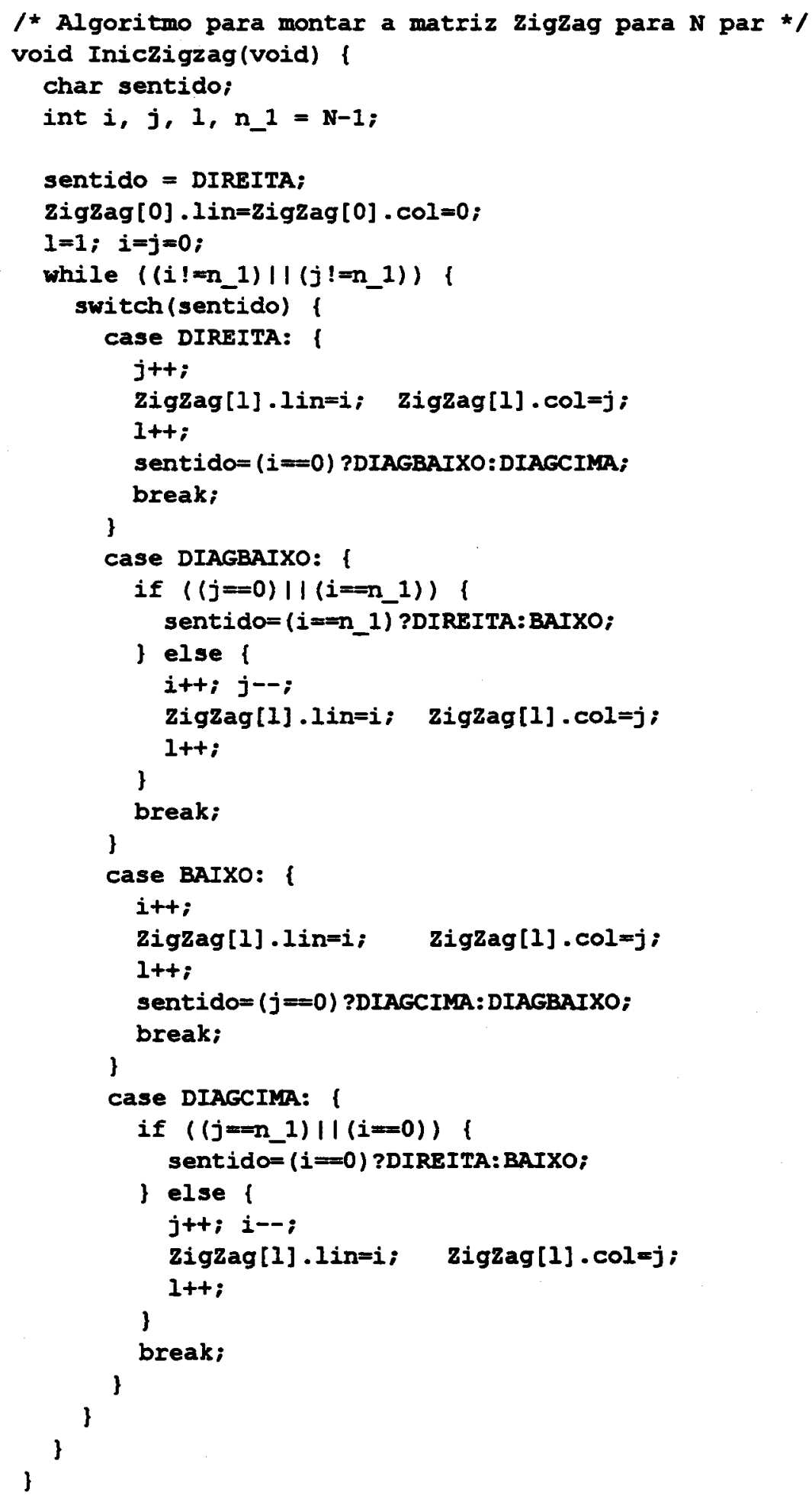

Uma vez inicializado o vetor denominado ZigZag, os valores quantizados são armazenados seqüencialmente em um vetor denominado sbuf. Este vetor irá conter todos os coeficientes quantizados da imagem. $\mathbf{O}$ código abaixo ilustra este processo:

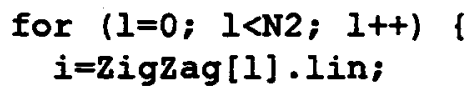


O aspecto de sbuf após a realização do ZigZag nos blocos da imagem será o seguinte:

$$
\text { sbuf }=\left(D C, A C_{1}, \ldots, A C_{63}\right)_{0}, \ldots,\left(D C, A C_{1}, \ldots, A C_{63}\right)_{\text {blocos }}
$$

De acordo com a figura acima, a primeira posição de cada bloco é denominada DC. Os 63 coeficientes restantes de um bloco são denominados AC, conforme mostra a figura 3.5 do capítulo 3.

A sequiência ZigZag gerada em buf, que é descrita por Tescher, em 1978 [Penn_93], cria um vetor 1-D de coeficientes, onde baixas freqüências tendem a ser de baixos índices, surgindo muitos valores nulos em seqüência.

Tem-se, ao final deste estágio, um vetor com grande ocorrência de valores nulos ao final de cada bloco linearizado. Para algoritmos de CoD estatísticos, esta característica é bastante explorada a fim de se obter uma alta taxa de entropia. Sendo assim, o próximo passo será a codificação de entropia aplicada aos coeficientes DC e AC.

\subsection{Codificação de entropia}

O processo Baseline, descrito pelo padrão JPEG, especifica a utilização da codificação Huffman como o algoritmo de codificação de entropia.

\subsubsection{Codificação de entropia para coeficientes DC}

A codificação Huffman é aplicada separadamente para os coeficientes DC e AC. Porém, esta codificação não é aplicada diretamente sobre os valores dos coeficientes. Segundo a padronização, os coeficientes DC devem sofrer uma codificação diferencial da seguinte forma:

$$
\begin{aligned}
& \mathrm{DIFF}[0]=0 \\
& \mathrm{DIFF}[i]=\mathrm{DC}[i]-\mathrm{DC}[i-I]
\end{aligned}
$$


onde o índice $i$ indica o i-ésimo bloco de 8x8. Uma vez calculada a diferença, o valor é mapeado segundo a tabela abaixo:

\begin{tabular}{ccc}
\hline \multicolumn{3}{c}{ Tabela de Codificação Huffman das diferenças DPCM } \\
\hline SSSS & diferença DPCM & bits adicionais (em binário) \\
0 & 0 & \\
1 & $-1,1$ & 0,1 \\
2 & $-3,-2,2,3$ & $00,01,10,11$ \\
3 & $-7, \ldots,-4,4, \ldots, 7$ & $000, \ldots, 011,100, \ldots, 111$ \\
4 & $-15, \ldots,-8,8, \ldots, 15$ & $0000, \ldots, 0111,1000, \ldots, 1111$ \\
$\ldots$ & $\ldots$ & $\ldots$ \\
16 & 32768 & \\
\hline
\end{tabular}

Esta tabela é utilizada para se codificar a diferença. Ou seja, se DIFF $=-2$, a quantidade de bits do código será SSSS $=2$ e o código binário correspondente 01 . O código binário é denominado de bits adicionais porque ele é acrescido à codificação Huffman do símbolo SSSS.

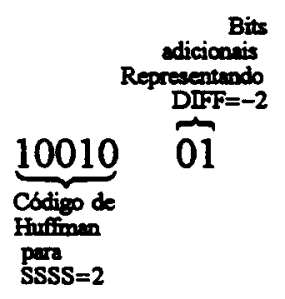

Neste trabalho, a tabela foi substituida pela seguinte rotina denominada DCPM: 


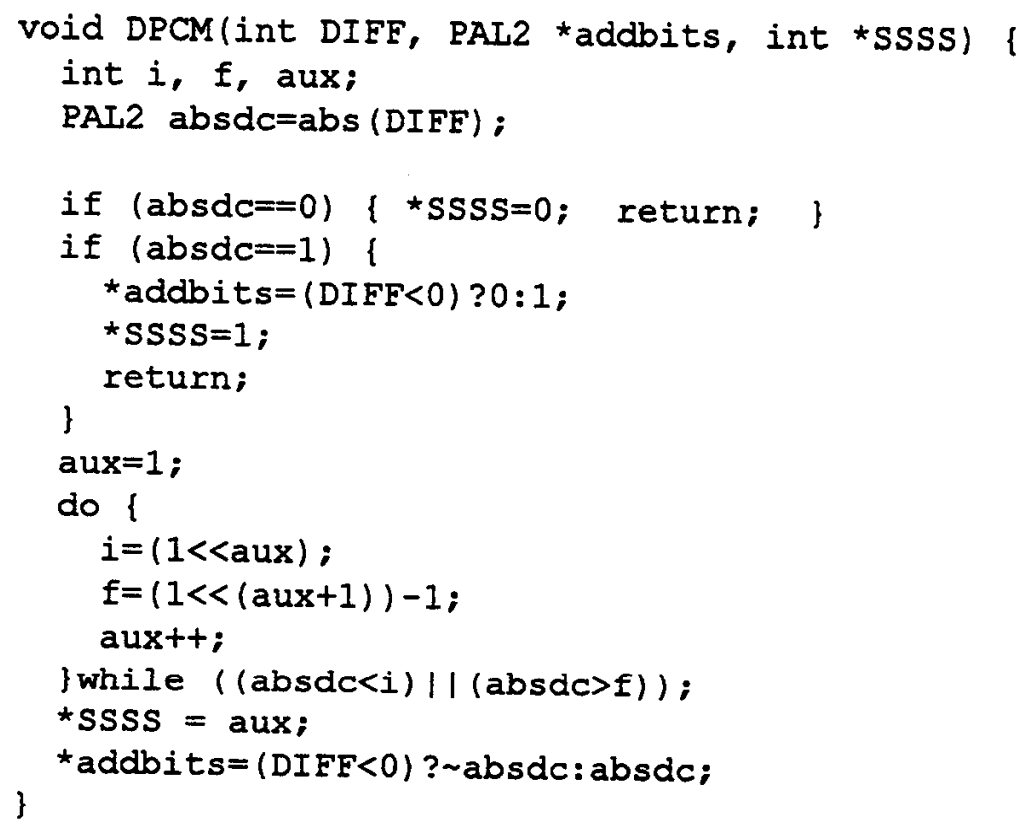

Se a diferença for zero, nenhum bit adicional é necessário, se igual a 1 , um único bit adicional é necessário. Caso contrário, encontra-se a categoria na qual DIFF pertence calculando-se os limites positivos de cada categoria. Quando a diferença é negativa, o código obtido sofre o complemento de um.

A padronização JPEG não determina nenhuma tabela de Huffman para codificação dos símbolos SSSS. Sendo assim, criou-se uma rotina para a contagem de freqüências SSSS, para gerar uma tabela de código de Huffman especifica para cada imagem:

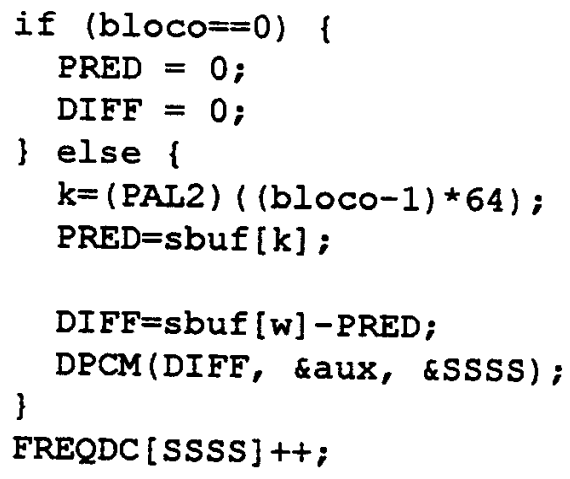

As freqüências são armazenadas no vetor FREQ para todos os possíveis valores de SSSS. No caso do processo Baseline, devido às amostras terem precisão de 8 bits, a quantidade máxima de valores distintos é pequena, não ultrapassando 12 . 
O processo para a obtenção da tabela de Huffman para coeficientes DC adaptado à realidade JPEG está, descrito na seção 4.3.3.

\subsubsection{Codificação de entropia para coeficientes AC}

Como foi dito anteriormente, os coeficientes AC possuem uma grande possibilidade de conter fileiras de zeros. Devido a esta característica, os coeficientes AC são codificados segundo o seguinte formato:

\section{RRRRSSSSBBBBB...B}

onde RRRR indica a quantidade de zeros existentes antes de um valor não zero. SSSS indica a quantidade de bits $\mathrm{B}$ adicionais que devem ser anexados ao código RRRRSSSS. Para se encontrar o valor de SSSS, bem como os bits adicionais, pode-se utilizar a mesma função DPCM definida para coeficientes DC.

Para ilustrar, considere que os coeficientes AC de um bloco $8 \times 8$ sejam as seguintes:

\begin{tabular}{|c|c|c|c|c|c|c|c|c|c|c|c|c|}
\hline Indice ZigZag & 1 & 2 & 3 & 4 & 5 & 6 & 7 & 8 & 9 & 10 & 11 & 63 \\
\hline Coeficientes AC & 0 & 0 & 0 & 0 & -6 & 0 & 0 & 1 & 0 & 0 & 0 & 0 \\
\hline RRRR & \multicolumn{4}{|c|}{4} & & \multicolumn{2}{|c|}{2} & & \multicolumn{4}{|c|}{ EOB } \\
\hline SSSS & & & & & 3 & & & 1 & & & 0 & \\
\hline RRRRSSSS & & & & & $0 \times 43$ & & & $0 \times 21$ & & & 0 & \\
\hline Bits Adicionais & & & & & 001 & & & 1 & & & - & \\
\hline
\end{tabular}

Assim, para os primeiros 5 coeficientes AC, o código gerado poderia ser:

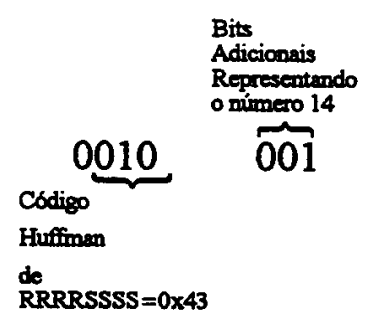

Da mesma forma que na codificação de DC, a padronização JPEG não especifica uma tabela de Huffinan de códigos para símbolos RRRRSSSS. Sendo assim, a implementação 
realiza a contagem de frequência dos símbolos com o intuito de se gerar uma tabela de codificação Huffman especifica para cada imagem sendo comprimida. $O$ seguinte fragmento ilustra a maneira como isso é realizado:

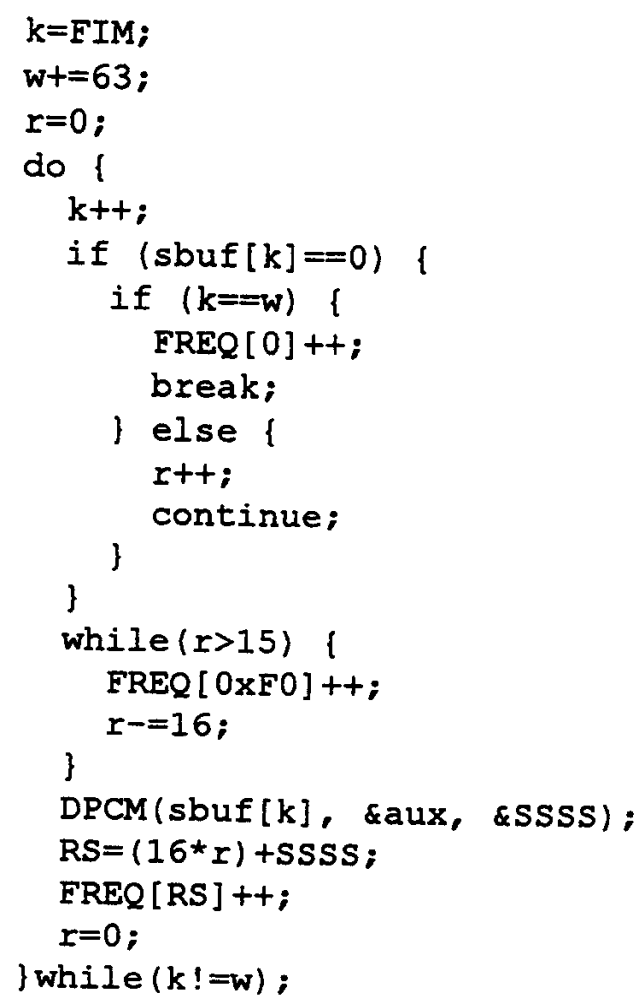

As freqüuências são computadas para todos os coeficientes AC's que compõem a imagem.

\subsubsection{Obtenção das tabelas de Huffman}

A especificação JPEG, para o processo Baseline, indica que devem ser gerados dois vetores para a codificação DC e dois para a codificação AC. $O$ processo para se gerar esse par de vetores a partir do vetor de freqüências é idêntico para ambos os casos. Assim sendo, implementou-se um conjunto de rotinas genéricas e parametrizadas para atender aos dois casos.

O par de vetores, gerados a partir do vetor de freqüências, são denominados BITS e HUFFVAL. BITS[i] armazena o número de ocorrências de códigos de tamanho i, e o vetor HUFFVAL armazena todos os possíveis códigos de símbolos. A seguinte rotina ilustra a seqüência de chamadas de subrotinas para a geração de tais vetores, conforme especificado no anexo $K$ da especificação JPEG [Draf_91]: 


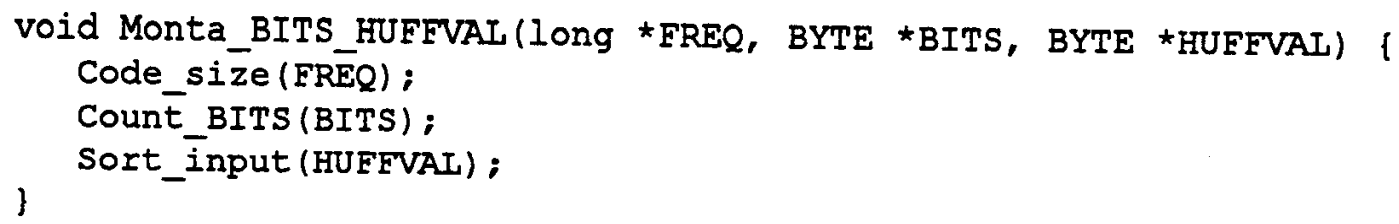

A rotina Code_size monta, internamente, a árvore de Huffman e produz como resultado uma vetor que conterá o número de bits necessários para codificar cada símbolo a ser comprimido. Esta rotina é apresentada a seguir:

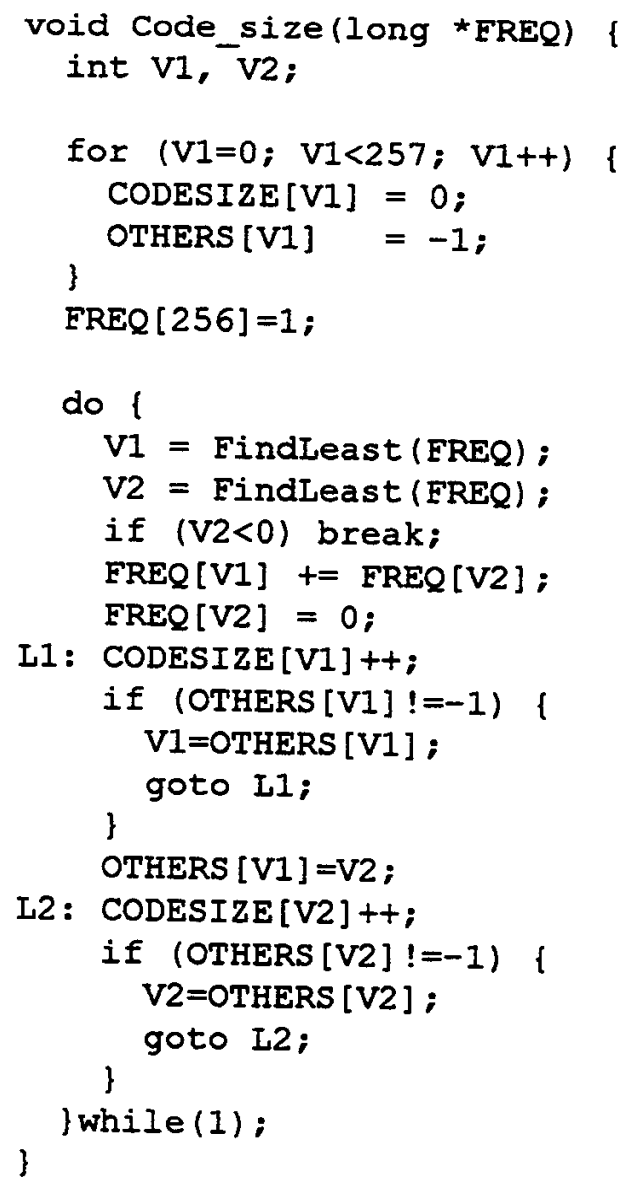

A função FindLeast (FREQ) retorna o índice do valor de freqüência no vetor FREQ. Ao ser executado pela segunda vez, na seqüência, a segunda execução despreza o valor encontrado anteriormente, buscando pelo próximo menor valor, como pode ser verificado na implementação da função abaixo: 


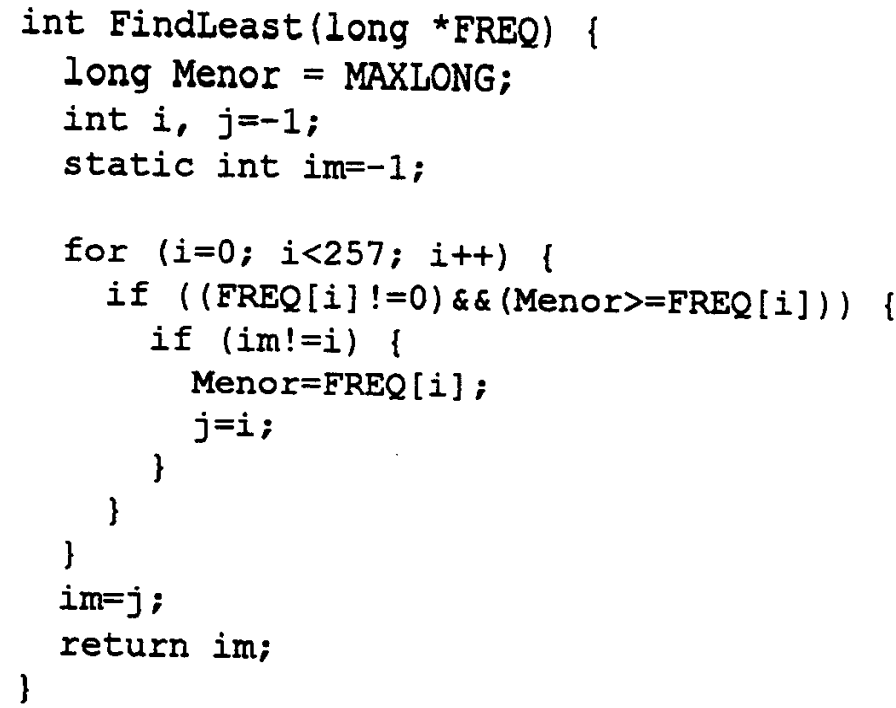

Na seqüência, a rotina Count_bits gera o vetor BITS a partir do vetor CODESIZE gerado pelo rotina Code_size.

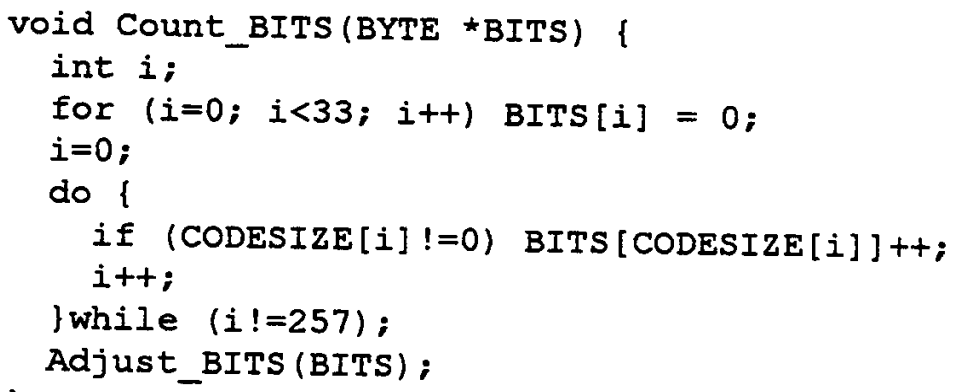

A rotina interna Adjust_BITS, utilizada por Count_BITS, normaliza o vetor BITS a fim de deslocar todos os bytes significativos do vetor de 32 bytes nos primeiros 16 bytes:

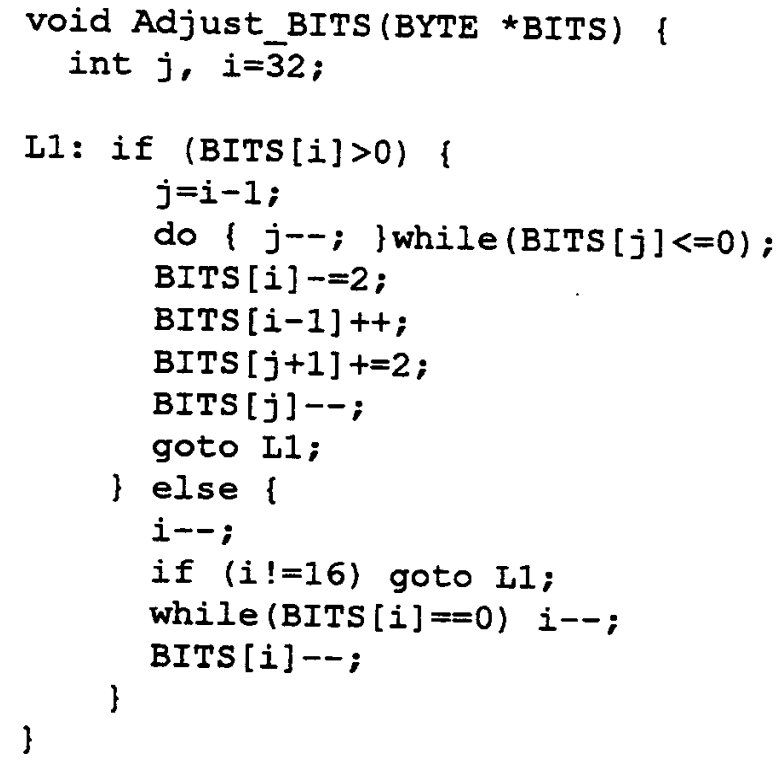


A partir do vetor CODESIZE, a rotina Sort_input gera o vetor HUFFVAL:

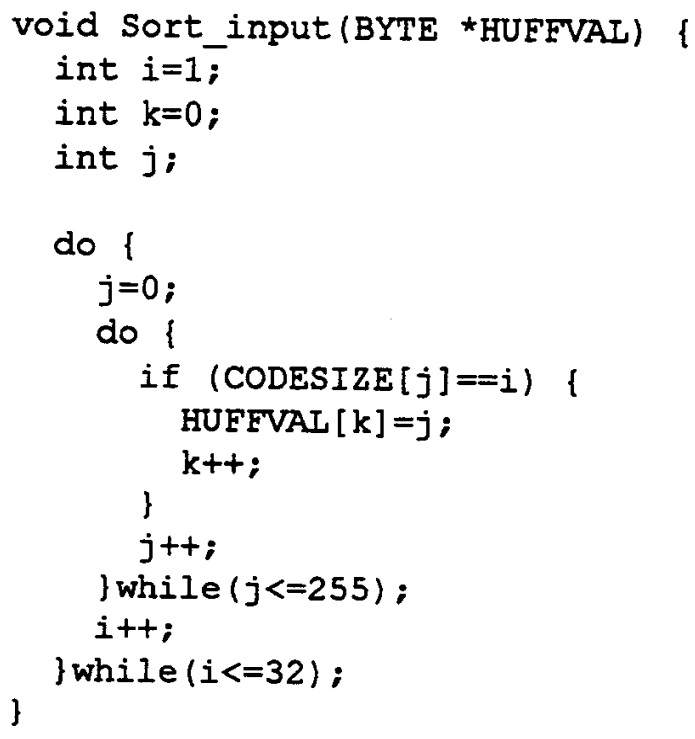

Os vetores BITS e HUFFVAL são, na realidade, a tabela de códigos Huffman codificada para ocupar somente o espaço de memória necessário a fim de incluí-la junto com os dados da imagem comprimida. Sendo assim, a entropia não pode ser iniciada sem que antes seja gerada a tabela de códigos Huffman. Este processo, especificado no anexo F em [Draf_91], foi implementado da seguinte forma:

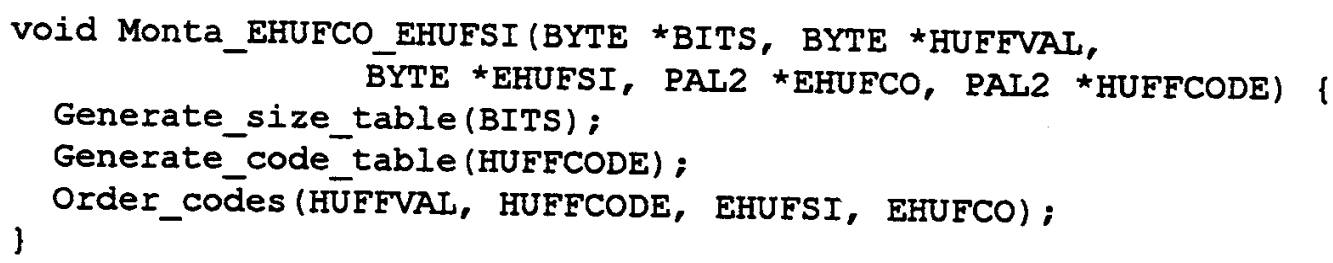

A rotina acima permite gerar, a partir de BITS e HUFFVAL os vetores EHUFCO e EHUFSI, equivalentes à tabela de Huffman. Para tanto, ela faz uso de três rotinas. A rotina Generate_size_table recebe como parâmetro o vetor BITS[i], que contém a quantidade de ocorrências de códigos Huffman de tamanho $i$, e inicializa o vetor HUFFSIZE [j] que conterá o tamanho, em bits, do código de Huffman para cada símbolo possivel j entre 0 a 255 : 


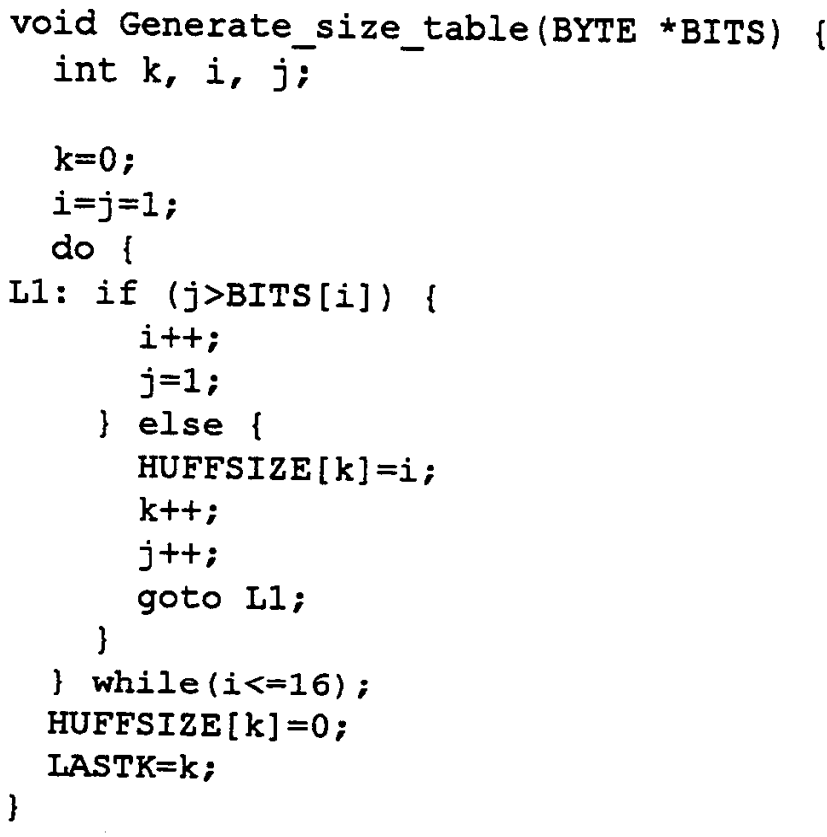

Dado que o vetor HUFFSIZE tenha sido inicializado, inicializa-se o vetor HUFFCODE com o código de Huffman de cada símbolo entre 0 a 255:

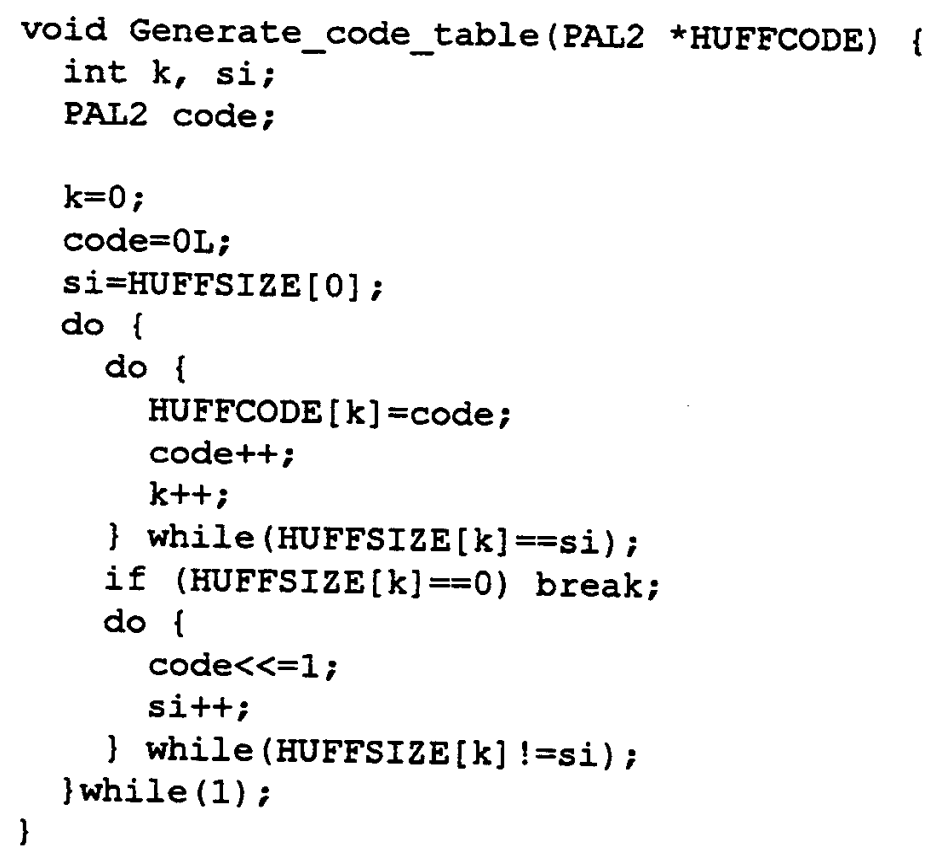

A rotina anterior gera a tabela de Huffman, porém ainda desordenada. Sendo assim, a rotina Order_codes ordena HUFFCODE e HUFFSIZE de acordo com a seqüência imposta por HUFFVAL. Os valores ordenados são colocados em EHUFCO e EHUFSI, respectivamente: 


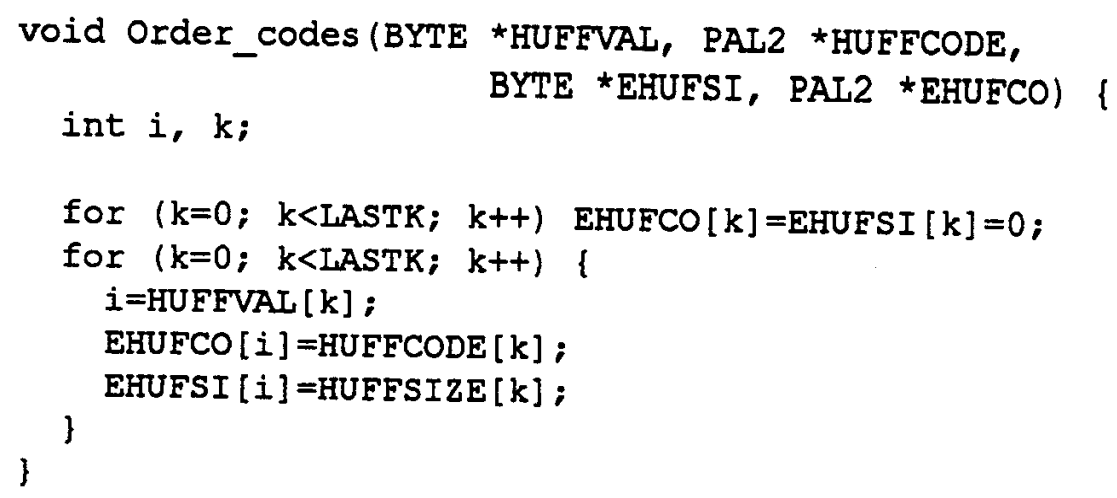

\subsubsection{A implementação da codificação de entropia}

Dado que os vetores EHUFCO e EHUFSI tenham sido gerados, o último estágio do processo de compressão Baseline-JPEG pode ser efetuado. Conforme pode ser verificado nas seções 4.3.1 e 4.3.2, os coeficientes DC e AC são codificados de maneira distinta. Porém, como os coeficientes quantizados estão dispostos linearmente, a codificação de entropia pode ser efetuada num único algoritmo, como demonstra a seguinte rotina:

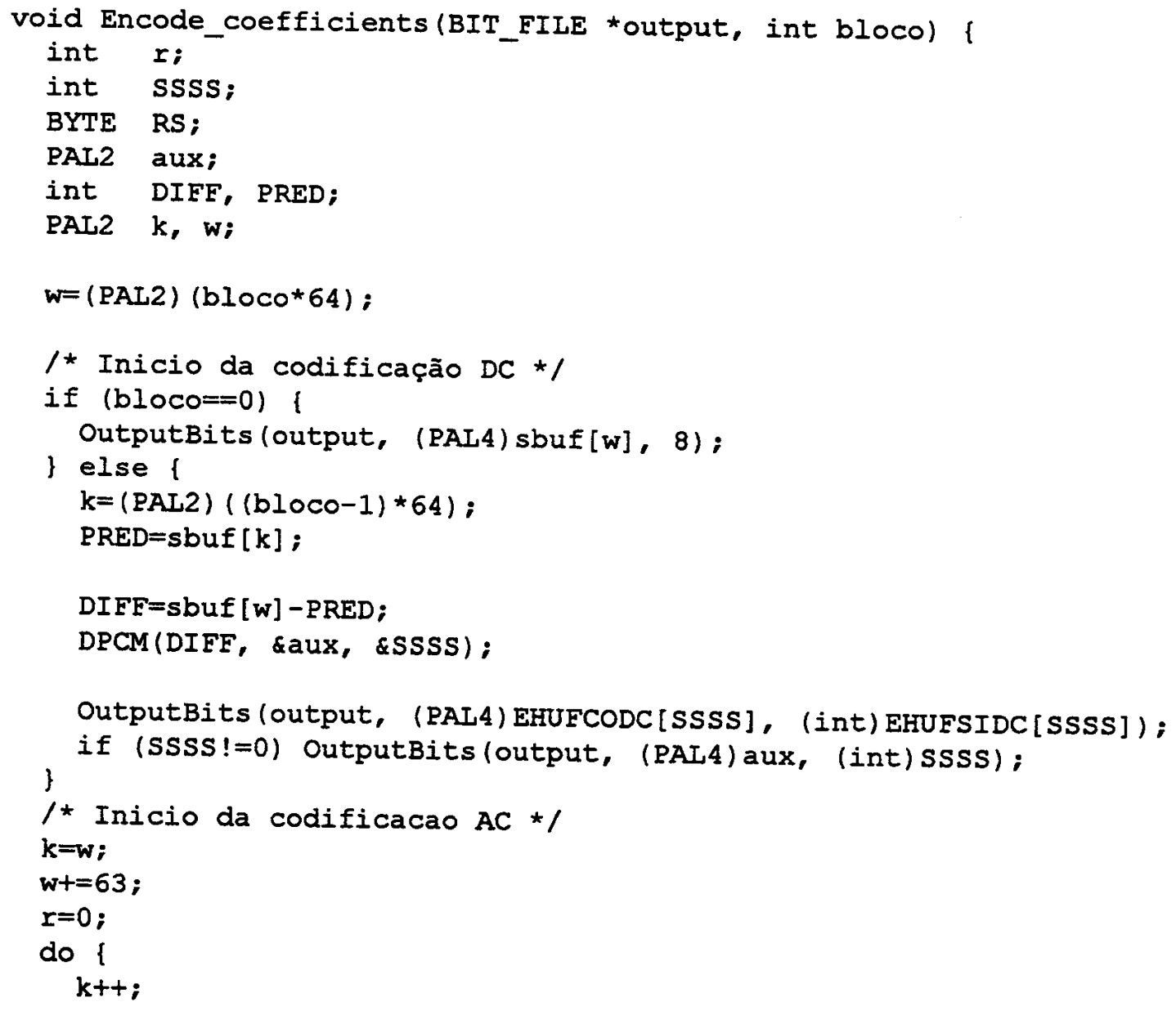




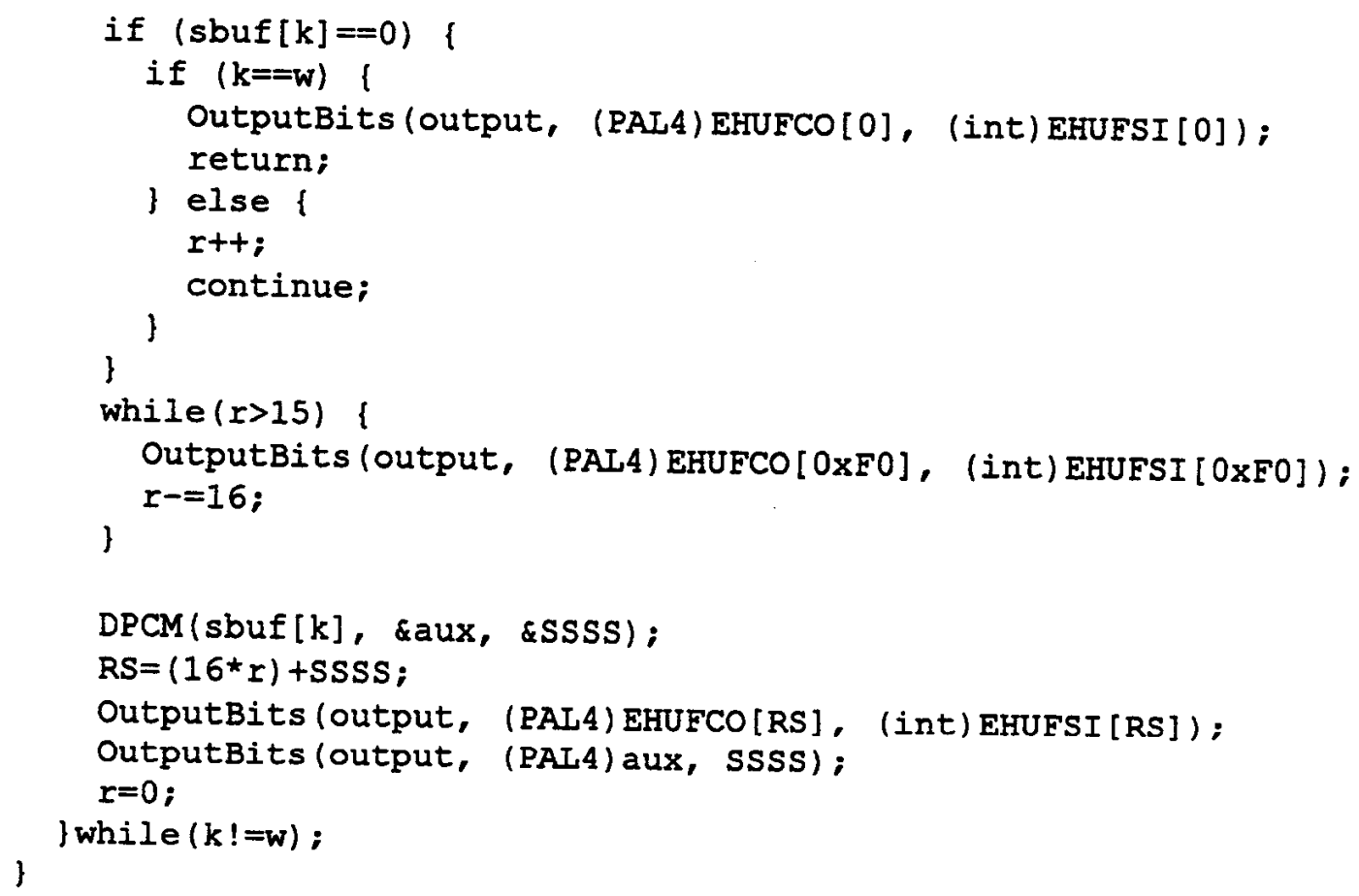

Esta rotina recebe como parâmetro um descritor para o arquivo que conterá os dados codificados e a indicação do bloco que está sendo codificado. A parte que realiza a codificação dos coeficientes DC encontra-se no início. Pode-se notar que o primeiro coeficiente DC não é codificado, sendo armazenado em sua forma original, ou seja, é assumido que o valor anterior para o DC é zero. Os DC's posteriores são tratados conforme já descrito na seção 4.3.1.

Na segunda parte da rotina encontra se a implementação do algoritmo de codificação AC. $O$ primeiro teste verifica se o coeficiente é zero. Isto é feito para se calcular a quantidade de zeros consecutivos. Caso a fileira de zeros se estenda até o último coeficiente do bloco $\left(\mathrm{AC}_{63}\right)$, é enviado para o arquivo de saida uma marcação indicando o final de bloco (EOB). Caso a fileira de zeros contenha 16 zeros, é enviado para o arquivo de saída o marcador 0xF0. Caso contrário, a codificação se processa da forma como descrito na seção 4.3.2.

A rotina outputBits realiza o salvamento de um número arbitrário de bits no arquivo de saída e foram retiradas de [Nels_92]. 


\subsection{Considerações finais}

Para ter-se uma idéia geral do processo de codificação Baseline, aplicado à compressão de imagens tomográficas, será descrito, a seguir, o programa principal.

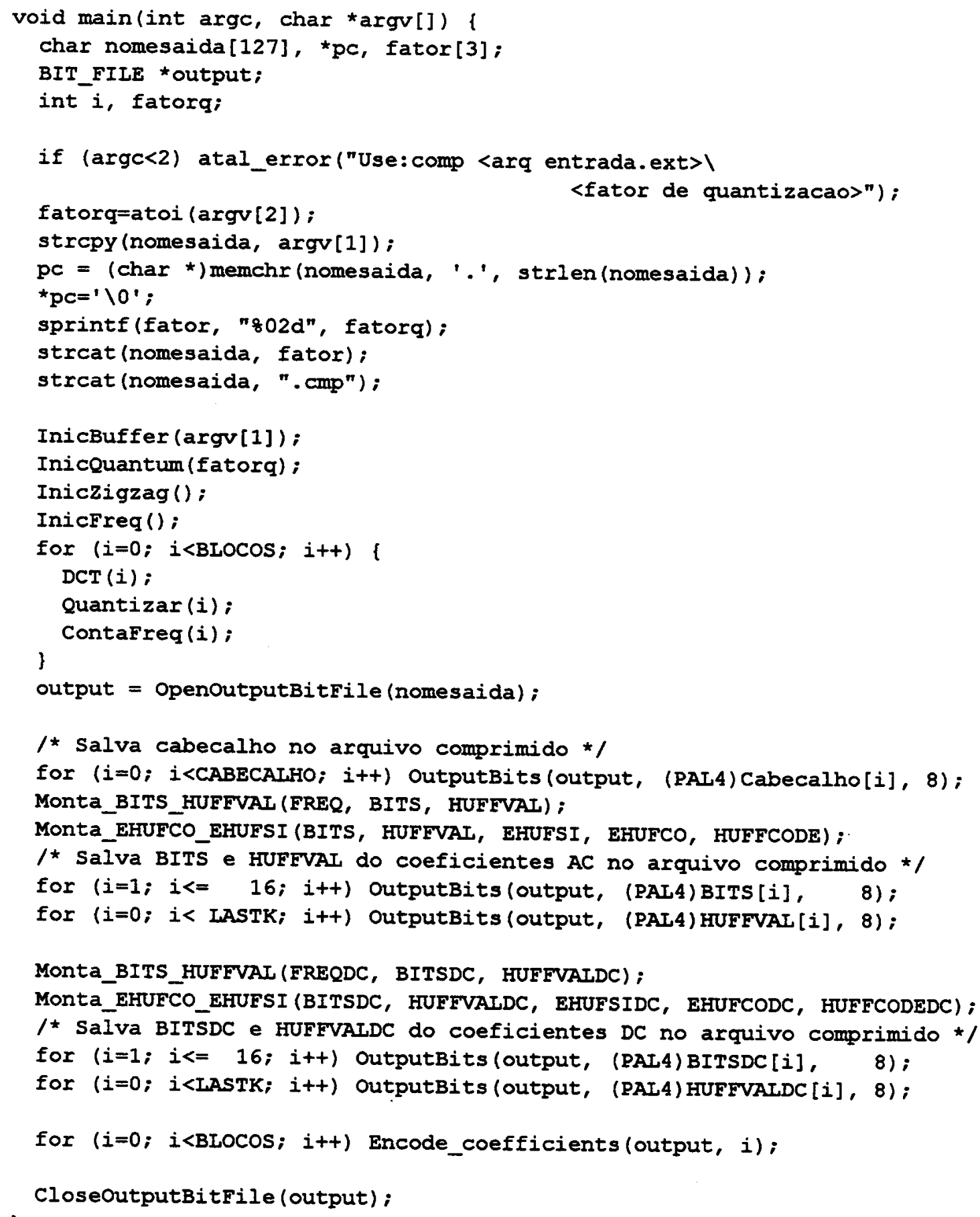

O programa deve ser executado com o nome do arquivo a ser comprimido, seguido do fator de qualidade para se gerar a matriz de quantização. 
Pode-se observar que a rotina InicBuffer está sendo chamada para realizar o carregamento dos dados em memória, organizados num vetor de blocos de 8x8. Posteriormente, é inicializada a matriz de quantização, a matriz ZigZag e o vetor de freqüências DC/AC.

Terminada a fase de inicialização, o programa executa para cada bloco a FDCT, a quantização e a contagem de freqüências DC/AC. Ao final da iteração, os dados estão prontos para serem submetidos ao algoritmo de entropia. Porém, antes que isso aconteça, é importante salvar o cabeçalho da maneira como estava no arquivo comprimido, e gerar as tabelas de Huffman para coeficientes AC/DC, salvando antes os vetores intermediários BITS e HUFFVAL. Isto tudo é feito para que o descodificador possa restaurar a imagem codificada.

Finalmente, a última coisa a ser feita é a codificação de entropia para cada bloco de $8 \times 8 \mathrm{da}$ imagem, segundo os vetores EHUFCO e EHUFSI.

A descompressão utiliza o caminho inverso adotado pela compressão. Para maiores detalhes, os códigos-fonte, tanto dos módulos de compressão quanto dos módulos de descompressão JPEG-Baseline, podem ser consultados no anexo III. 


\section{Capítulo 5.}

\section{Conclusão e Propostas de Trabalhos Futuros}

O presente trabalho teve por objetivo inicial a construção de um sistema modular que realizasse a compressão e descompressão de imagens geradas por tomografia, baseada no Processo Baseline, contido no padrão internacional conhecido como JPEG. Neste sentido, foram desenvolvidos os módulos que compõem este processo.

Assim, pode-se avaliar o desempenho da implementação em função da escolha do fator de qualidade, sendo este o parâmetro que gera o vetor de quantização. Este fator é escolhido para minimizar a relação sinal-ruído da imagem reconstruída. $O$ ruído é inserido na imagem reconstruída, dado que o processo baseline é classificado como "lossy", isto é, a imagem reconstruída traz muitas características da imagem fonte, mas não é exatamente a mesma. Porém, ela pode ser reconhecida, pois o processo explora características inerentes ao sistema de visão do homem.

No desenvolvimento do algoritmo de compressão, foi escolhido o algoritmo que calcula de modo rápido DCT [Loef_89], constituindo um dos módulos do processo baseline do JPEG. Este algoritmo, se implementado diretamente como mostra a figura 4.1 não gera o cálculo do DCT conforme fórmula ideal, descrita no início da seção 4.2 , pois existe um erro nos parâmetros do cálculo da rotação presente no terceiro estágio. Este erro foi corrigido durante a implementação e ainda, para que a saída da DCT implementado fosse compativel com a saída do cálculo da fórmula ideal, foi inserido um fator para realizar este ajuste, tanto no cálculo da DCT, como no cálculo da Inversa da DCT. A figura 4.1 mostra como os dados devem ser gerados na saída, na referência aparece uma inversão entre os índices $6 \mathrm{e}$ 2 , já corrigidos na figura.

A tabela 5.1 foi construída para fornecer subsídios para a discussão, em função do sistema proposto. Nela são encontrados o nome da imagem gerada por tomografia, seu tamanho em bytes, seguido do fator de quantização, o tamanho em bytes do arquivo comprimido, a fração de redução, em percentagem, e o erro médio quadrático, MSE ("Mean Square Error").

Da análise da tabela vê-se, claramente, que quanto maior o fator de qualidade maior é taxa de compressão do arquivo original, o que torna efetivo o objetivo inicial de preservar as imagens em tamanhos reduzidos, uma vez que existe uma limitação dos sistemas de 
armazenamento de massa existentes e, ao mesmo tempo, quanto maior o fator de qualidade maior é o ruído contido na imagem reconstruída. Esta é uma característica do processo de codificação visto que tal processo é "lossy". O ruído inserido pode esconder ou mesmo camuflar informações na imagem, que será depurada por especialista clínico, usando a imagem para aplicar o tratamento ou descobrir anomalias. Por outro lado, deve-se escolher um fator de qualidade apropriado, minimizando a relação sinal-ruído e maximizando a taxa de compressão, conforme mostra a fração de redução, na tabela 5.1 .

Como sugestão para trabalhos futuros, propõe-se um levantamento em várias imagens geradas por tomografia, com o objetivo de gerar tabelas de Huffman que sejam adequadas ao processo de codificação proposto por JPEG. Estas tabelas seriam construídas considerando-se diferentes regiões do corpo humano. Fazendo-se este levantamento, mesmo que não sejam obtidas tabelas muito diferentes, ainda restam as vantagens do processos de compressão e descompressão realizados em menor tempo de processamento, pois não seria necessária a construção da tabela de Huffman durante a execução do sistema de codificação, a exemplo do que ocorre nos processos de compressão, em programas comerciais, que se valem de tabelas proprietárias. Além disso, para diferentes aplicações, não só aquelas relacionadas à área médica como, por exemplo, as aplicações ligadas às áreas de engenharia, tabelas específicas poderiam previamente geradas.

Uma outra sugestão, seria incluir o sistema, descrito no capítulo 4, como um subsistema ou função de CoD em um sistema de gerenciamento de arquivos de imagens, uma vez que, ao longo do tempo, um equipamento de tomografia gera um coleção enorme de dados de imagens, necessitando gerenciamento ou, ainda, incorporá-lo como uma ferramenta de Banco de Dados. No Instituto de Ciências Matemáticas de São Carlos, da USP, está sendo desenvolvido um Sistema Gerenciador de Banco de Dados Orientado a Objetos, que atenderia rapidamente a este propósito.

A seguir tem-se a tabela 5.1 que demonstra os resultados obtidos pela aplicação do presente sistema, seguido de algumas imagens que foram utilizadas para demonstração da eficácia do sistema, inicialmente apresentado a imagem original com extensão PAC e as suas correspondentes imagens recuperadas com extensão REC, sendo usado formato de arquivos BMP, que é padrão e usual em sistemas Windows. 


\begin{tabular}{|c|c|c|c|c|c|}
\hline Imagem & $\begin{array}{l}\text { Original } \\
\text { (Bytes) }\end{array}$ & $\begin{array}{c}\text { Fator de } \\
\text { Qualidade }\end{array}$ & $\begin{array}{c}\text { Comprimida } \\
\text { (Bytes) }\end{array}$ & $\begin{array}{c}\text { Fração de } \\
\text { Redução (\%) }\end{array}$ & Erro MSE \\
\hline c81t1 & 65540 & 2 & $\begin{array}{r}199 \\
\end{array}$ & 89 & 2,97 \\
\hline c81t3 & 65540 & 2 & 13659 & 79 & 3,66 \\
\hline c81t5 & 65540 & 2 & 12580 & 80 & 3,62 \\
\hline $\mathrm{c} 81 \mathrm{t} 7$ & 65540 & 2 & 11351 & 82 & 3,54 \\
\hline c81t9 & 65540 & 2 & 10571 & 83 & 3,56 \\
\hline c81t1 & 65540 & 5 & 3293 & 94 & 4,44 \\
\hline c81t3 & 65540 & 5 & 7578 & 88 & 6,72 \\
\hline c81t5 & 65540 & 5 & 6696 & 89 & 6,48 \\
\hline c81t7 & 65540 & 5 & 5822 & 91 & 6,17 \\
\hline c81t9 & 65540 & 5 & 4926 & 92 & 6,05 \\
\hline c81t1 & 65540 & 10 & 1736 & 97 & 5,33 \\
\hline c81t3 & 65540 & 10 & 4232 & 93 & 9,71 \\
\hline c81t5 & 65540 & 10 & 3687 & 94 & 9,12 \\
\hline c81t7 & 65540 & 10 & 3136 & 95 & 8,63 \\
\hline c81t9 & 65540 & 10 & 2603 & 96 & 8,39 \\
\hline c81t1 & 65540 & 25 & 891 & 98 & 6,23 \\
\hline c81t3 & 65540 & 25 & 1901 & 97 & 12,88 \\
\hline c81t5 & 65540 & 25 & 1677 & 97 & 11,93 \\
\hline c81t7 & 65540 & 25 & 1383 & 97 & 10,83 \\
\hline c81t9 & 65540 & 25 & 1087 & 98 & 10,74 \\
\hline c82s 1 & 65540 & 2 & 9222 & 85 & 3,18 \\
\hline $\mathrm{c82s} 3$ & 65540 & 2 & 12808 & 80 & 3,68 \\
\hline $\mathrm{c82s} 5$ & 65540 & 2 & 11851 & 81 & 3,63 \\
\hline c82s7 & 65540 & 2 & 13313 & 79 & 3,81 \\
\hline c82s9 & 65540 & 2 & 10329 & 84 & 3,45 \\
\hline $\mathrm{c} 82 \mathrm{~s} 1$ & 65540 & 5 & 4619 & 92 & 5,44 \\
\hline $\mathrm{c} 82 \mathrm{~s} 3$ & 65540 & 5 & 6649 & 89 & 6,47 \\
\hline c82s5 & 65540 & 5 & 5896 & 91 & 6,17 \\
\hline c82s7 & 65540 & 5 & 6744 & 89 & 6,65 \\
\hline c82s9 & 65540 & 5 & 5116 & 92 & 5,78 \\
\hline c82s1 & 65540 & 10 & 2402 & 96 & 7,21 \\
\hline $\mathrm{c} 82 \mathrm{~s} 3$ & 65540 & 10 & 3503 & 94 & 8,86 \\
\hline c82s5 & 65540 & 10 & 3040 & 95 & 8,18 \\
\hline c82s7 & 65540 & 10 & 3517 & 94 & 9,18 \\
\hline c82s9 & 65540 & 10 & 2617 & 96 & 7,63 \\
\hline $\mathrm{c82s} 1$ & 65540 & 25 & 1056 & 98 & 8,62 \\
\hline c82s3 & 65540 & 25 & 1554 & 97 & 11,14 \\
\hline $\mathrm{c} 82 \mathrm{~s} 5$ & 65540 & 25 & 1398 & 97 & 10,14 \\
\hline c82s7 & 65540 & 25 & 1502 & 97 & 11,66 \\
\hline c82s9 & 65540 & 25 & 1228 & 98 & 9,13 \\
\hline
\end{tabular}

Tabela 5.1: Relação entre Imagem Fonte e Imagem Comprimida via Figura de Mérito e Erro MSE para imagens geradas por tomografia. 

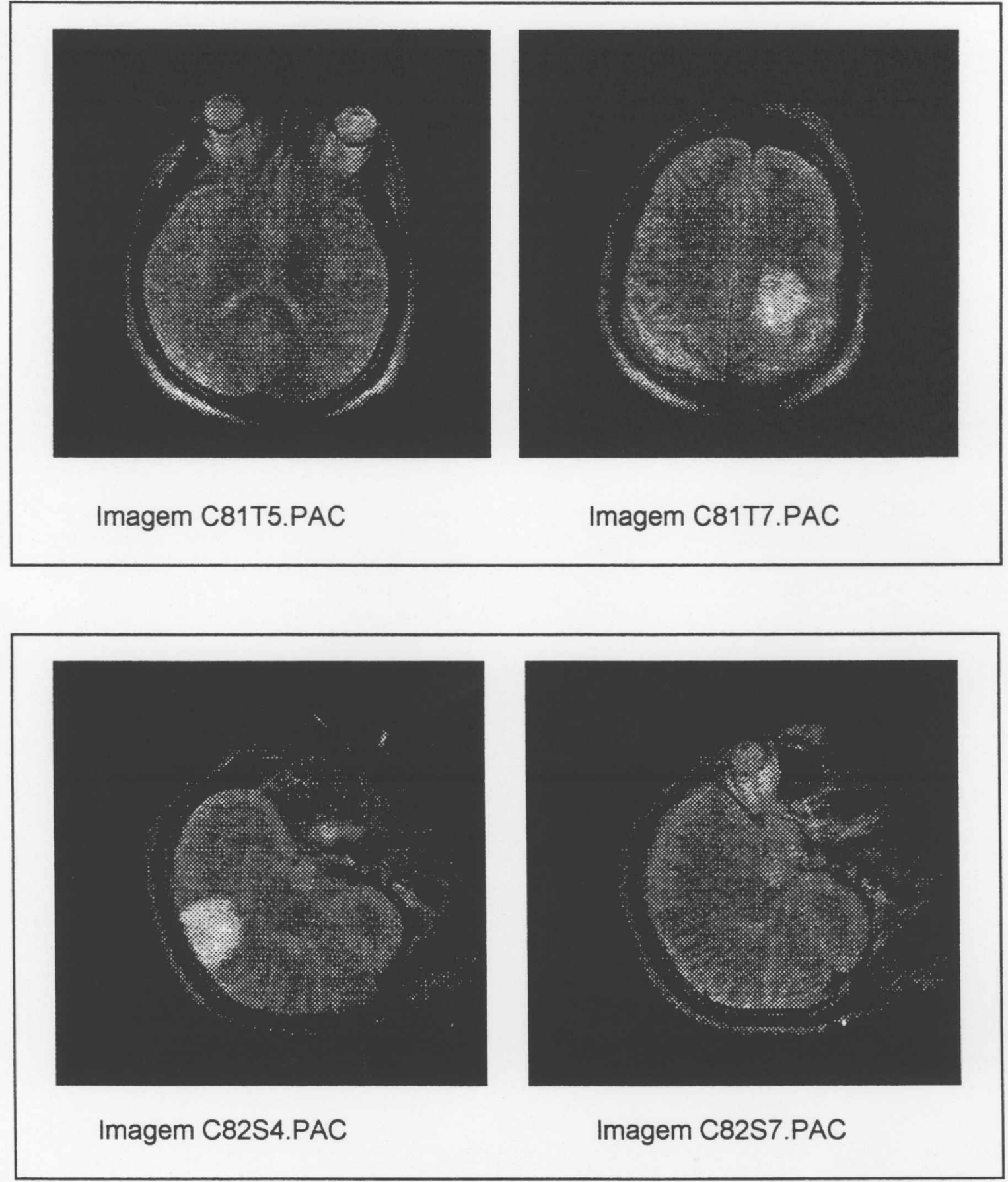

Imagens originais utilizadas para demonstrar o Sistema Desenvolvido 


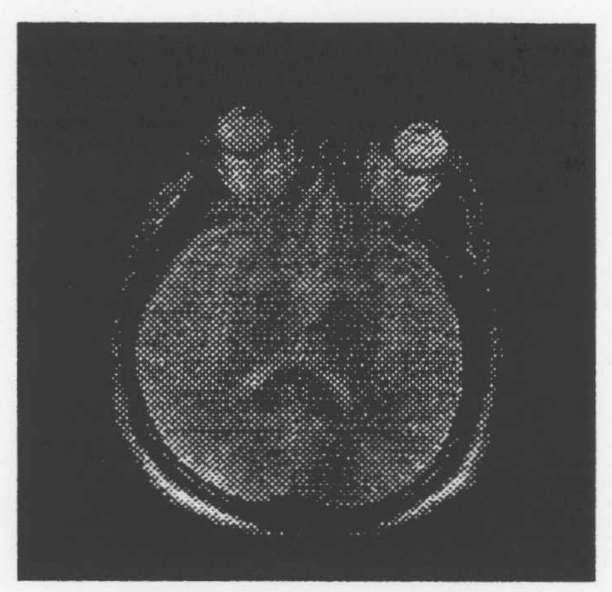

Imagem C81T502.REC

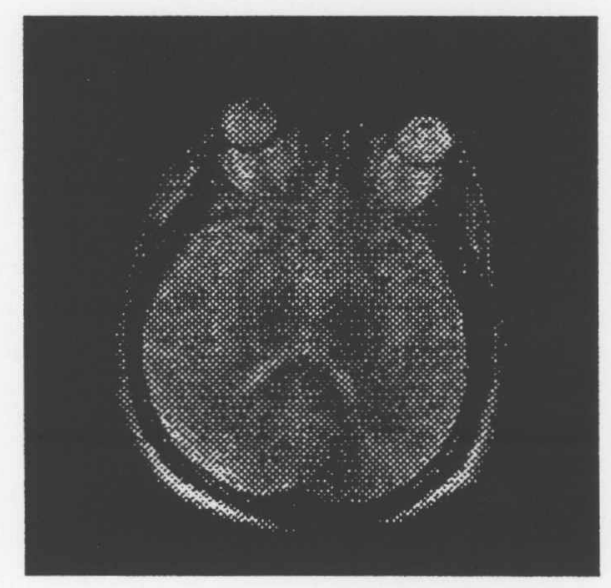

Imagem C81T510.REC

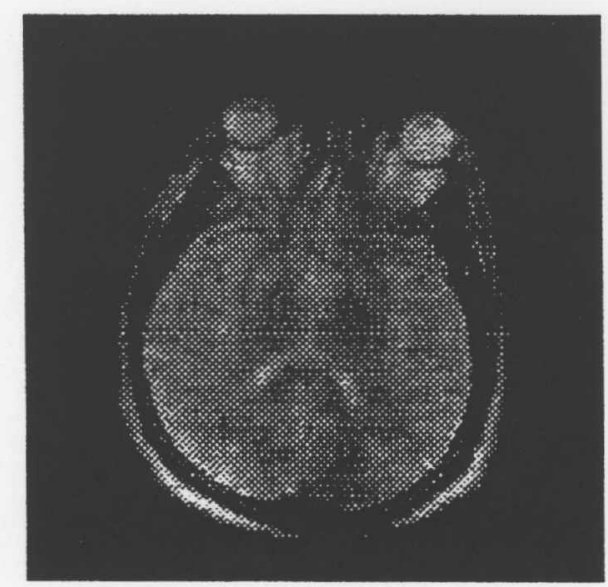

Imagem C81T520.REC

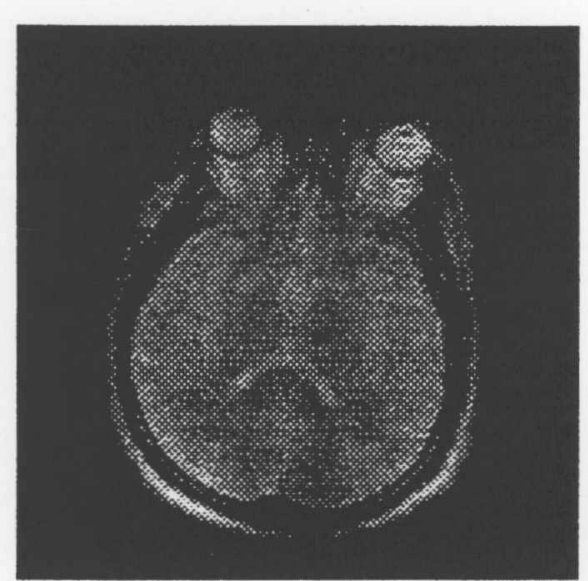

Imagem C81T505.REC

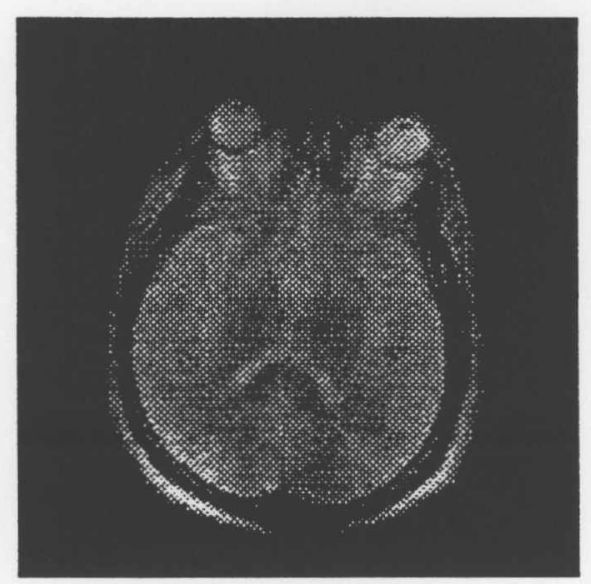

Imagem C81T15.REC

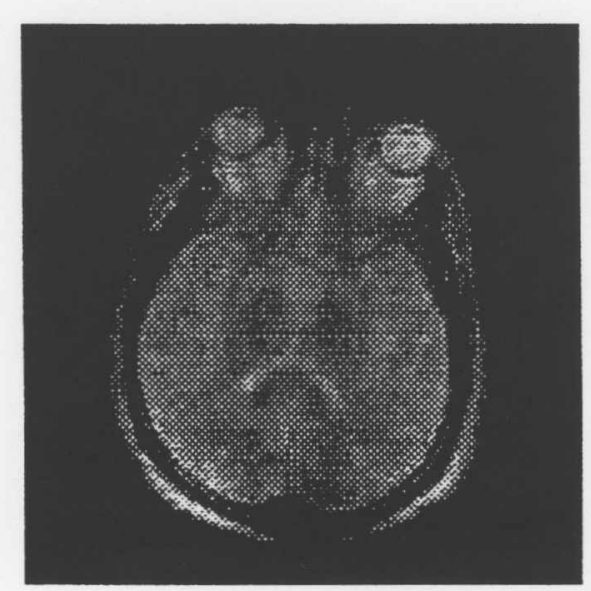

Imagem C81T525.REC

$$
\begin{gathered}
15 \mathrm{~F} \text {.... SERVICO DE BIBLIOTECA E } \\
\text { INFOFNACAOO }
\end{gathered}
$$




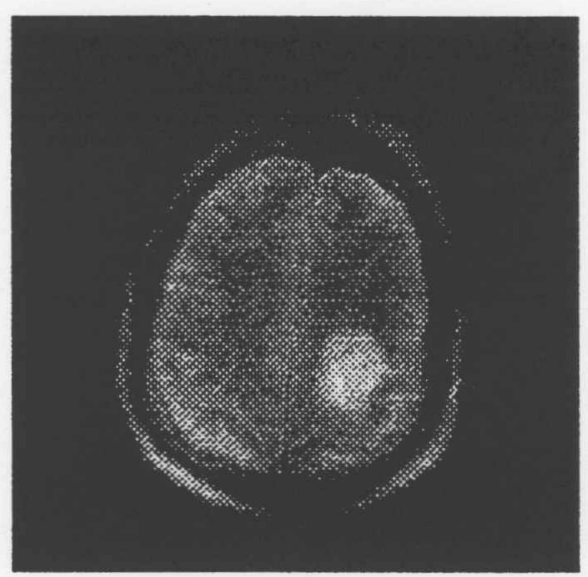

Imagem C81T702.REC

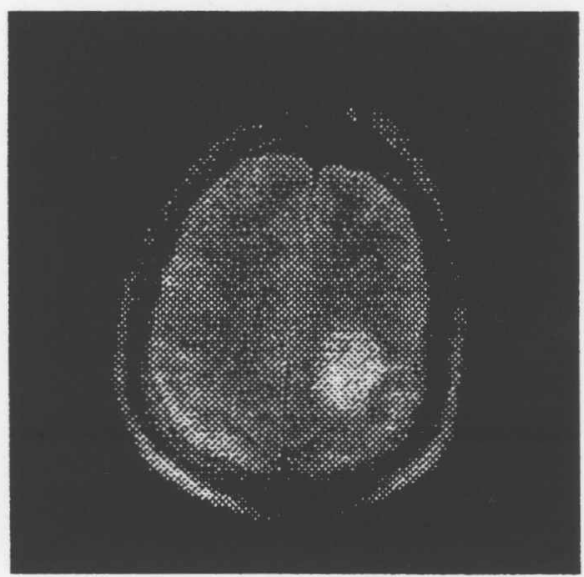

Imagem C81T710.REC

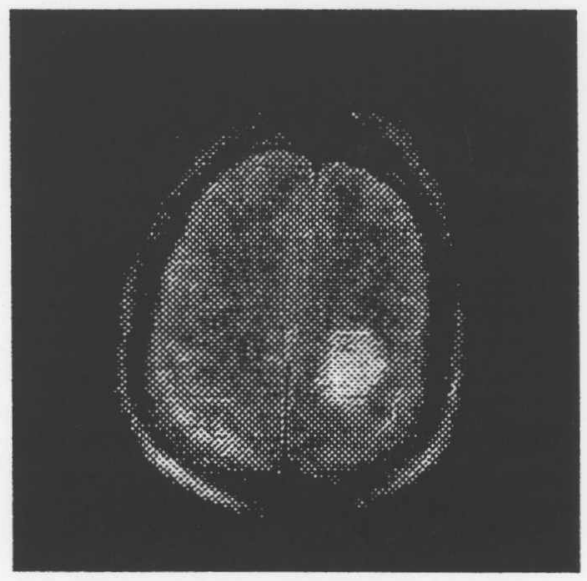

Imagem C81T720.REC

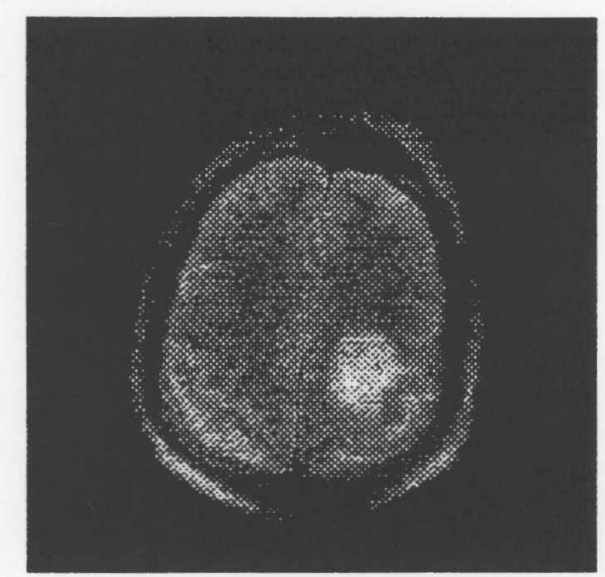

Imagem C81T705.REC

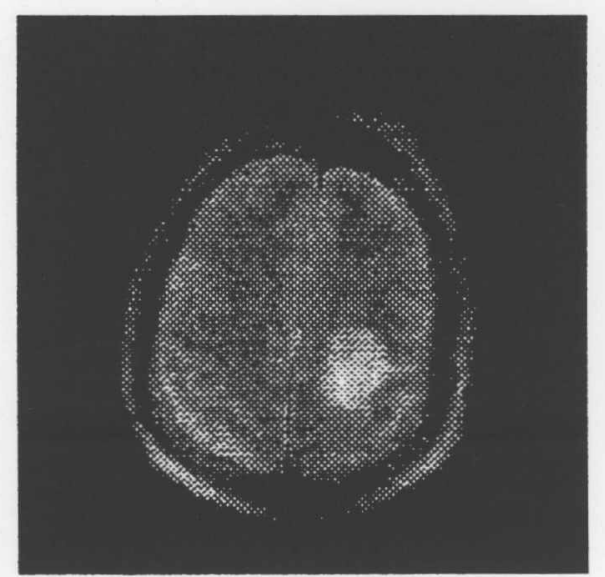

Imagem C81T15.REC

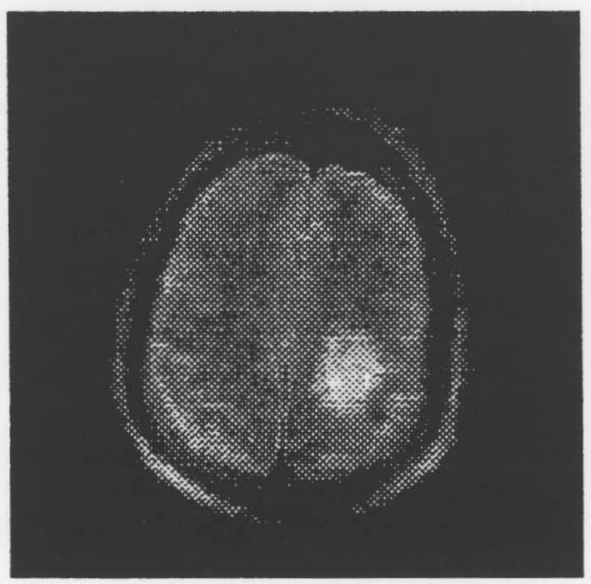

Imagem C81T725.REC 


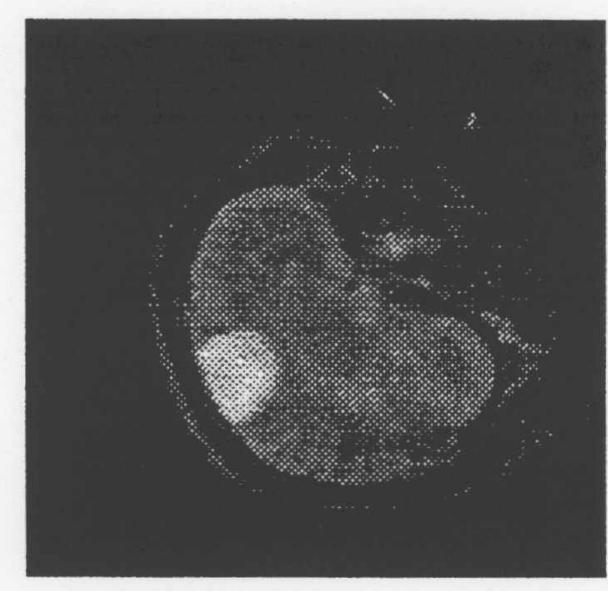

Imagem C82S402.REC

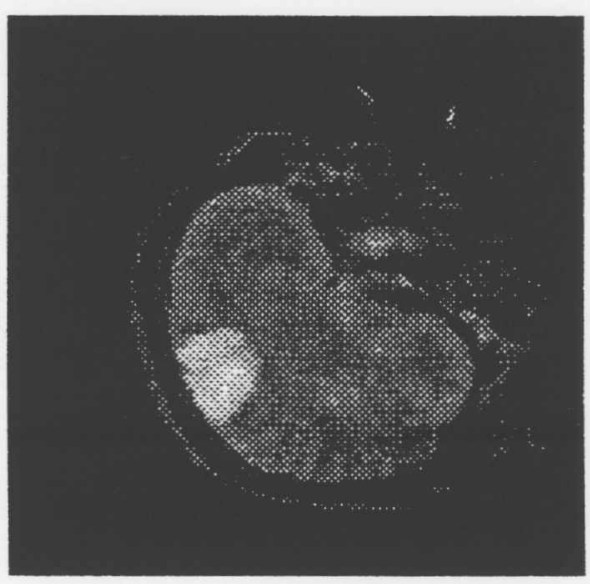

Imagem C82S410.REC

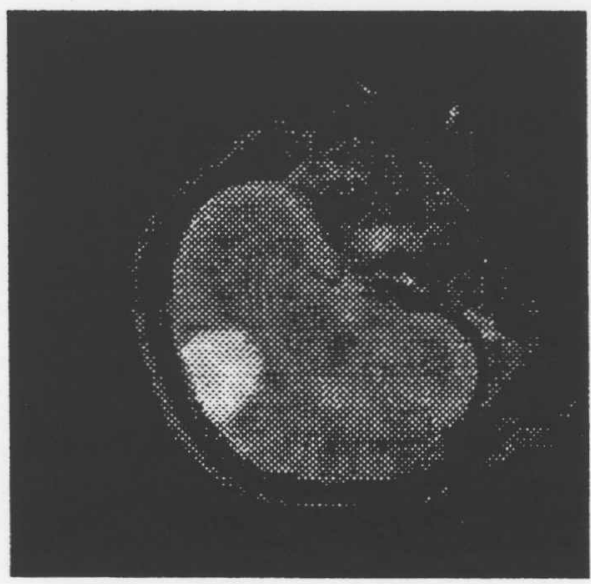

Imagem C82S420.REC

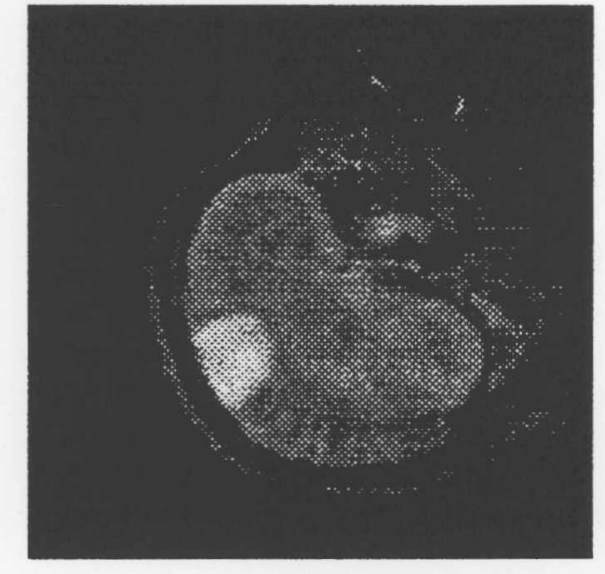

Imagem C82S405.REC

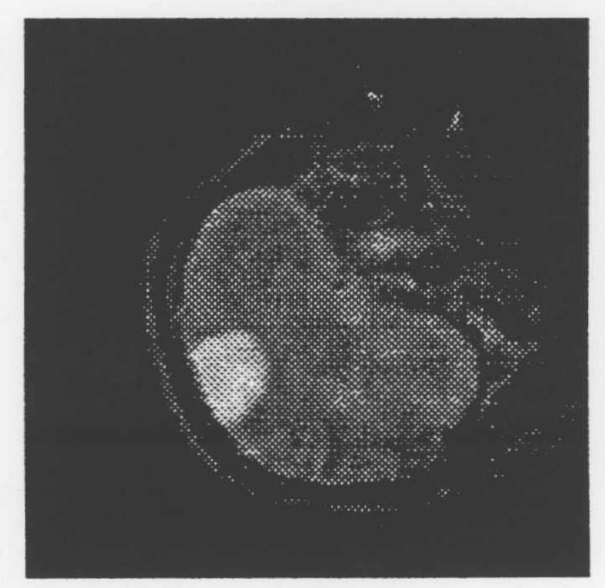

Imagem C82S415.REC

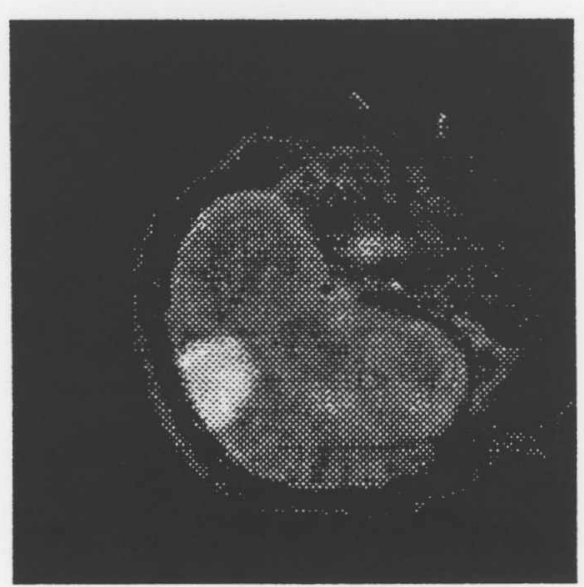

Imagem C82S425.REC 


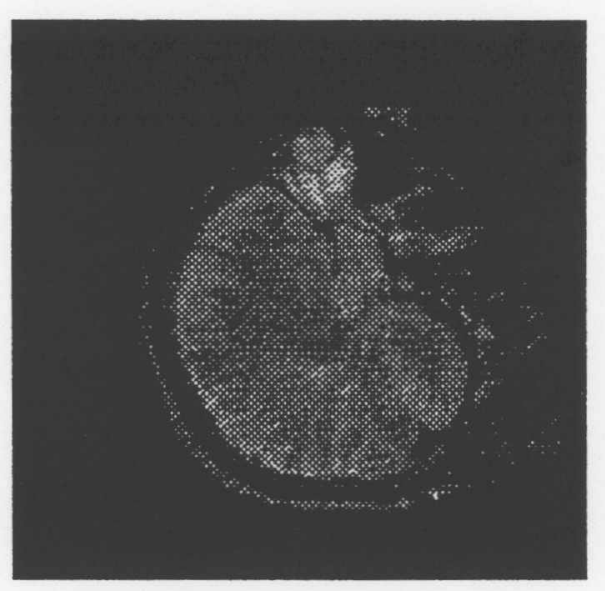

Imagem C82S702.REC

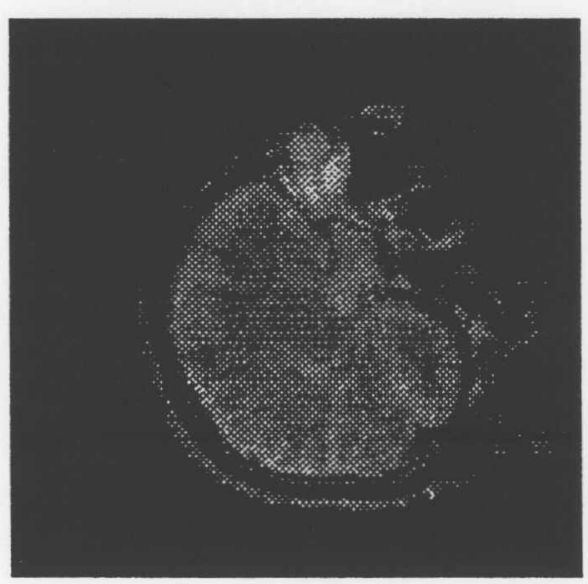

Imagem C82S710.REC

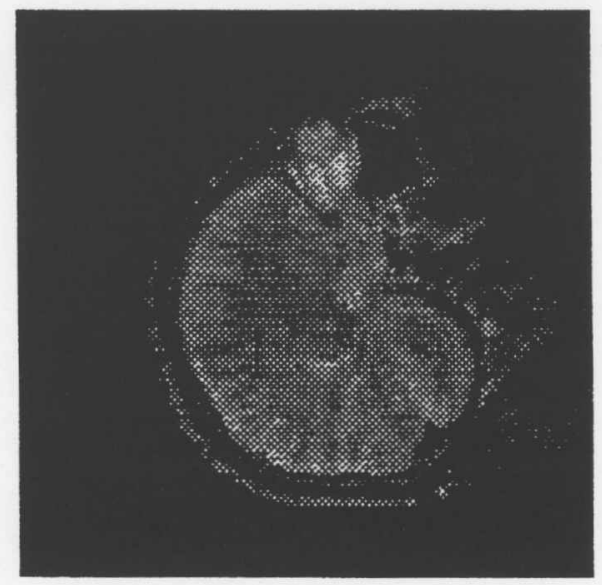

Imagem C82S720.REC

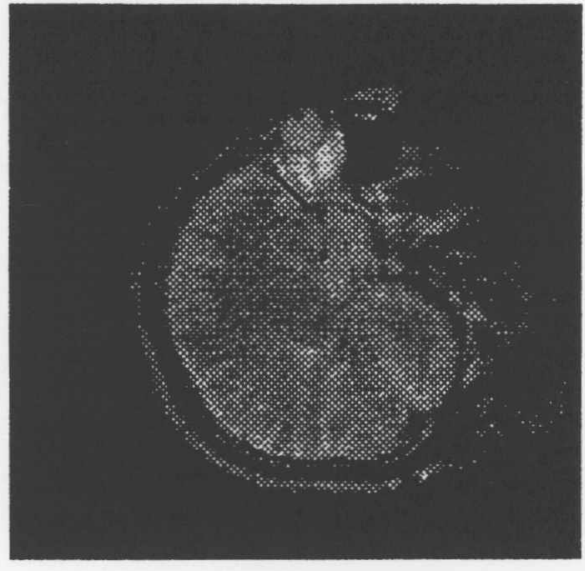

Imagem C82S705.REC

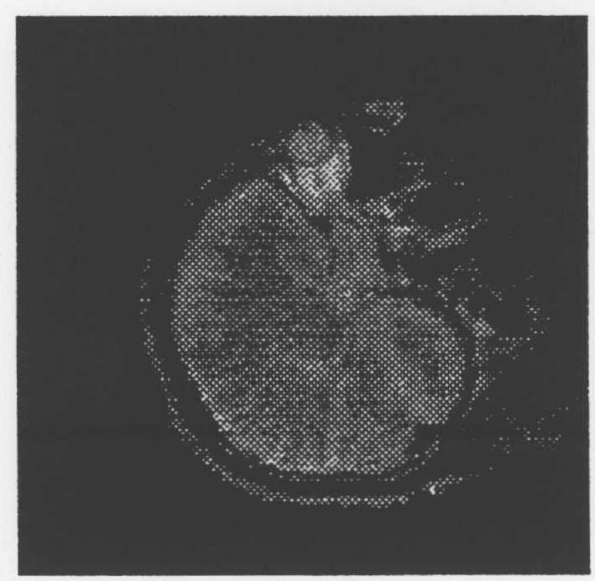

Imagem C82S715.REC

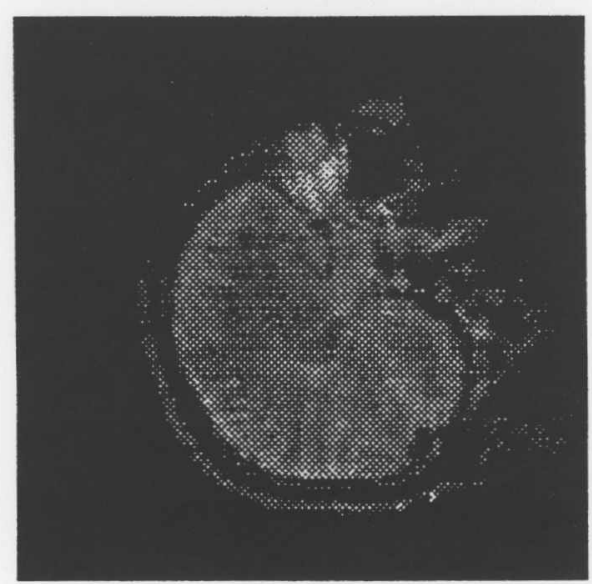

Imagem C82S725.REC 


\section{Bibliografia.}

[Ahme_74] Ahmed, N., Natarajan, T., Rao, K.R. Discrete Cosine Transform, IEEE Transaction on Computer, 1974 January, pp 90-93.

[Draf_91] Draft ISO 10918, JPEG, Digital compression and coding of continuos-tone still images, 1991.

[Elma_94] Elmasri, R., Navathe, S.B.: Fundamentals of Database System, 2th Edition, Benjamin Cummings Publishing Co. Inc., 1994.

[Fox_91] Fox, E.A: Advances in Interactive Digital Multimedia System, COMPUTER, 1991, October, pp 9-21.

[Gall_92] Le Gall, D.J.: MPEG Video Compression Algorithm, Signal Processing: Image Communication, Vol. 4, No. 2, 1992 April, pp129-140.

[Held_91] Held, G.: Data Compression, John Wiley \& Sons ltd, 1991.

[Huff_52] Huffman, D.A.: A Method for the construction of minimum redundancy codes, In Procedings IRE, Vol. 40 No. 9, 1952 September, pp 1098-1101.

[Lang_84] Langdon, G.G.: An Introduction to Arithmetic Coding, IBM J. Res. Develop., Vol. 28 No. 2, 1984 March, pp 135-149.

[Lele_87] Lelewer, D.A., Hirchberg, D.S.: Data Compression, ACM Computing Surveys, Vol. 19, No. 3, 1987 September.

[Loef 89] Loeffler, C., Ligtenberg, A., Moschytz, G.S.: Practical Fast 1-D DCT Algorithms wtih 11 Multiplications, ICASSP 1989, pp 988-991.

[Nels 89] Nelson, M.R. LZW Data Compression, Dr. Dobbs's Journal, 1989, October, pp 29-36.

[Nels_92] Nelson M.: The Data Compression Book, M \& T Puublishing, Inc., 1992.

[Paiv_90] Paiva, M.S.: Projeto de uma Arquitetura de Hardware para Visualização de Imagens Digitais, Tese de Doutoramento apresentada no IFQSC - Agosto 1990.

[Pane 85] Panepucci, A; Donoso, J.C.; Tannus, A.; Beckmann, N.: Novas Imagens do Corpo, Ciência Hoje, Vol. 20 No. 4, 1985 Set/Out, pp 44-56.

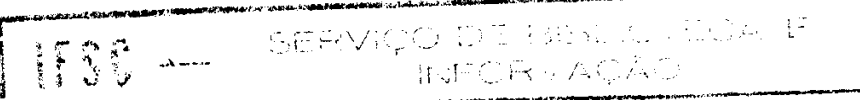


[Penn_93] Pennebaker, W.B. and Mitchell, J.L.: JPEG Still Image Compression Standard, Van Nostrand Reinhold, New York, 1993.

[Tann_87] Tannús A.: Desenvolvimento de Tecnologia de Tomorafia por Ressonância Magnética Nuclear - tese de Doutoramento apresentada no IFQSC - Agosto 1987.

[Trai 91] Traina, A.J.M.: Estudo e Implementação de Software Dedicado para um Sistema de Vizualização de Imagens, Tese de Doutoramento apresentada no IFQSC - Julho 1991.

[Wall 91] Wallace, G.K.: Overview of the JPEG Still Picture Compression Algorithm, COMMUNICATIONS of the ACM, Vol. 34, No. 4, 1991 April, pp 31-44.[Wall_92]

[Wall_92] Wallace, G.K.: Data Compression for Multimedia System - Panel, SIGGRAPH 1992, Chicago, July, pp 416. 


\section{Anexo I - Informações sobre JPEG}

Joint Photographic Expert Group - JPEG, no relatório 10.918 do processo ISO/IEC CCITT para o desenvolvimento de padrões internacionais, define as linhas básicas de requisitos e implementações para o processo de codificação e descodificação de imagens em tons-contínuos e para a representação de dados de imagens comprimidas para intercâmbio entre aplicações. Estes processos e representações são voltadas para aplicações genéricas, isto é, aplicáveis uma a larga gama de aplicações que necessitem utilizar imagens coloridas ou em tons-de-cinza para sistemas de comunicação e computadores.

O comitê envolvido com este padrão é o ISO/IEC JTC1/SC2/WG10, Codificação de Imagens Fotográficas, em colaboração com o CCITT SGVIII. Antes do estabelecimento da WG10 em 1990, o comitê existia como um grupo fixo, conhecido como Joint Photographic Experts Group (JPEG), do ISO/IEC JTC1/SC2/WG8. Tanto o comitê quanto o processo têm desenvolvido continuamente a padronização conhecida informalmente como JPEG.

O "joint" em JPEG refere-se ao comitê propriamente dito, mas informalmente, significa: em colaboração com o comitê Especial de Relatório Q16 da CITT SGVIII. Nesta colaboração, WG10 desempenha o trabalho de selecionar, desenvolver, documentar e testar os processos genéricos de compressão. CCITT SGV III tem fornecido os requisitos, quais desses processos deve satisfazer as necessidades específicas de aplicações de comunicação de imagens, tais como: faxsimile, vídeo-texto e teleconferências. Com o objetivo de que, este processo genérico, seja incorporado nas várias recomendações da CCITT para equipamentos finais desta aplicação. Houve a colaboração de outros orgãos internacionais:

- ISO/IEC JTC1/SC18/WG5 ODA Content Architecture and Colour;

- International Press Telecommunication Council (IPTC).

O comitê JPEG tem desenvolvido uma padronização de compressão para encontrar as necessidades de outras aplicações: desktop publishing, artes gráficas, imagens médicas e científicas. 


\section{Anexo II - Definições Matemáticas}

\section{II.1. Dimensões e amostragem relativa}

Como mostrado na figura II. 1, a imagem fonte é definida para consistir de componentes Nf. Cada componente, com um único identificador $\mathrm{C}$, é definido para consistir de um vetor retangular de amostras de $x_{i}$ colunas por $y_{i}$ linhas. A imagem possui, como um todo, amostras de dimensões $\mathrm{X}$ por $\mathrm{Y}$, onde $\mathrm{X}$ é $\mathrm{o}$ máximo dos valores de $\mathrm{x}_{\mathrm{i}}$ na horizontal e $\mathrm{Y}$ é $\mathrm{o}$ máximo dos valores $y_{i}$ na vertical, para todos os componentes do frame. Para cada componente, fatores de amostragem $\mathrm{H}_{\mathrm{i}}$ e $\mathrm{V}_{\mathrm{i}}$ são definidos relacionando dimensões das componentes $x_{i}$ e $y_{i}$ para as dimensões $X$ e $Y$ da imagem como um todo, de acordo com as seguintes expressões:

$$
x_{i}=\left\lceil X \times \frac{H_{i}}{H_{\max }}\right\rceil \text { e } y_{i}=\left\lceil Y \times \frac{V_{i}}{V_{\max }}\right\rceil
$$

onde $\mathrm{H}_{\max } \mathrm{e} \mathrm{V}_{\max }$ são os fatores de amostragem máximos para todos os componentes no frame, e \lceil\rceil é a função que retorna o valor do maior inteiro.

Como um exemplo, considere uma imagem de dimensões 512 linhas por 512 linhas e 3 componentes amostrados de acordo com os seguintes fatores de amostragem:

$$
\begin{array}{ll}
\text { Componente } 0 & \mathrm{H}_{0}=4, \mathrm{~V}_{0}=1 \\
\text { Componente 1 } & \mathrm{H}_{1}=2, \mathrm{~V}_{1}=2 \\
\text { Componente 2 } & \mathrm{H}_{2}=1, \mathrm{~V}_{2}=1
\end{array}
$$

Então, $X=512, Y=512, H_{\max }=4$ e $V_{\max }=2$, e $x_{1}$ e $y_{i}$ para cada componente são:

$$
\begin{array}{ll}
\text { Componente } 0 & \mathrm{x}_{0}=512, \mathrm{y}_{0}=256 \\
\text { Componente 1 } & \mathrm{x}_{1}=256, \mathrm{y}_{1}=512 \\
\text { Componente 2 } & \mathrm{x}_{2}=128, \mathrm{y}_{2}=256
\end{array}
$$

\section{II.2 Precisão da amostra}

A amostra é definida para ser um inteiro com precisão $P$ bits, com qualquer valor na faixa $\left[0,2^{P}-1\right]$. Todas as amostras de todos os componentes dentro da mesma imagem fonte teriam a mesma precisão $P$. 


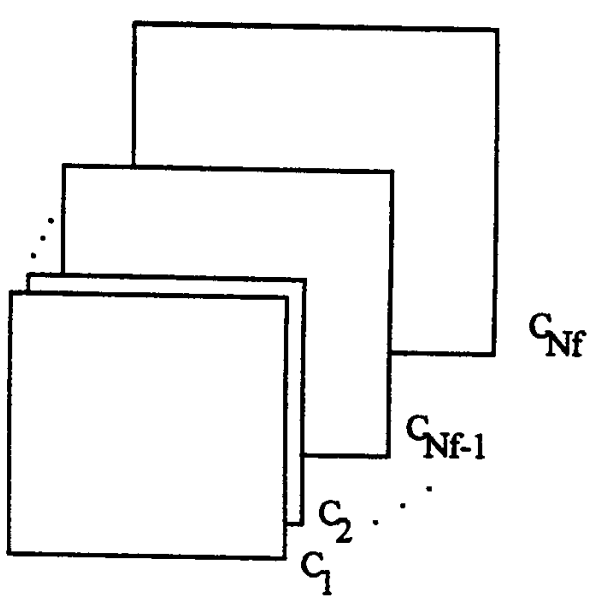

(a) Imagem Fonte com Multiplos Componentes

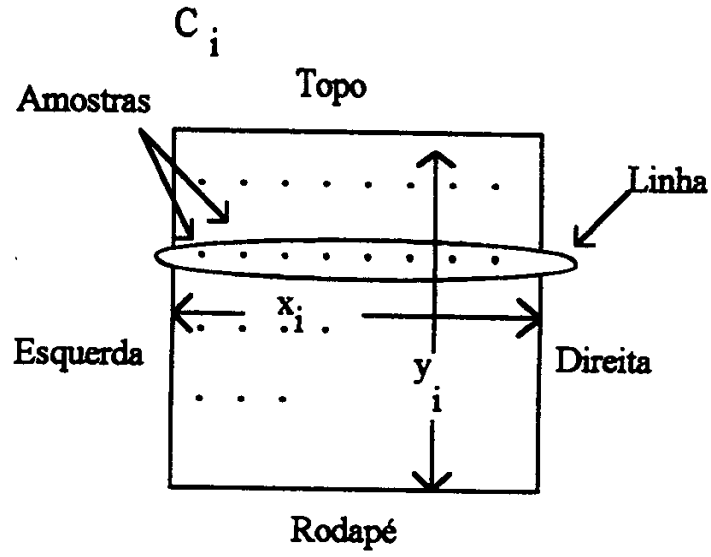

(b) Caracteristicas de um Componente de Imagem

\section{Fugura II. 1: Caracteristicas da Imagem Fonte}

\section{II.3 Orientação}

A figura II.1 indica a orientação de uma componente de uma imagem através dos termos topo, base, esquerda e direita. A ordem, através da qual as unidades de dados de uma componente de imagem são entradas para a compressão pelos procedimentos de compressão, é definida como sendo da esquerda para a direita e do topo para a base, dentro do componente (esta ordenação é definida precisamente em II.4). É da responsabilidade das aplicações definir quais arestas de uma imagem fonte seriam consideradas topo, base, esquerda e direita.

\section{II.4 Ordem de codificação de dados da imagem fonte}

O cabeçalho de varredura especifica a ordem através da qual as unidades de dados da imagem fonte seriam codificadas e colocadas dentro dos dados da imagem comprimida. Para uma dada varredura, se o parâmetro cabeçalho de verredura é $\mathrm{Ns}=1$, então os dados de somente uma componente fonte - o componente especificado pelo parâmetro $\mathrm{Cs}_{1}$ - seria apresentado pela varredura. Este dado é não-entrelaçado se $\mathrm{Ns}>1$, então os dados das componentes $\mathrm{Ns}$ de $\mathrm{Cs}_{1}$ até $\mathrm{Cs}_{\mathrm{Ns}}$ estariam presentes dentro da varredura, este dado seria sempre entrelaçado. A ordem de componentes em uma varredura estaria de acordo com a ordem especificada no cabeçalho do frame. 


\section{II.4.1 Unidade de Código Mínimo - MCU}

Para dados não-entrelaçados o MCU é uma unidade de dados. Para dados entrelaçados o MCU é a seqüência das unidades de dados definidas pelos fatores amostrados dos componentes de varredura.

Quando Ns = 1 (Ns é o numero de componentes na varredura), a ordem da unidade de dados sem a varredura será da esquerda para direita e de cima para baixo, como mostrado na figura II.2. Este ordenamento se aplica sempre que $\mathrm{Ns}=1$, regardless dos valores de $\mathrm{Hi}$ e Vi.

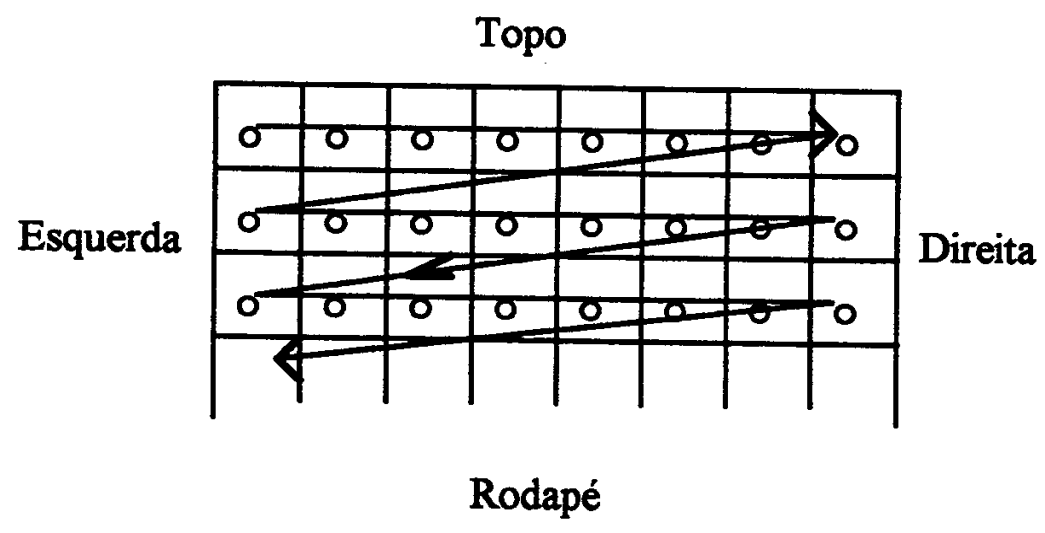

Figura II.2: Ordenamento de Dados Não-Entrelaçados

Quando Ns > 1, cada componente da varredura Csi é particionada em matrizes das unidades de dados horizontal Hk e vertical Vk. $O$ subescrito $k$ indica que Hk e Vk são da posição especificação do componente no cabeçalho do frame para o qual $\mathrm{Ck}=\mathrm{Csi}$. Sem cada matriz $\mathrm{Hk}$ por $\mathrm{Vk}$, as unidade de dados são ordenados da esqueda para a direita e de cima para baixo.

Como mostrado na figura II.3, exemplificado para $\mathrm{Ns}=4$, onde $\mathrm{MCU}_{1}$ consiste de unidade de dados tratado primeiro de cima-esquerda seguindo até o fim da linha para então tratar o resto da região de $\mathrm{Cs}_{1}$ linha por linha, seguido pela unidade de dados a matriz de $\mathrm{Cs}_{2}$, então de $\mathrm{Cs}_{3}$ e depois $\mathrm{Cs}_{4}$. $\mathrm{MCU}_{2}$ segue o mesmo ordenamento dos dados para as quatro componentes. 

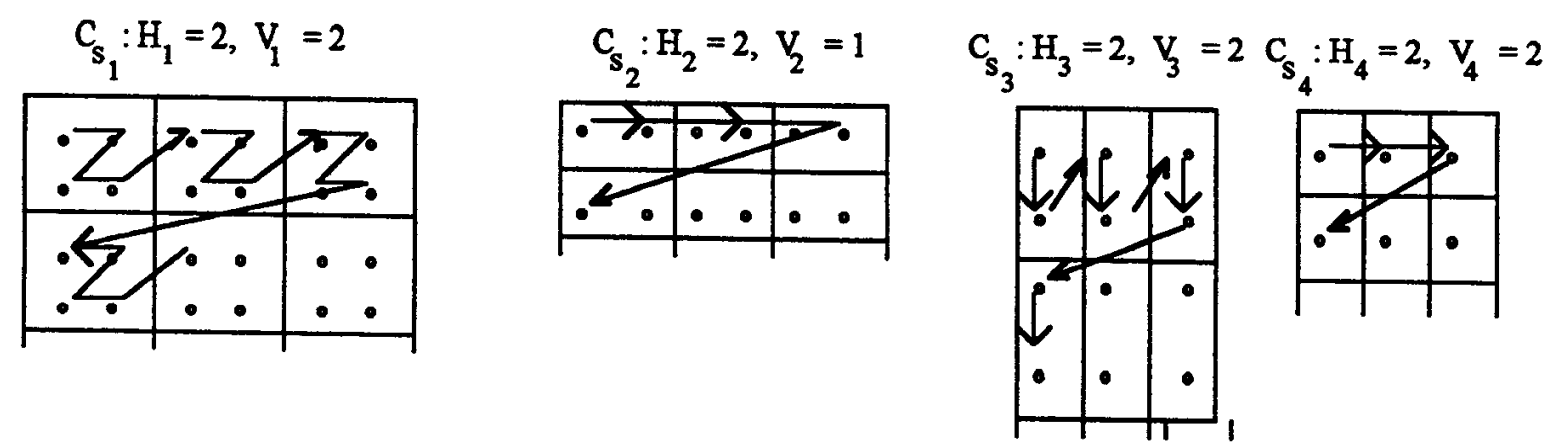

$$
\begin{aligned}
& M C U_{1}=d_{\infty 0}^{1} \quad d_{01}^{1} \quad d_{10}^{1} \quad d_{11}^{1} \quad d_{\infty}^{2} \quad d_{01}^{2} \quad d_{00}^{3} \quad d_{10}^{3} \quad d_{\infty}^{4}
\end{aligned}
$$

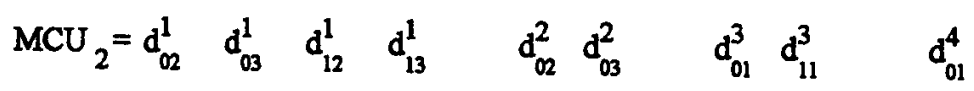

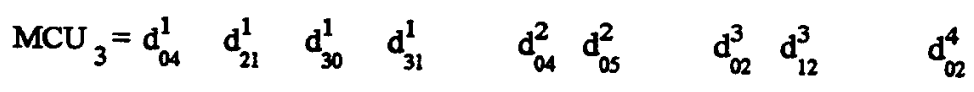

$$
\begin{aligned}
& M_{4} U_{4}=d_{20}^{1} \quad d_{21}^{1} \quad d_{30}^{1} \quad d_{31}^{1} \quad d_{10}^{2} \quad d_{11}^{2} \quad d_{20}^{3} \quad d_{30}^{3} \quad d_{10}^{4} \\
& \text { Unidade de Dados: } \begin{array}{cccc}
\mathrm{C}_{1} & \mathrm{C}_{3} & \mathrm{Cs}_{3} & \mathrm{Cs}_{4}
\end{array}
\end{aligned}
$$

Figura III.3: Exemplo de Ordenamento de Dados Entrelaçados

\section{II.5 Compressão DCT}

\section{II.5.1 Transformação dos dados da Amostra}

Antes de calcular o processo de codificação de um frame não-diferencial o FDCT para um bloco de amostra da imagem fonte, a amostra é tranformada pela subtração de $2^{\mathrm{P}-1}$, para obter uma representação do sinal no intervalo $-2^{\mathrm{P}-1}$ a $2^{\mathrm{P}-1}-1$, onde $\mathrm{P}$ é o paramentro precisão. Assim, quando $P=8$ o deslocamento é de 128 e, quando $P=12$ o deslocamento é de 2048.

Depois do processo de descodificação de um frame não-diferencial é calculado IDCT e então produzido um bloco de reconstrução da imagem, segue então, a restauração da representação da amostra, com o deslocamento apropiado em função da precisão da amostra. 


\section{II.5.2 Orientação da amostra para calculo de FDCT.}

A figura II. 4 mostra uma componente a qual foi particionada em blocos de $8 \times 8$ para 0 cálculo do FDCT. A figura II.4 também define a orientação da amostra através da exibição dos índices usados no FDCT, equação II.1.

A definição do particionamento do bloco e orientação da amostra também aplica-se a qualquer processo de descodificação DCT e saída da reconstrução da imagem. Qualquer extensão da amostra adicionado por um processo de descodificação seria removido pelo processo de descodificação.

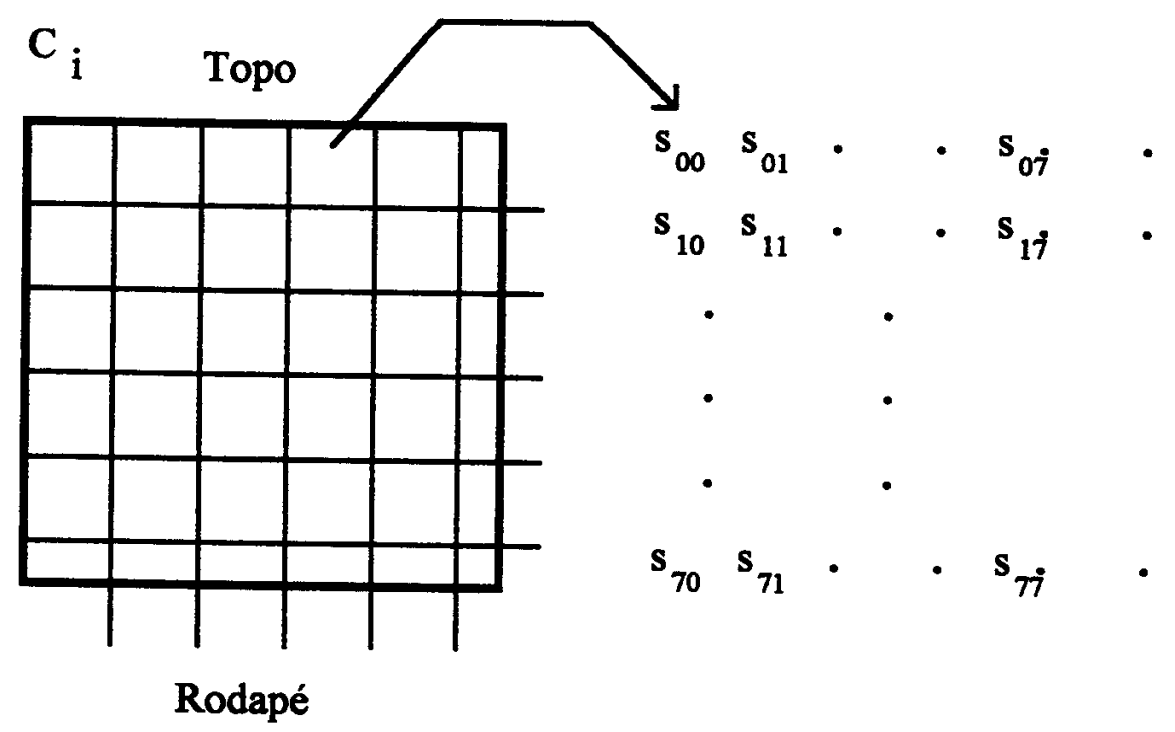

Figura II.4: Partição e Orientação das amostras em blocos de 8x8.

As equações a seguir tem-se a função ideal de FDCT e IDCT.

$$
\begin{gathered}
\text { FDCT : } S_{v u}=\frac{1}{4} C_{u} C_{v} \sum_{x=0 y=0}^{7} \sum_{y x}^{7} \cos \frac{(2 x+1) u \pi}{16} \cos \frac{(2 y+1) v \pi}{16} \\
\text { IDCT : } S_{y x}=\frac{1}{4} \sum_{u=0 v=0}^{7} \sum_{u}^{7} C_{v} S_{v u} \cos \frac{(2 x+1) u \pi}{16} \cos \frac{(2 y+1) v \pi}{16} \\
\text { onde: } C_{u}, C_{v}=1 / \sqrt{2} \text { para } u, v=0 \\
C_{u}, C_{v}=1 \text { caso contrário. }
\end{gathered}
$$

Equação - I.1 Funções ideais de FDCT e IDCT 


\section{II.5.3 Quantização e desquantização do coeficiente DCT}

Depois do cálculo de FDCT para um bloco, cada um dos 64 coeficientes da DCT é quantizado por um quantizador uniforme. $O$ quantizador para cada coeficiente $S v u$ é um valor de correspondência com o elemento Qvu da tabela de quantização especificada pelo parâmetro de frame do plano da amostra.

O quantizador uniforme é definido pela equação a seguir, visando o arrendondamento para o inteiro mais próximo.

$$
S q_{v u}=\operatorname{round}\left(\frac{S_{v u}}{Q_{v u}}\right)
$$

$S q_{v u}$ é o coeficiente DCT quantizado, normalizado pelo tamanho do passo do quantizador.

Para o descodificador, esta normalização é removida pela equaão a seguir, na qual define a desquantização.

$$
R_{v u}=S q_{v u} x Q_{v u}
$$

Assim, temos a figura II.5 que demonstra a relação entre as equações, FDCT e IDCT e, Quantização e Desquantização. 


$$
\begin{aligned}
& s_{00} s_{01} \ldots s_{07} \stackrel{\text { FDCT }}{\longrightarrow} s_{00} s_{01} \ldots s_{07} \stackrel{\text { Quantiz. }}{\longrightarrow} s_{10} s_{11} s q_{01} \ldots . s q_{07} \\
& s_{10} s_{11} \ldots s_{17} \quad s_{10} s_{11} \ldots . s_{17} \quad s q_{10} s q_{11} \ldots . s q_{17} \\
& s_{70} s_{71} \ldots s_{77} \\
& \begin{array}{c}
\mathbf{s}_{70} \mathbf{s}_{71} \ldots \mathbf{s}_{77} \\
\text { Amostra da Imagem Fonte }
\end{array} \\
& S_{70} S_{71} \ldots S_{77} \\
& \text { Coeficientes DCT } \\
& \text {. } \left.\quad \text { Rounda } \frac{s_{m w}}{s_{m}}\right)-s_{q} \text {. } \\
& \uparrow \quad \mathrm{sq}_{70} \mathrm{Sq}_{11} \ldots . \mathrm{sq}_{77} \\
& \text { Coeficientes DCT Quantizados } \\
& Q_{\infty} Q_{01} \cdot \cdots \cdot Q_{07} \\
& Q_{10} Q_{11} \ldots Q_{17} \\
& \mathrm{Q}_{70} \mathrm{Q}_{71} \ldots \mathrm{Q}_{77} \\
& \text { Tabela de Quantização }
\end{aligned}
$$

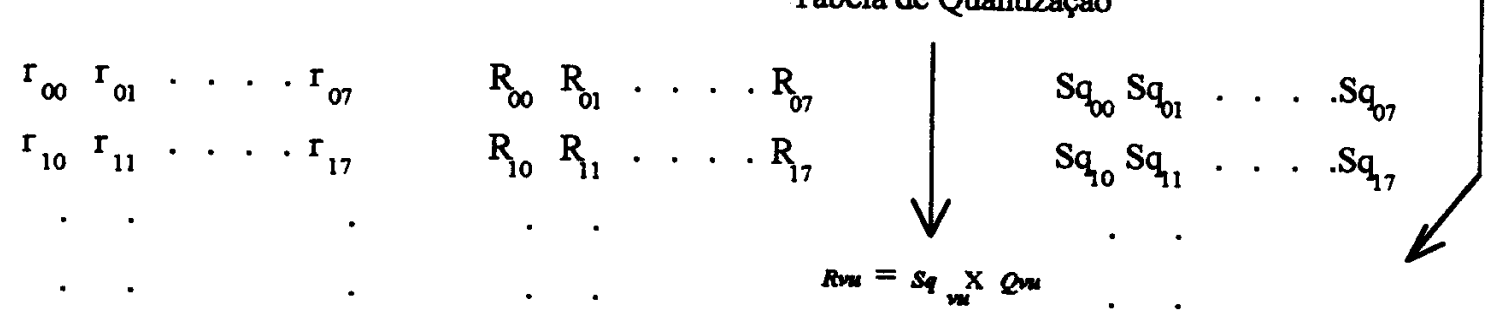

$$
\begin{aligned}
& \mathrm{r}_{70} \mathrm{r}_{71} \ldots \mathrm{r}_{n} \\
& \text { Amostra da Imagem } \\
& \text { Reconstruída } \\
& R_{70} R_{71} \ldots R_{77} \\
& \text { Coeficientes DCT } \\
& \text { Desquantizados }
\end{aligned}
$$

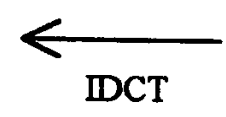

Figura II.5: Relação entre Blocos de Amostras de 8x8 e Coeficientes DCT

\section{II.5.4 Codificação do diferencial DC}

Depois da quantização, e na preparação para codificação da entropia, a quantização do coeficiente DC Sq $q_{00}$ é tratado separadamente dos 63 coeficientes AC. A codificação do coeficiente diferencial é tratado como: $\mathrm{DIFF}=\mathrm{DC}_{\mathrm{i}}-\mathrm{PRED}$, onde PRED é o valor quantizado DC $\left(\mathrm{Sq}_{00}\right)$ do bloco de precedente de mesma componente no entrelaçamento. 


\section{II.5.5 Seqüência zig-zag}

Depois da quantização, e na preparação para codificação de entropia, os coeficientes quantizados $\mathrm{AC}$ são convertidos na seqüência zig-zag. $\mathrm{O}$ coeficiente quantizado $\mathrm{DC}$ (coeficiente zero na matriz) é tratado separadamente. A seqüência zig-zag é especificada a seguir:

$$
\begin{array}{rcrrrrrr}
0 & 1 & 5 & 6 & 14 & 15 & 27 & 28 \\
2 & 4 & 7 & 13 & 16 & 26 & 29 & 42 \\
3 & 8 & 12 & 17 & 25 & 30 & 41 & 43 \\
9 & 11 & 18 & 24 & 31 & 40 & 44 & 53 \\
10 & 19 & 23 & 32 & 39 & 45 & 52 & 54 \\
20 & 22 & 33 & 38 & 46 & 51 & 55 & 60 \\
21 & 34 & 37 & 47 & 50 & 56 & 59 & 61 \\
35 & 36 & 48 & 49 & 57 & 58 & 62 & 63
\end{array}
$$

Figura II.6 - Seqüência zig-zag dos coeficiente quantizados 


\section{Anexo III. Sistema Desenvolvido}

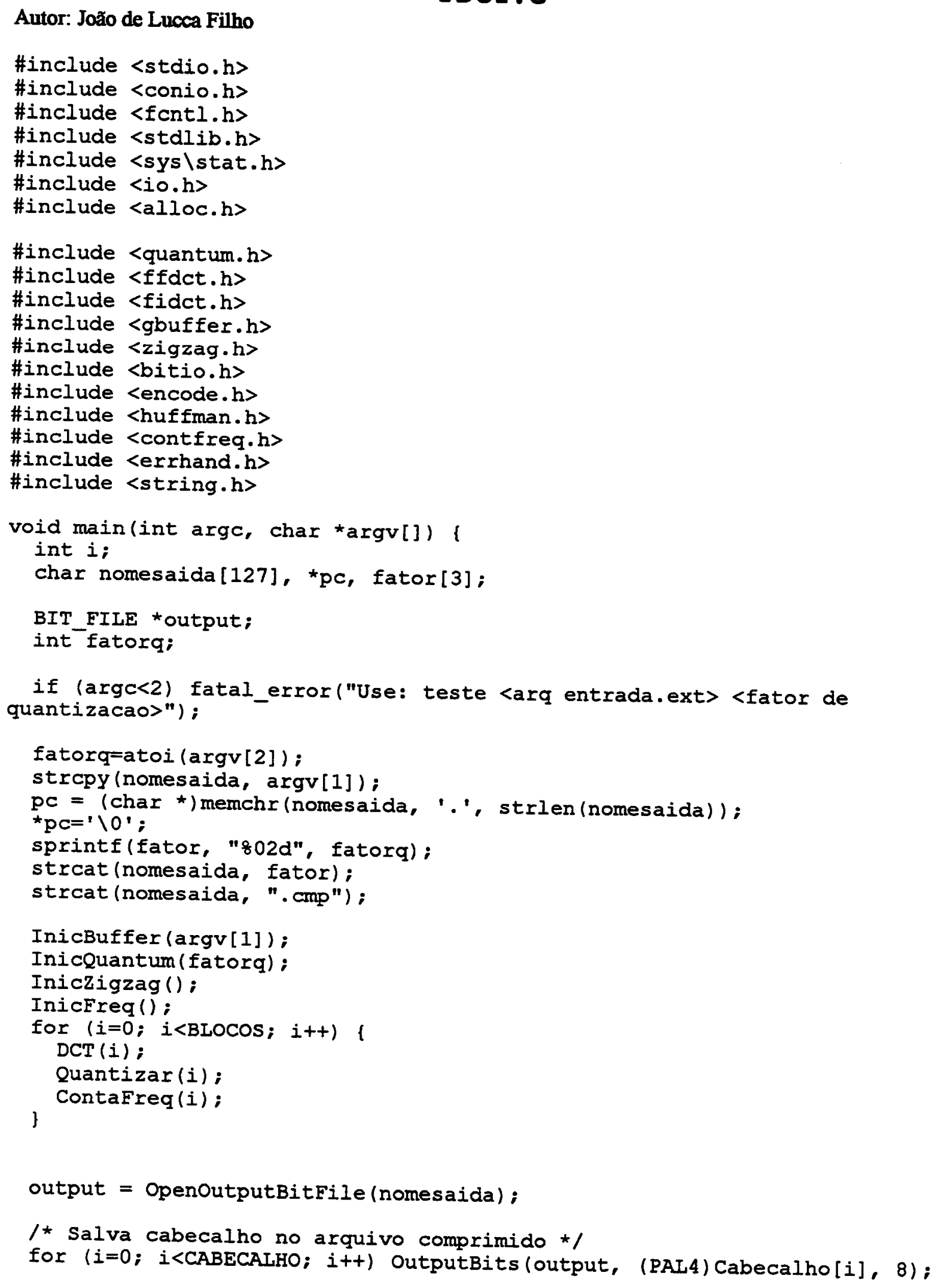




\section{EDCT.C (continuação)}

Autor: João de Lucca Filho

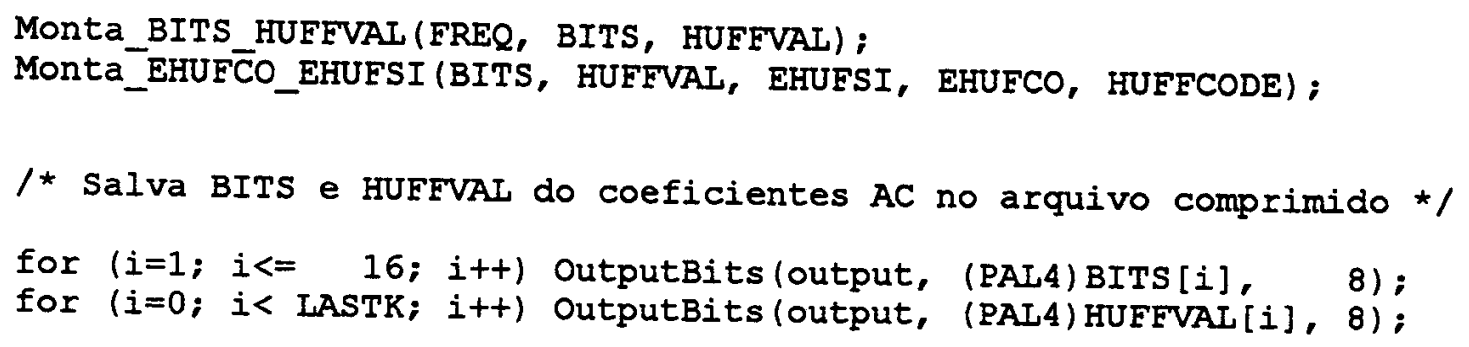




\section{GBUFE'R. C}

Autor: João de Lucca Filho

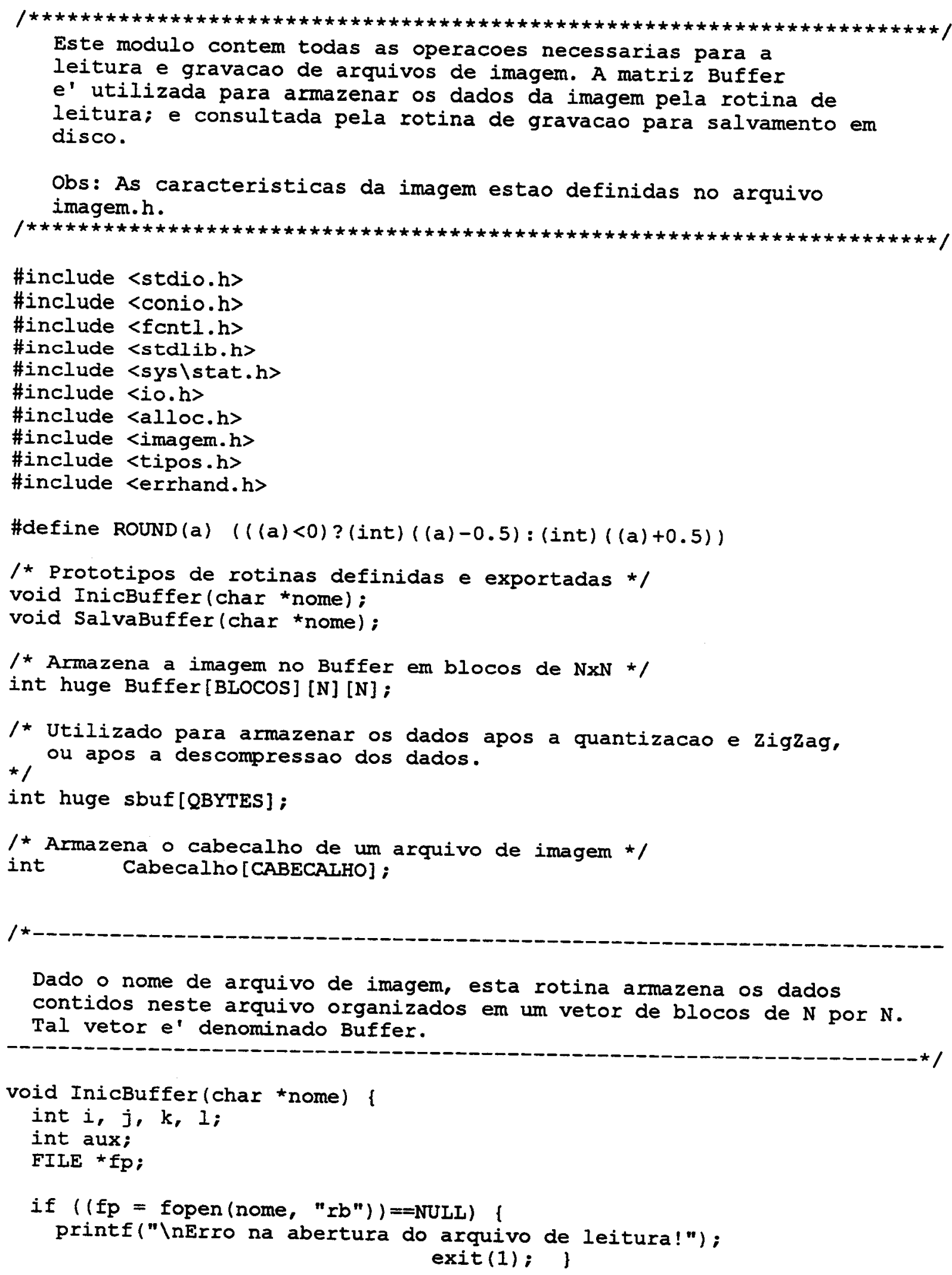




\section{GBUFFER.C (continuação)}

Autor: João de Lucca Filho

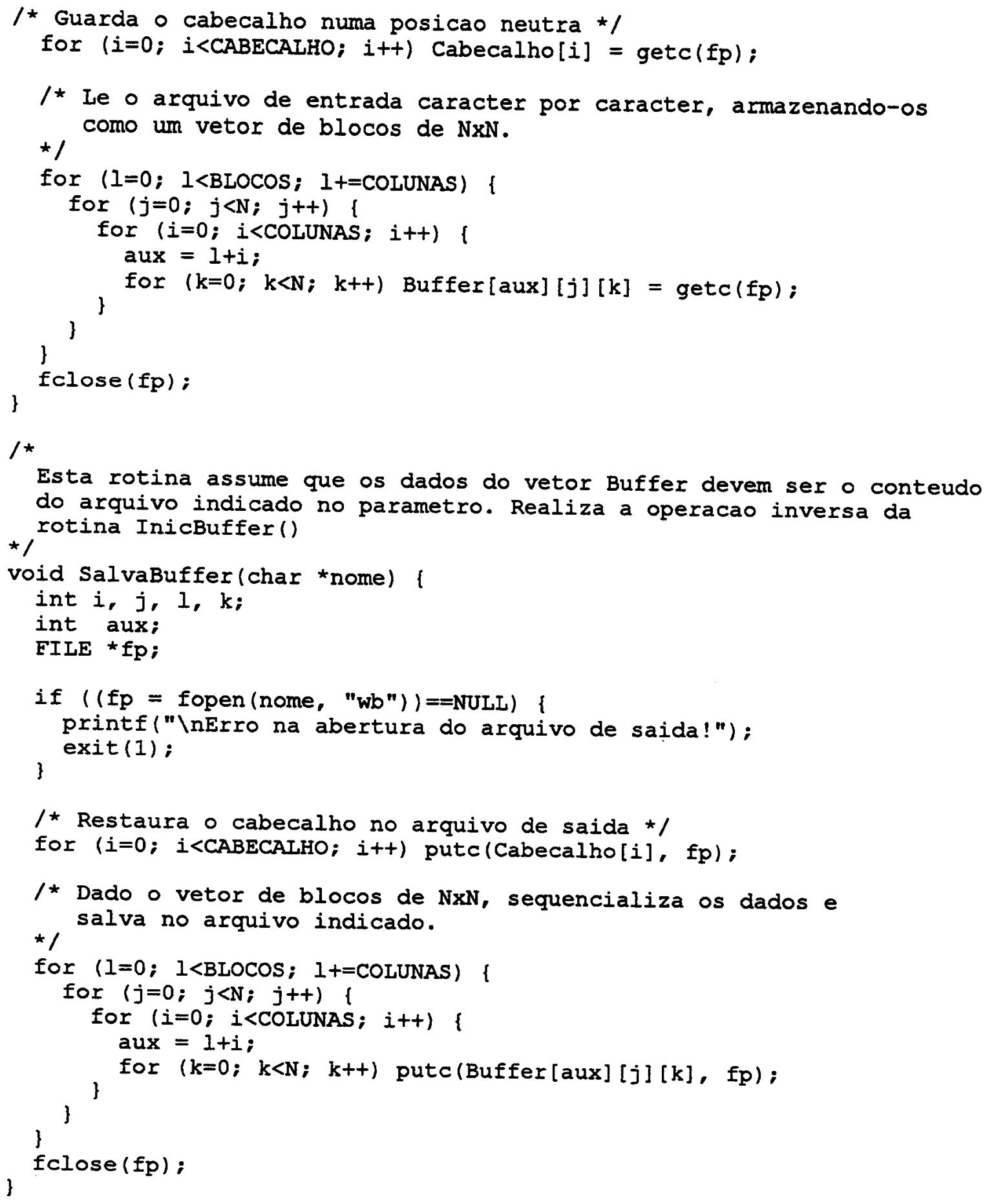




\section{FEDCT.C}

Autor: João de Lucca Filho

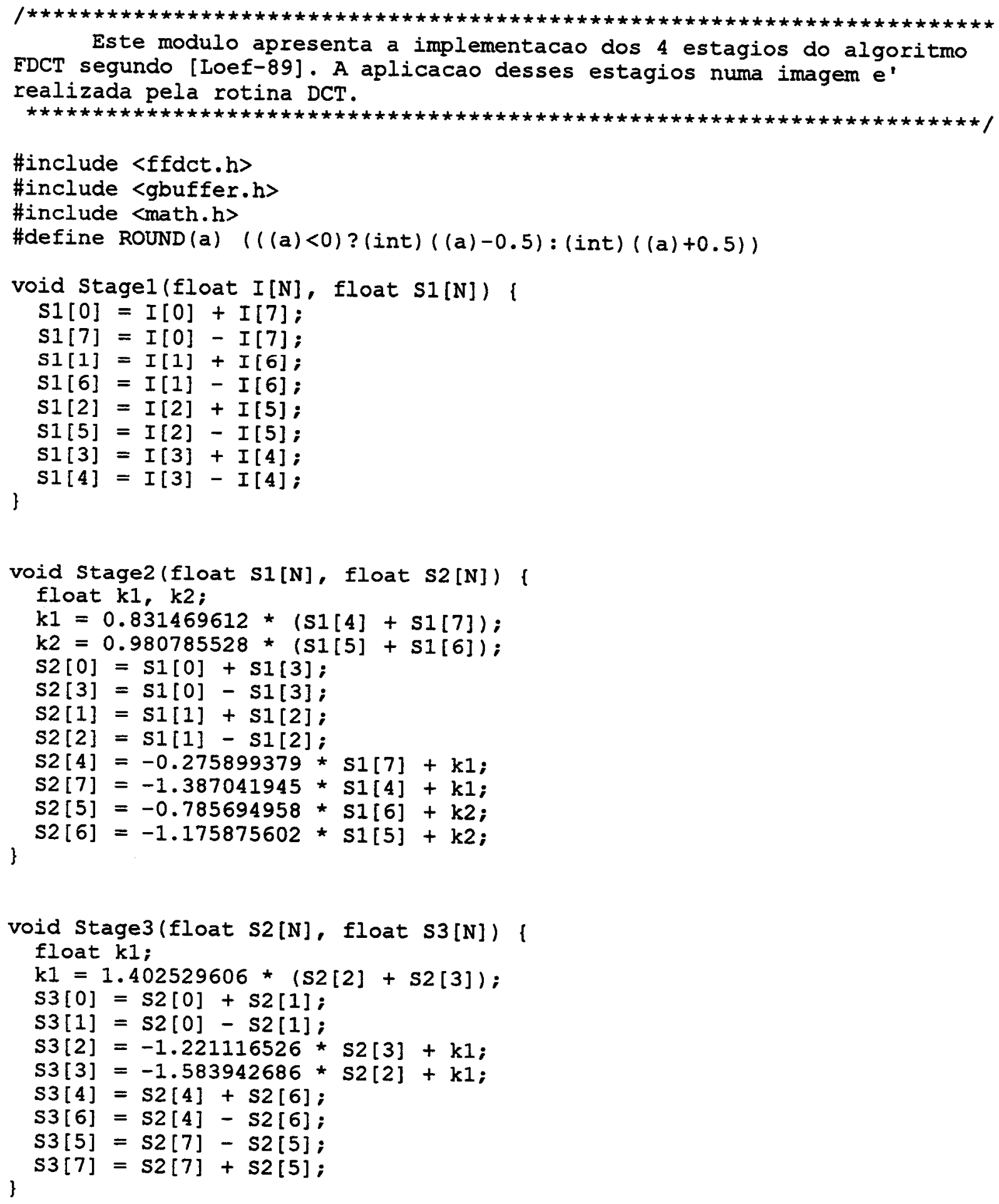




\section{FFDCT.C (continuação)}

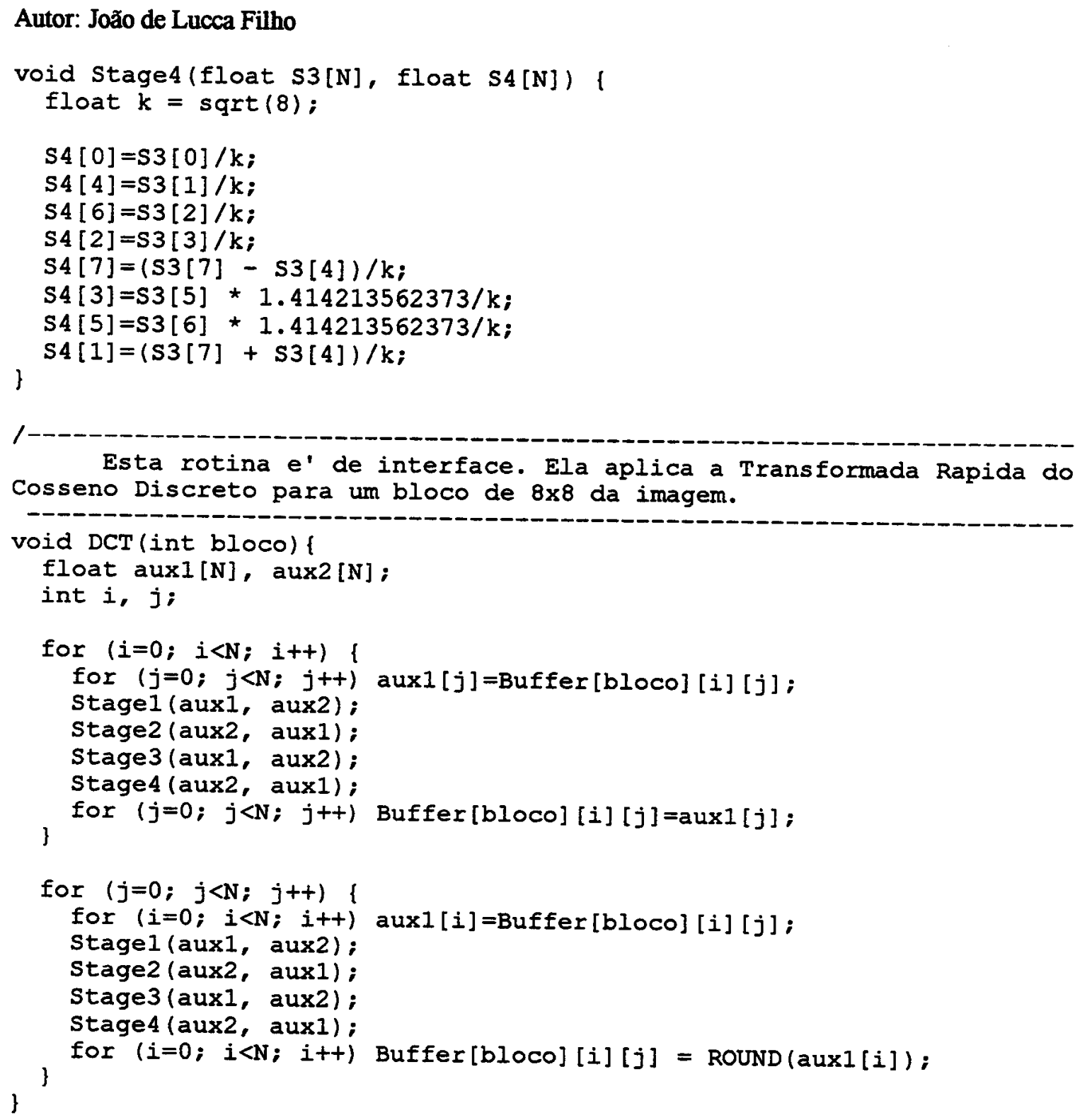




\section{QUANTUM.C}

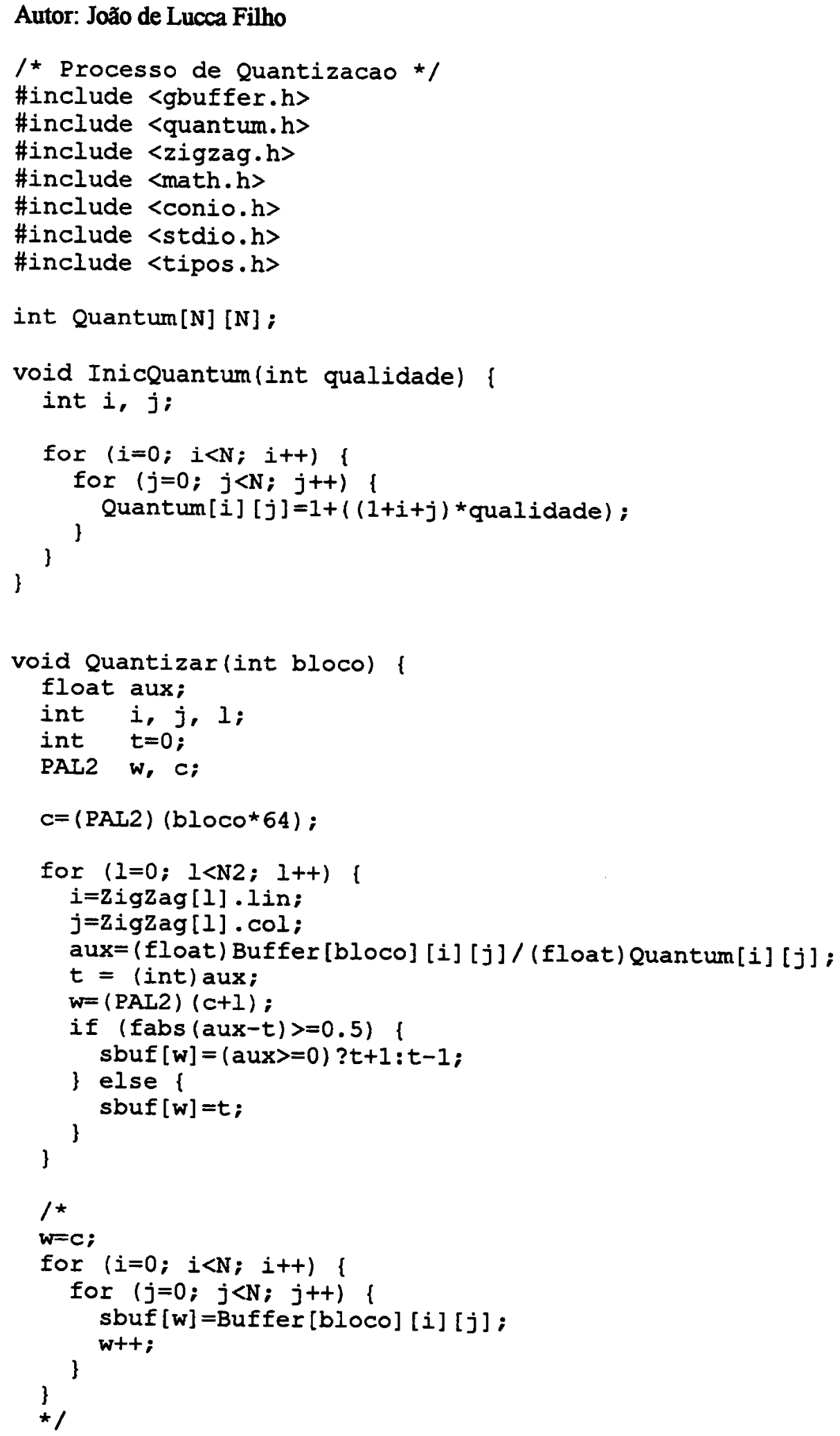




\section{QUANTUM.C (continuação)}

Autor: João de Lucca Filho

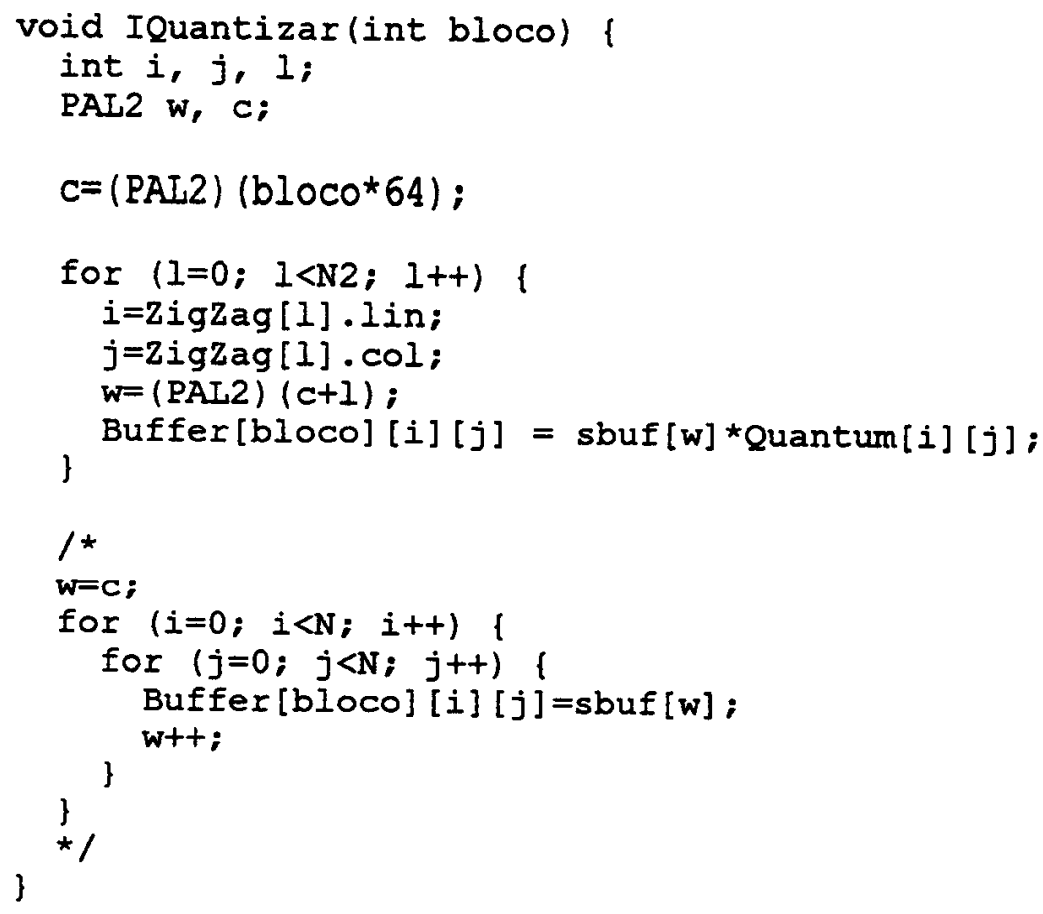




\section{ZIGZAG.C}

Autor: João de Lucca Filho

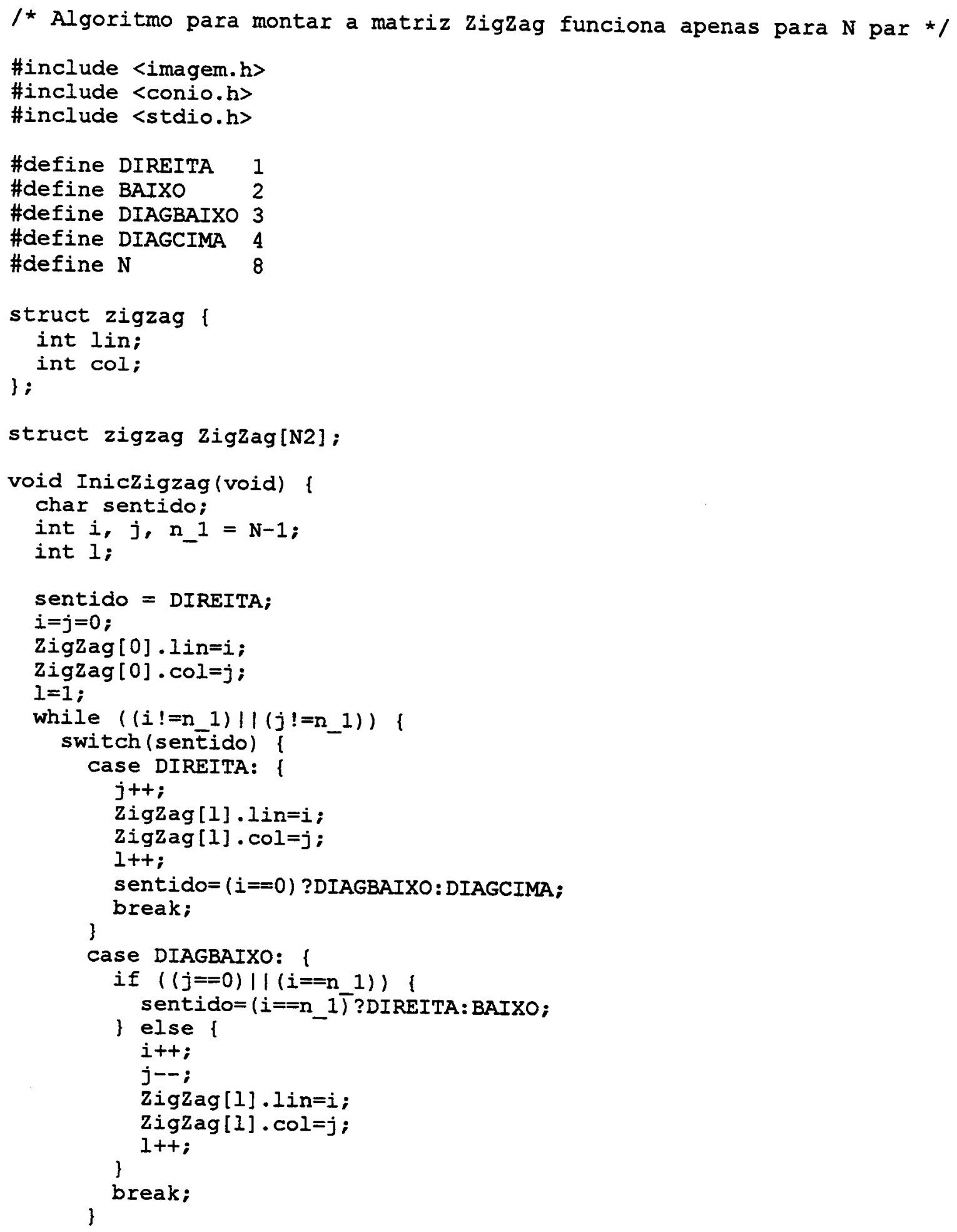


ZIGZAG.C (continuação)

Autor: João de Lucca Filho

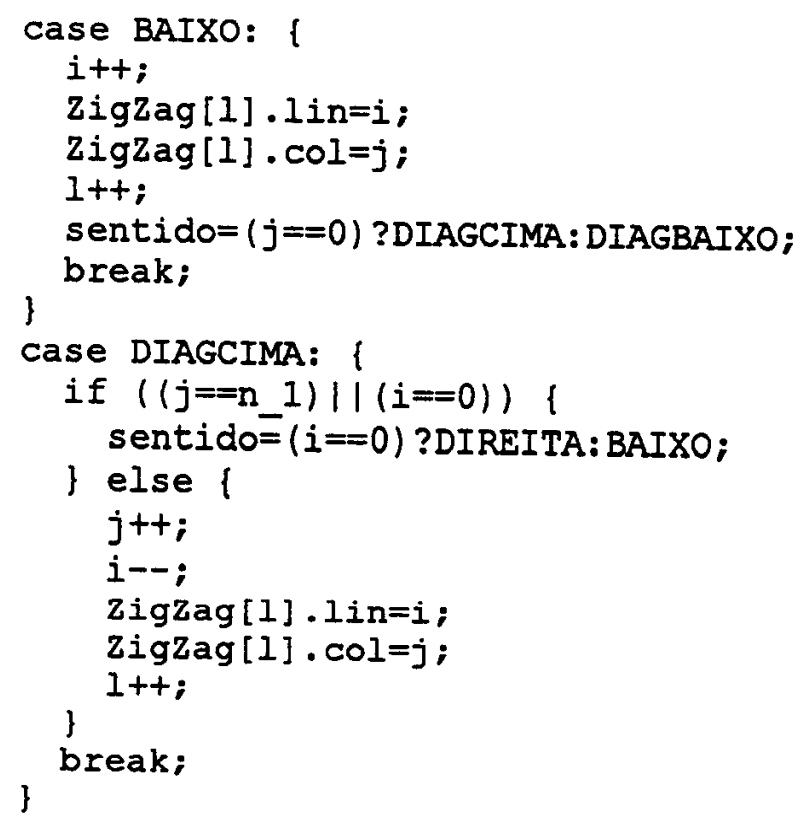




\section{DPCM.C}

Autor: João de Lucca Filho

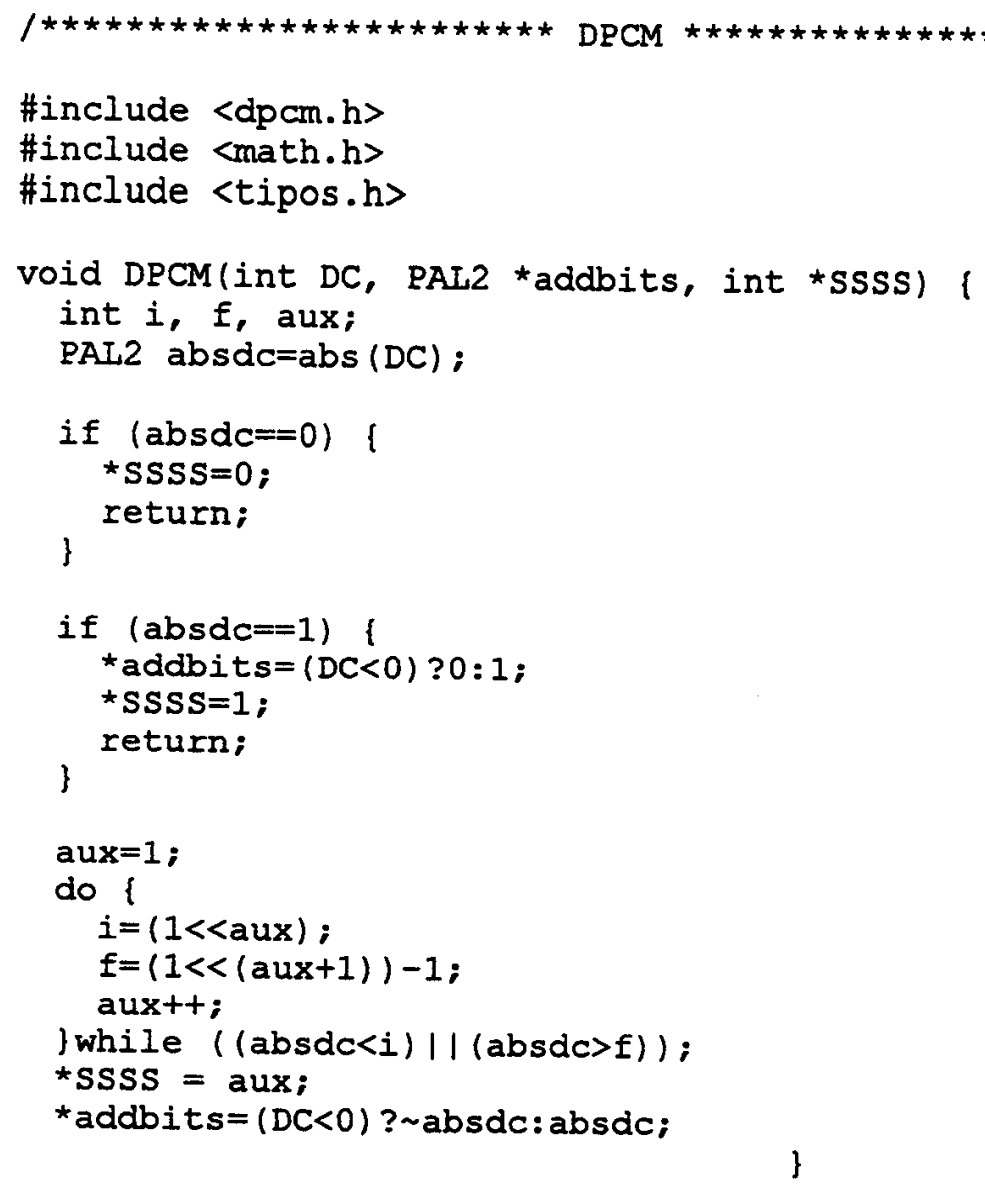




\section{CONTEREQ.C}

Autor: João de Lucca Filho

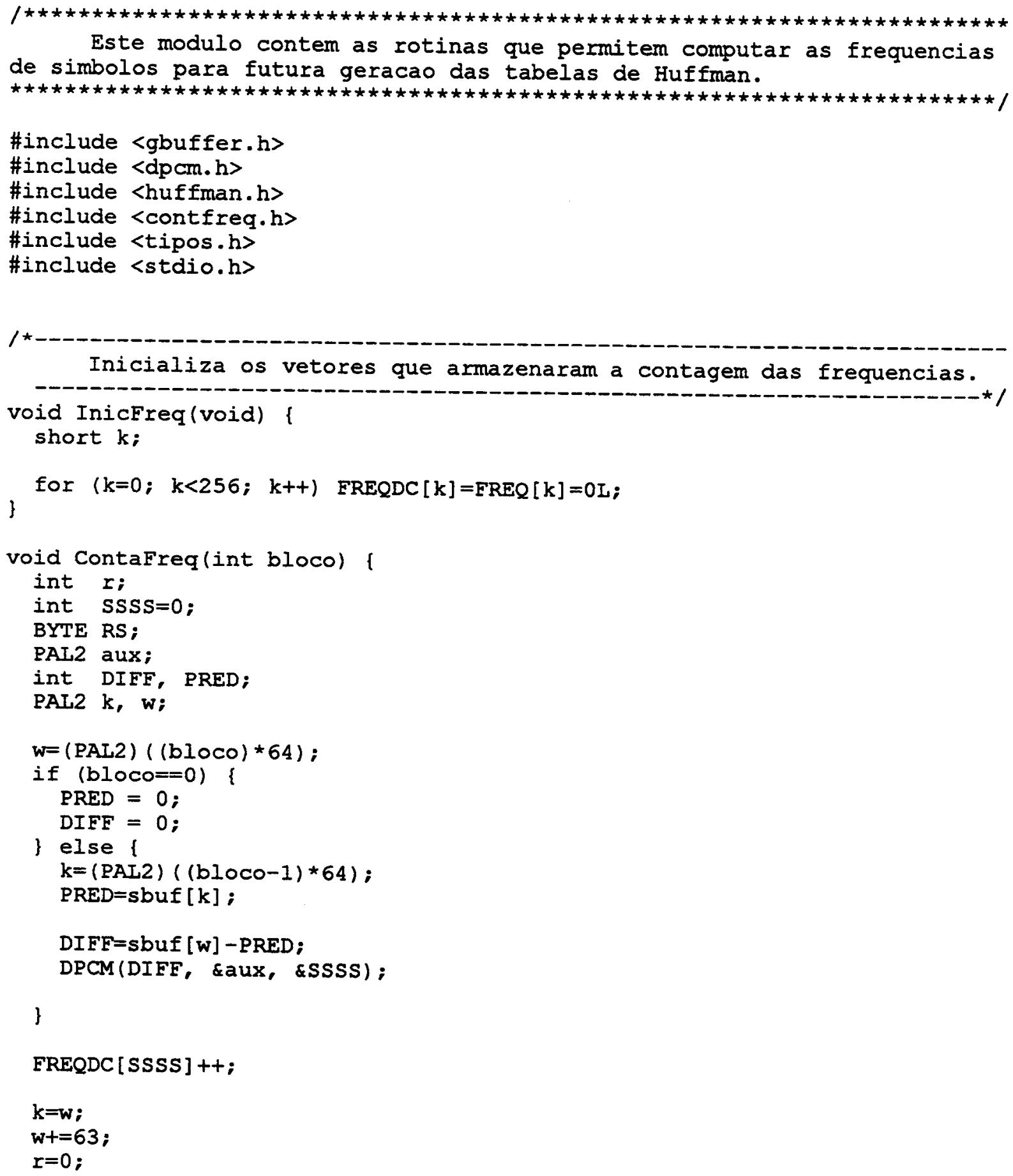




\section{CONTFREQ.C (continuação)}

Autor: João de Lucca Filho

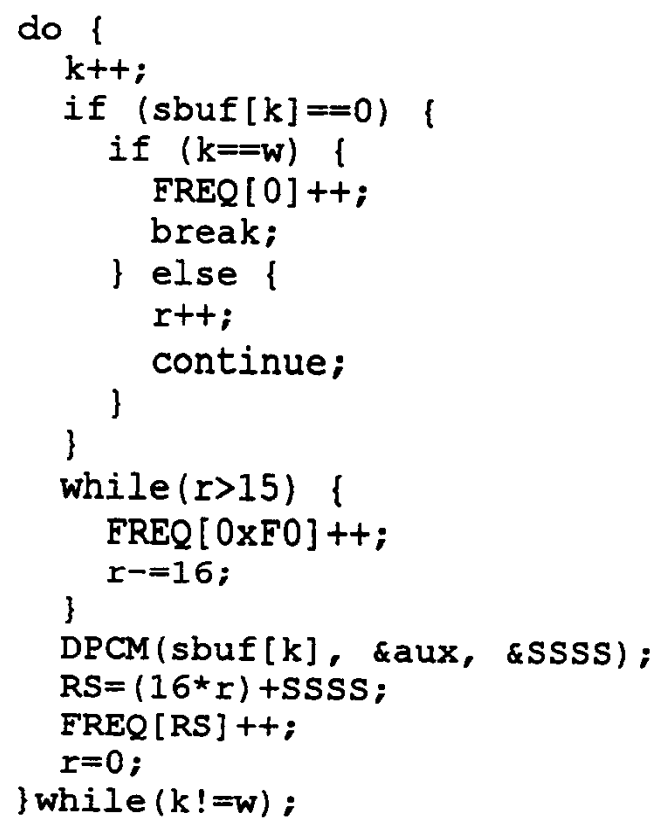




\section{HUFESIZE . C}

Autor: João de Lucca Filho

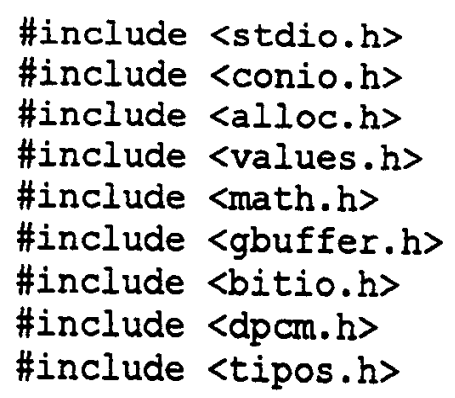


HUFFSIZE.C (continuação)

Autor: João de Lucca Filho

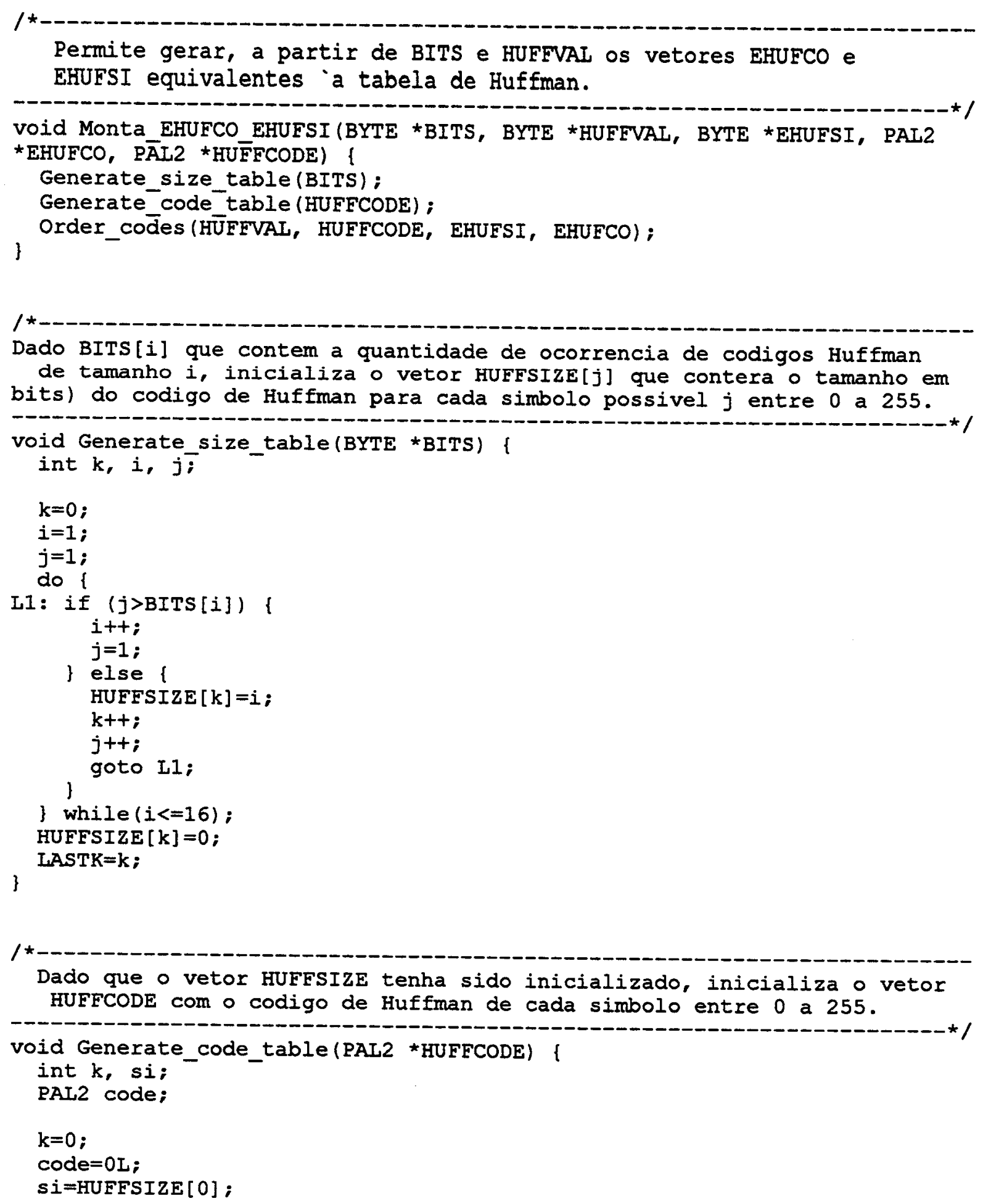




\section{HUFFSIZE.C (continuação)}

Autor: João de Lucca Filho

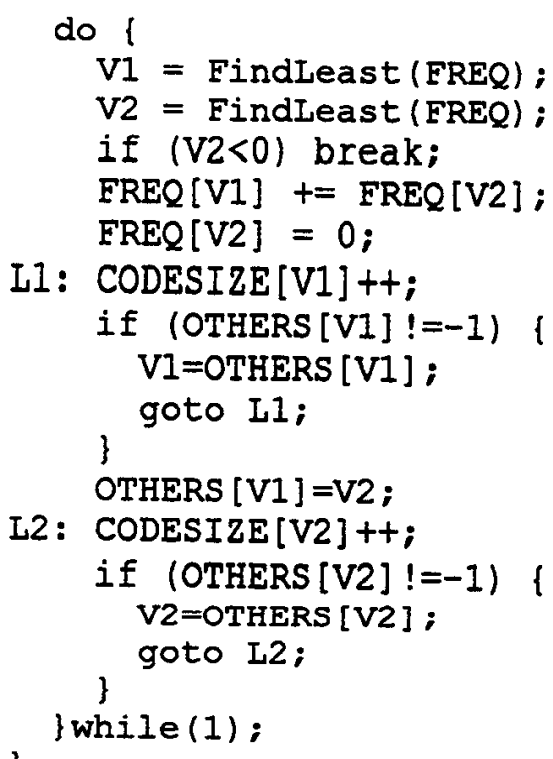

Dado o vetor CODESIZE, inicializa o vetor BITS.

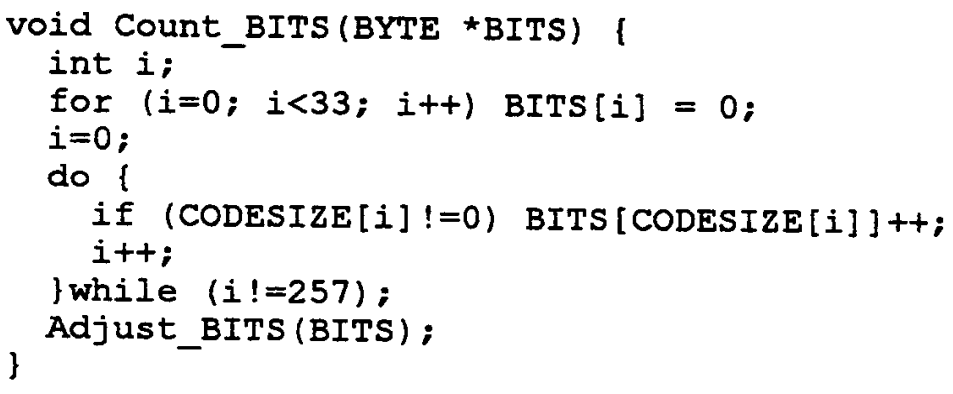


xviii

\section{HUFFSIZE.C (continuação)}

Autor: Joåo de Lucca Filho

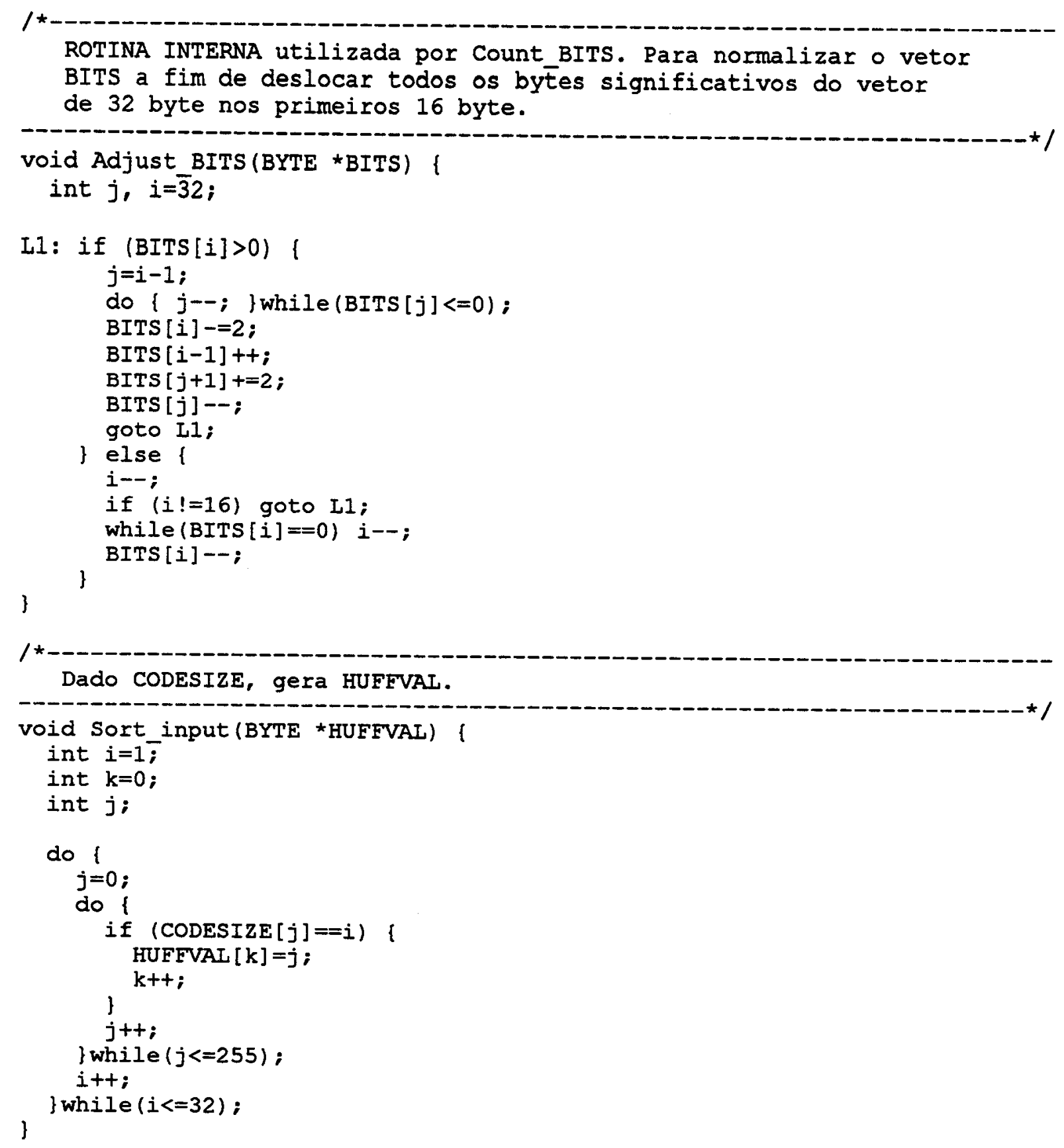


HUETSIZE . C (continuação)

Autor: João de Lucca Filho

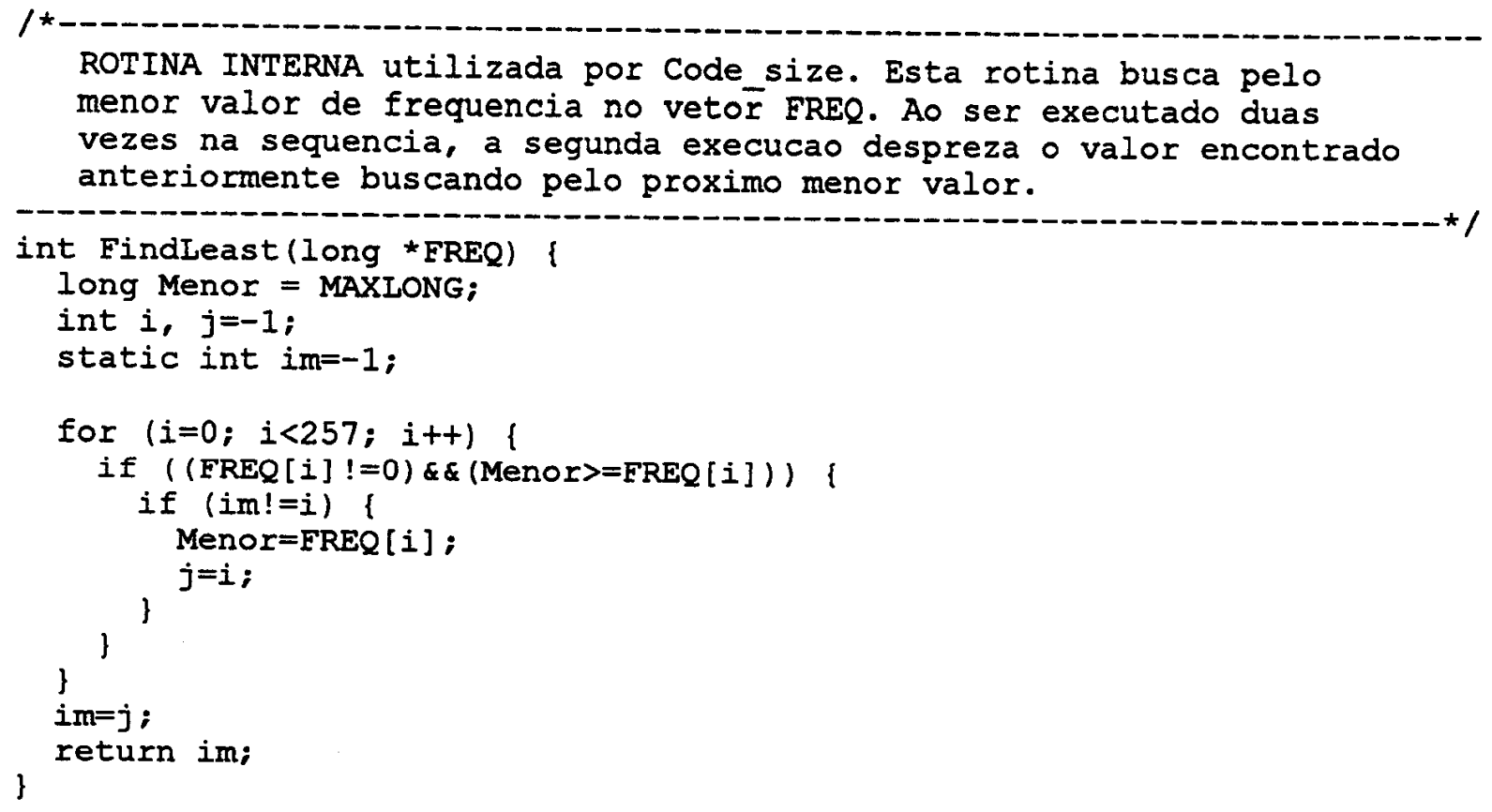




\section{ENCODE.C}

Autor: Joåo de Lucca Filho

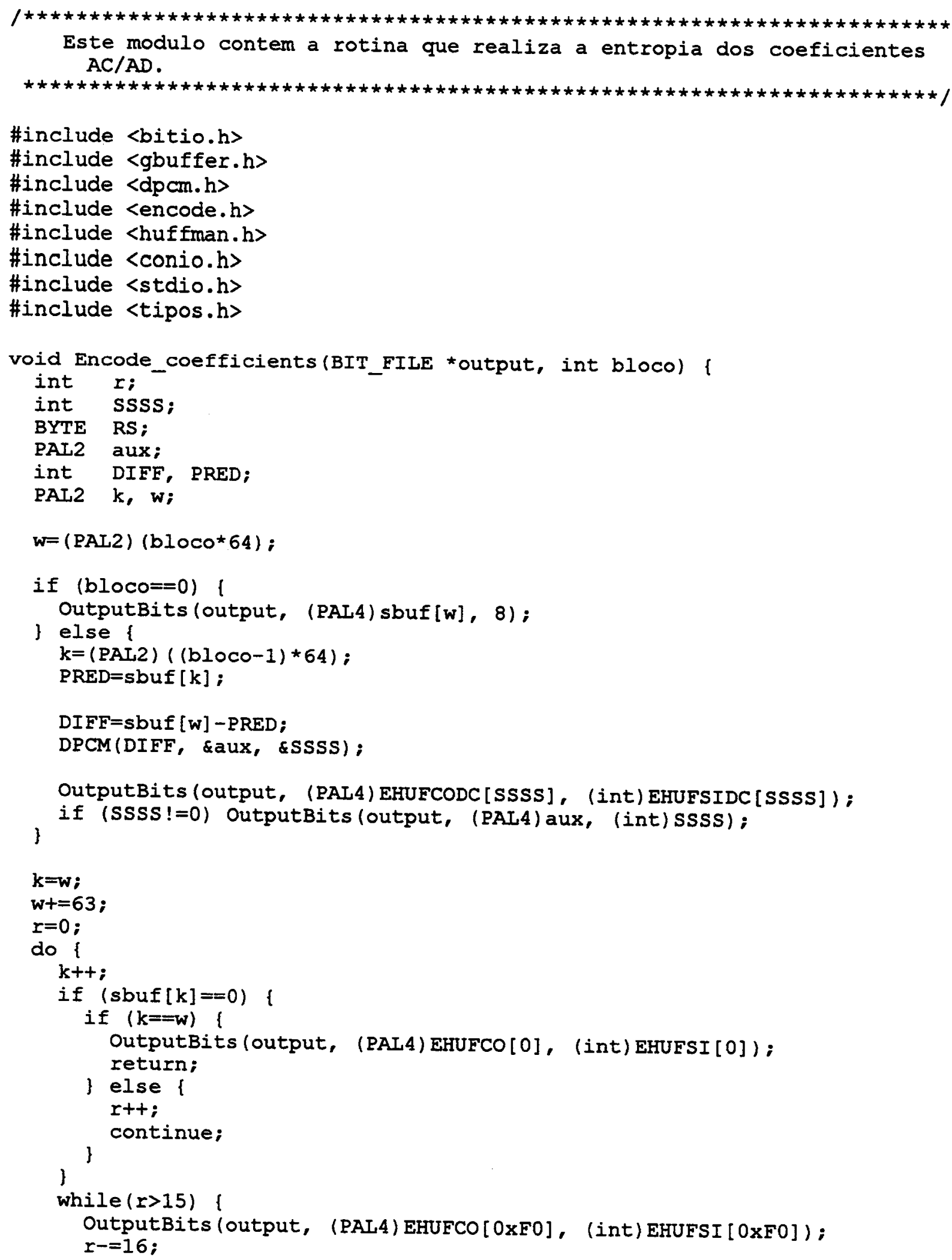


ENCODE . C (continuação)

Autor: João de Lucca Filho

$\operatorname{DPCM}$ (sbuf $[k]$, \&aux, \&SSSS);

RS $=(16 * r)+S S S$;

OutputBits (output, (PAI4) EHUFCO[RS], (int) EHUFSI [RS]);

OutputBits (output, (PAI4)aux, sSSS);

$r=0$;

\}

\} while $(k !=w)$; 


\section{BITIO.C}

Autor: Mark Nelson, 1992 [Nels_92]

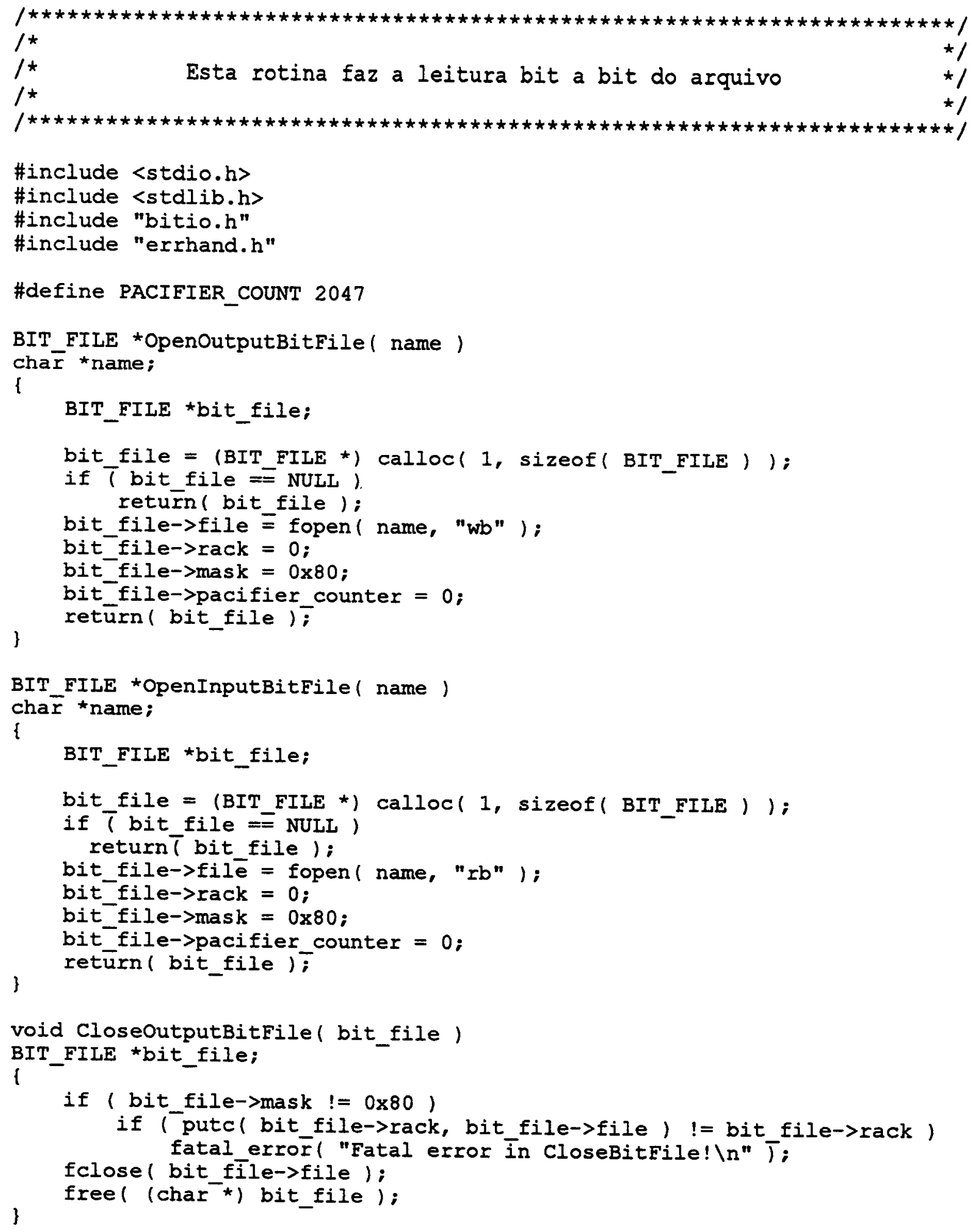




\section{BITIO.C (continuação)}

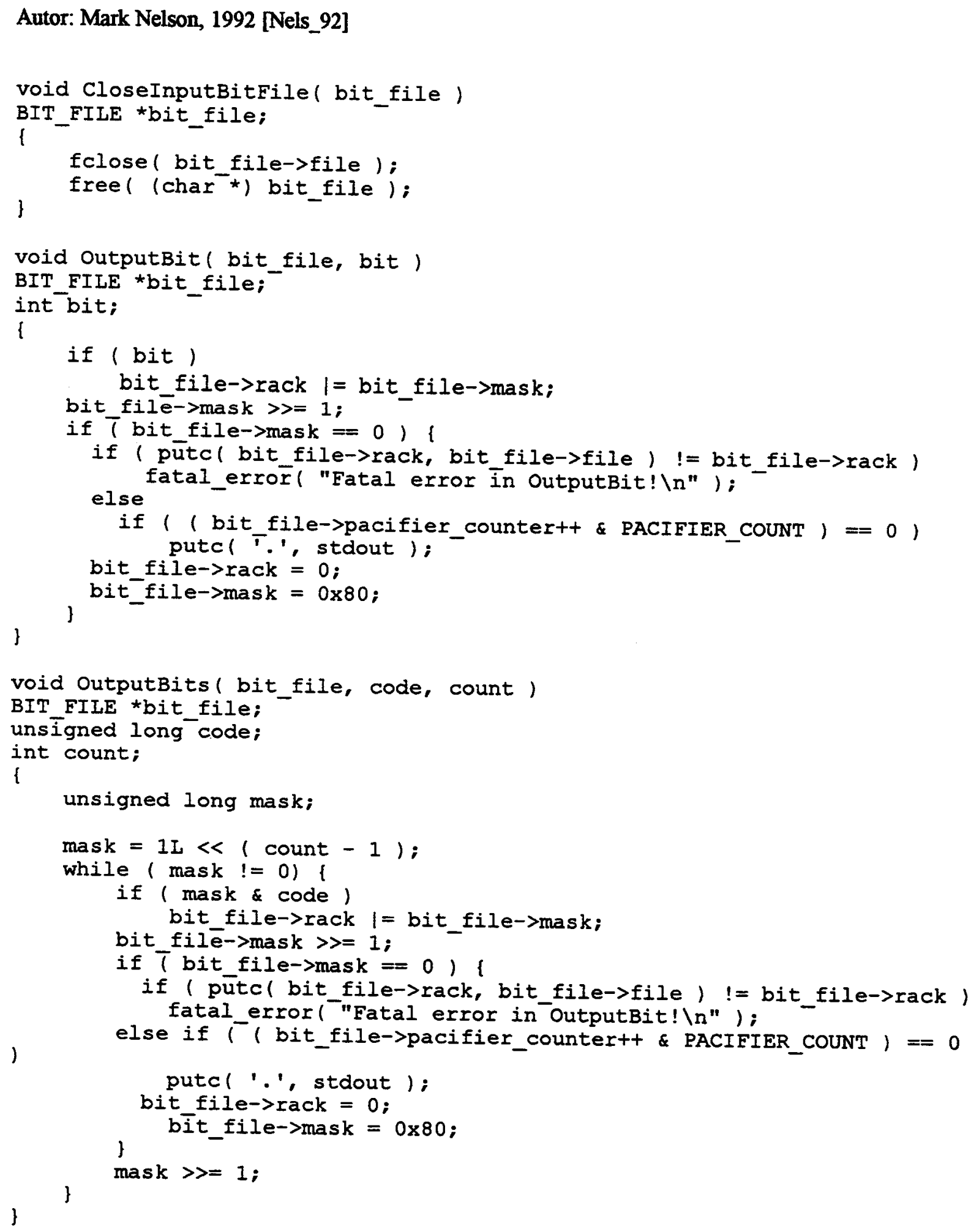




\section{BITIO.C (continuação)}

Autor: Mark Nelson, 1992 [Nels_92]

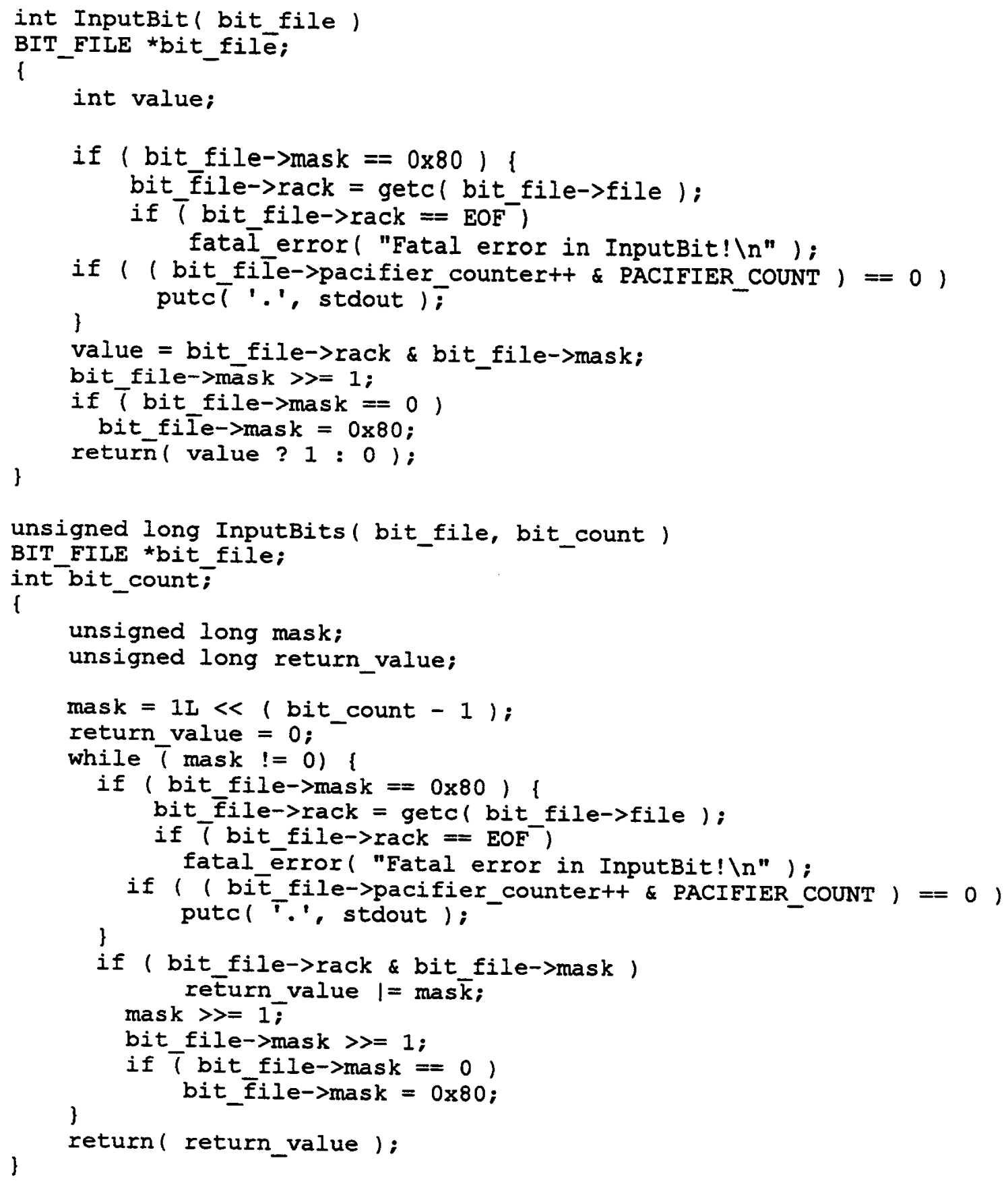




\section{BITIO.C (continuação)}

Autor: Mark Nelson, 1992 [Nels_92]

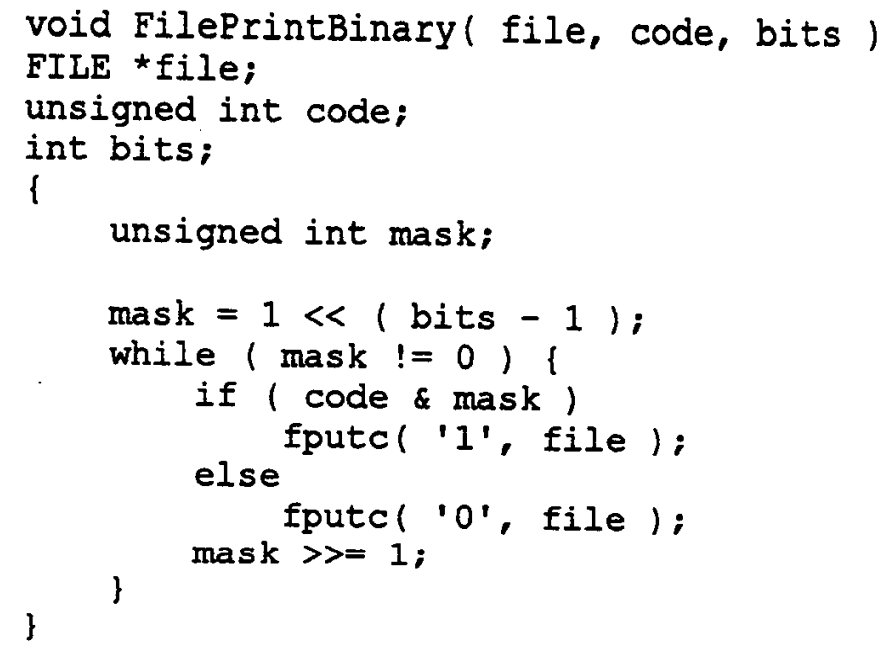




\section{ERRHAND.C}

Autor: Mark Nelson, 1992 [Nels_92]

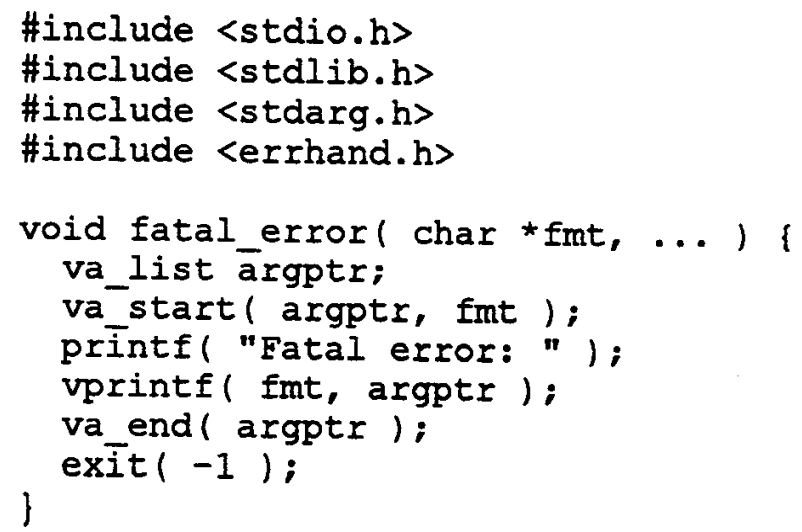




\section{IECMP.C}

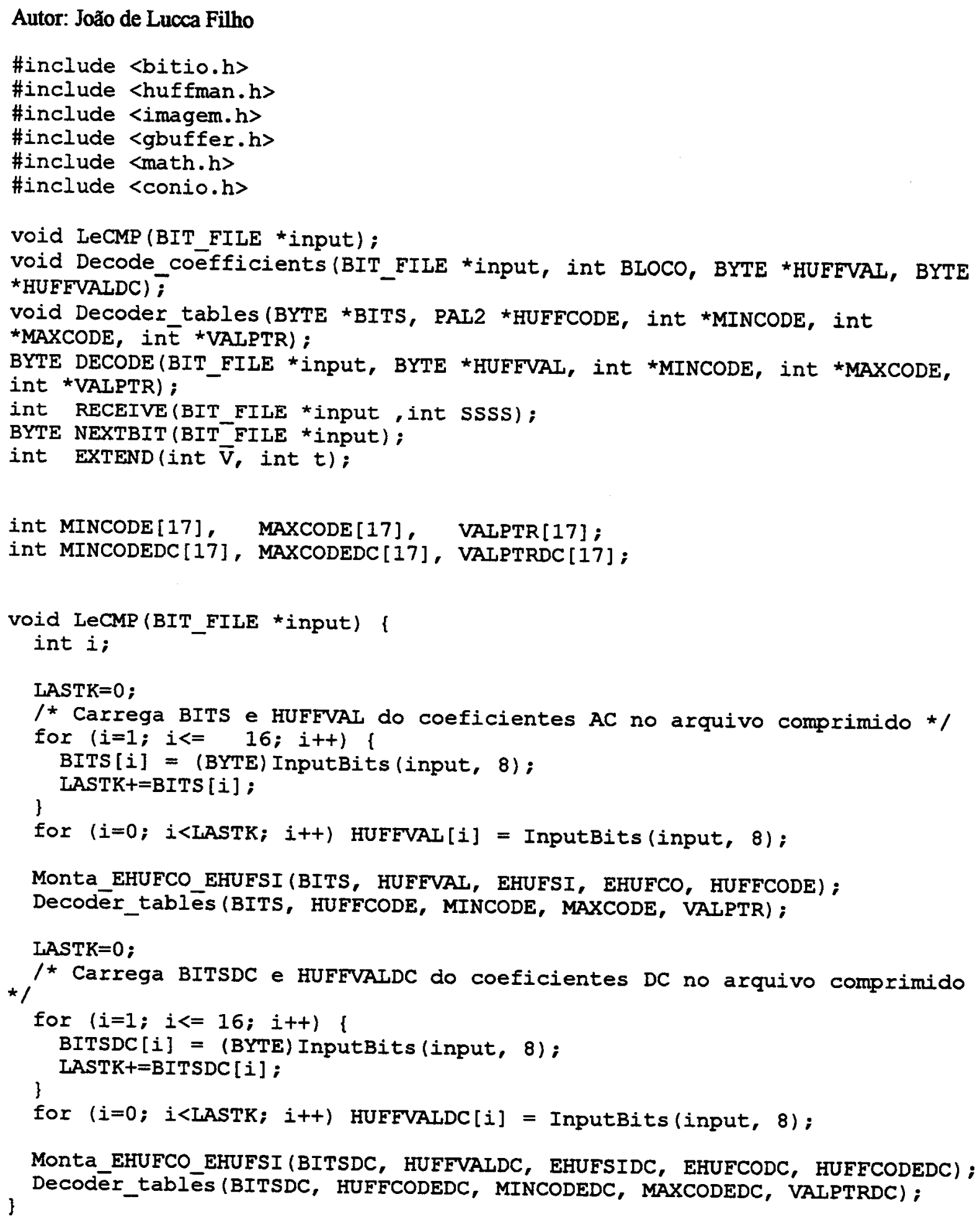


xxviii

IFCMP.C (continuação)

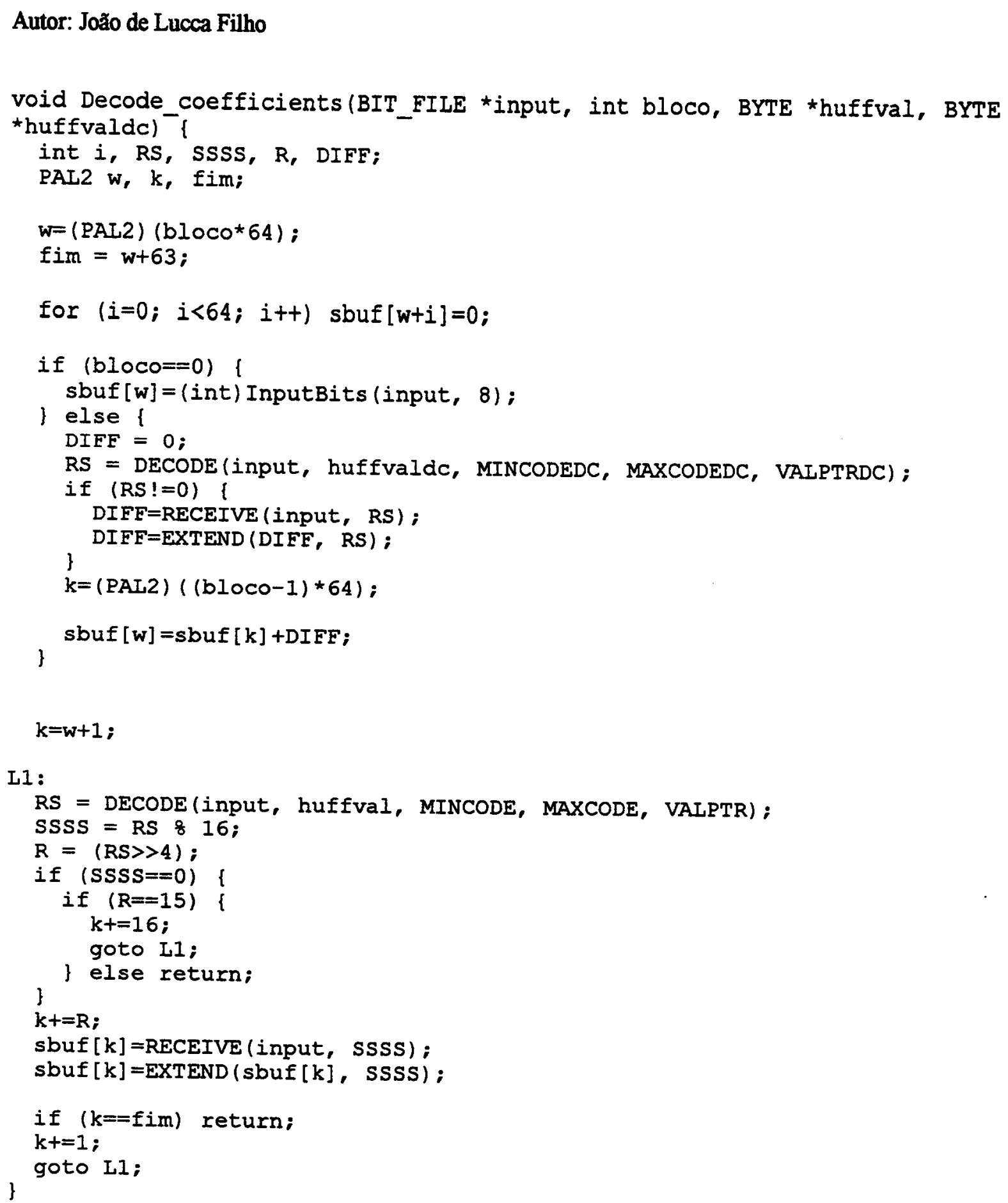




\section{IECAMP.C (continuação)}

Autor: João de Lucca Filho

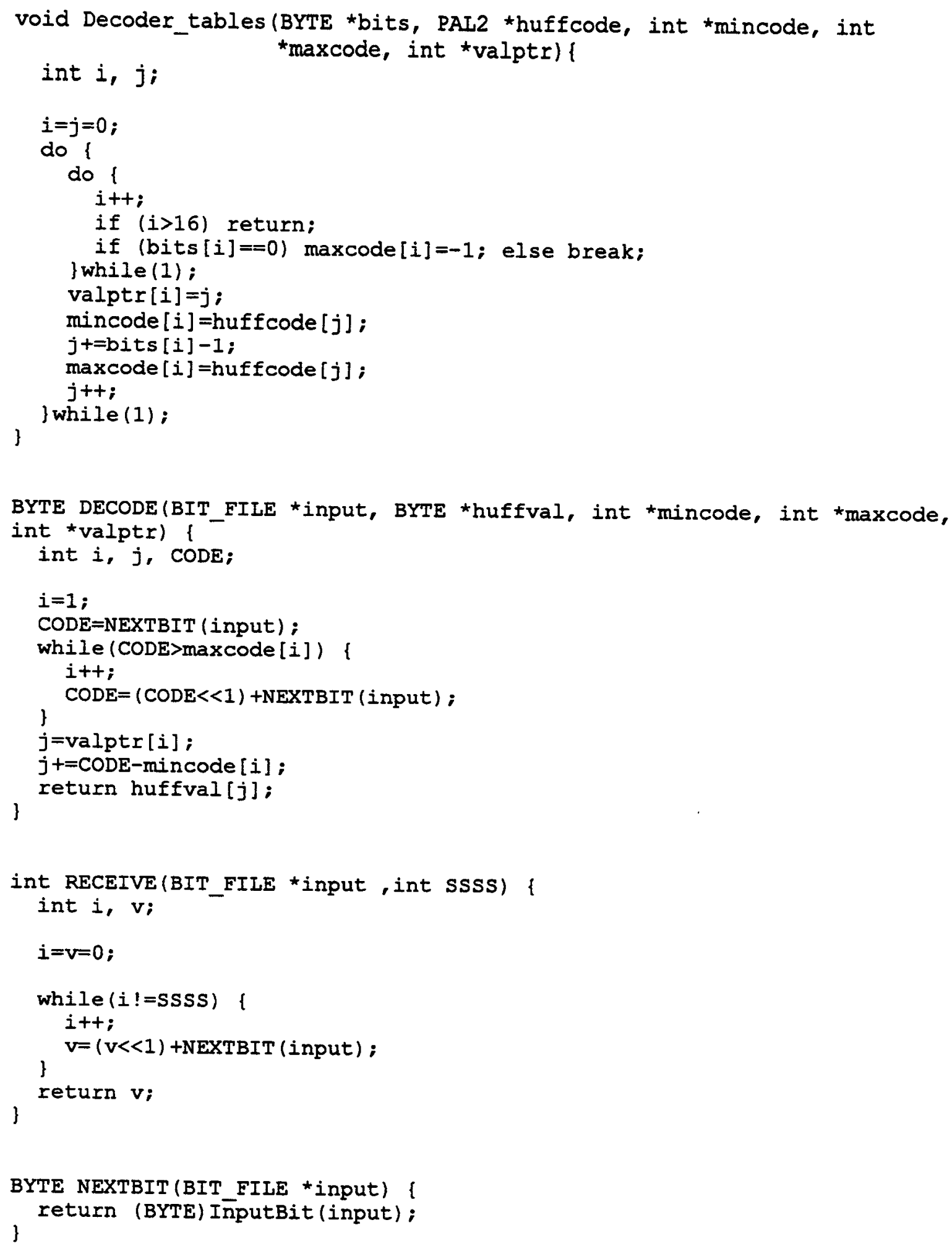




\section{LECMP.C (continuação)}

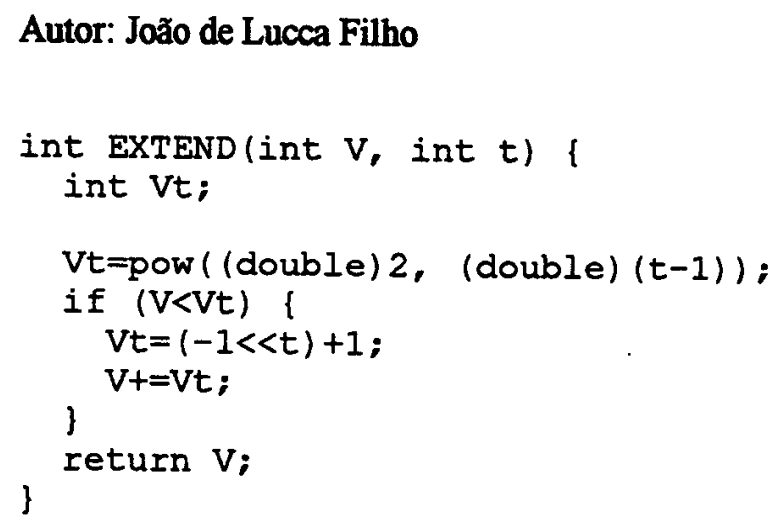


IDCT.C (continuação)

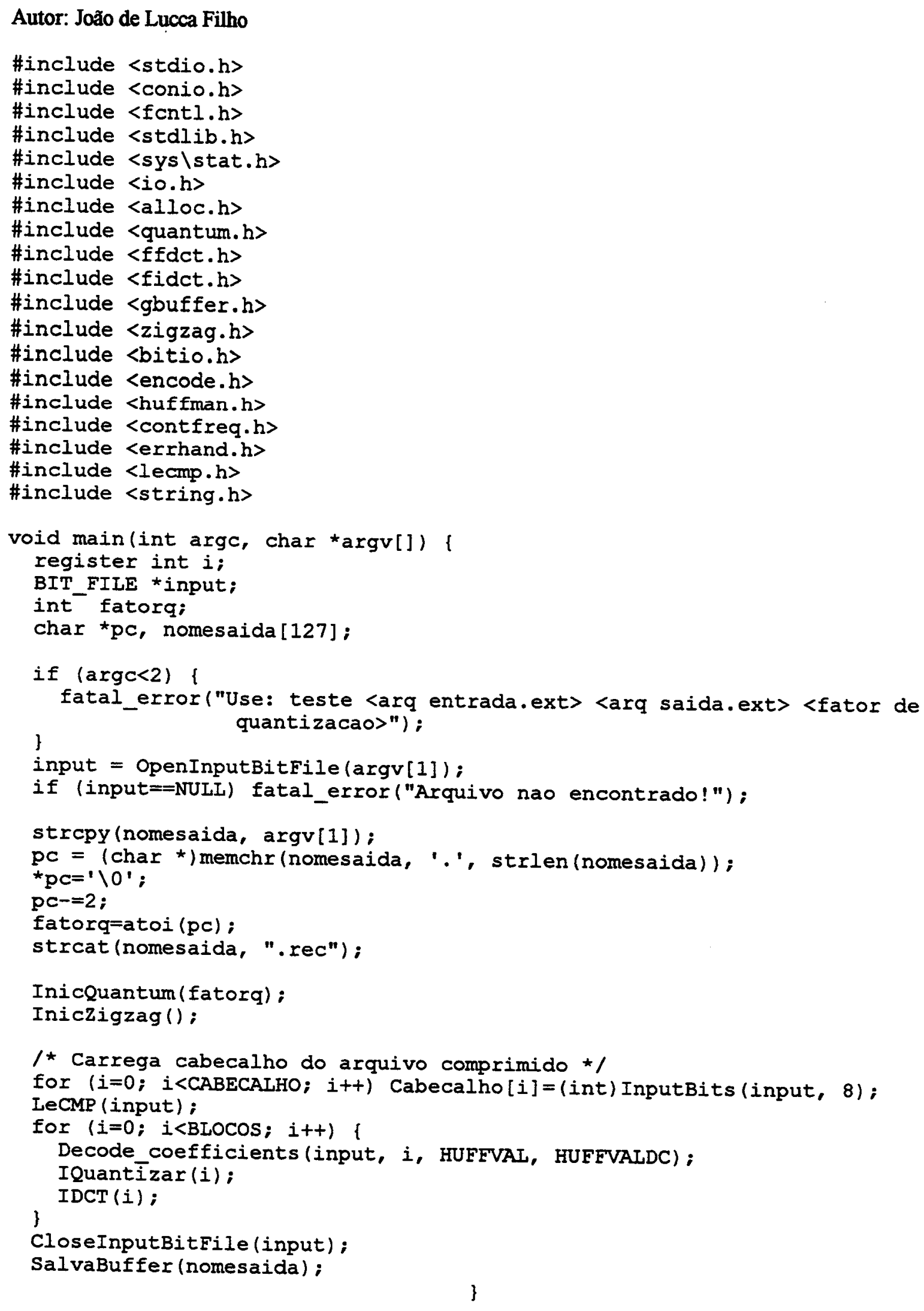




\section{FIDCT.C}

Autor: João de Lucca Filho

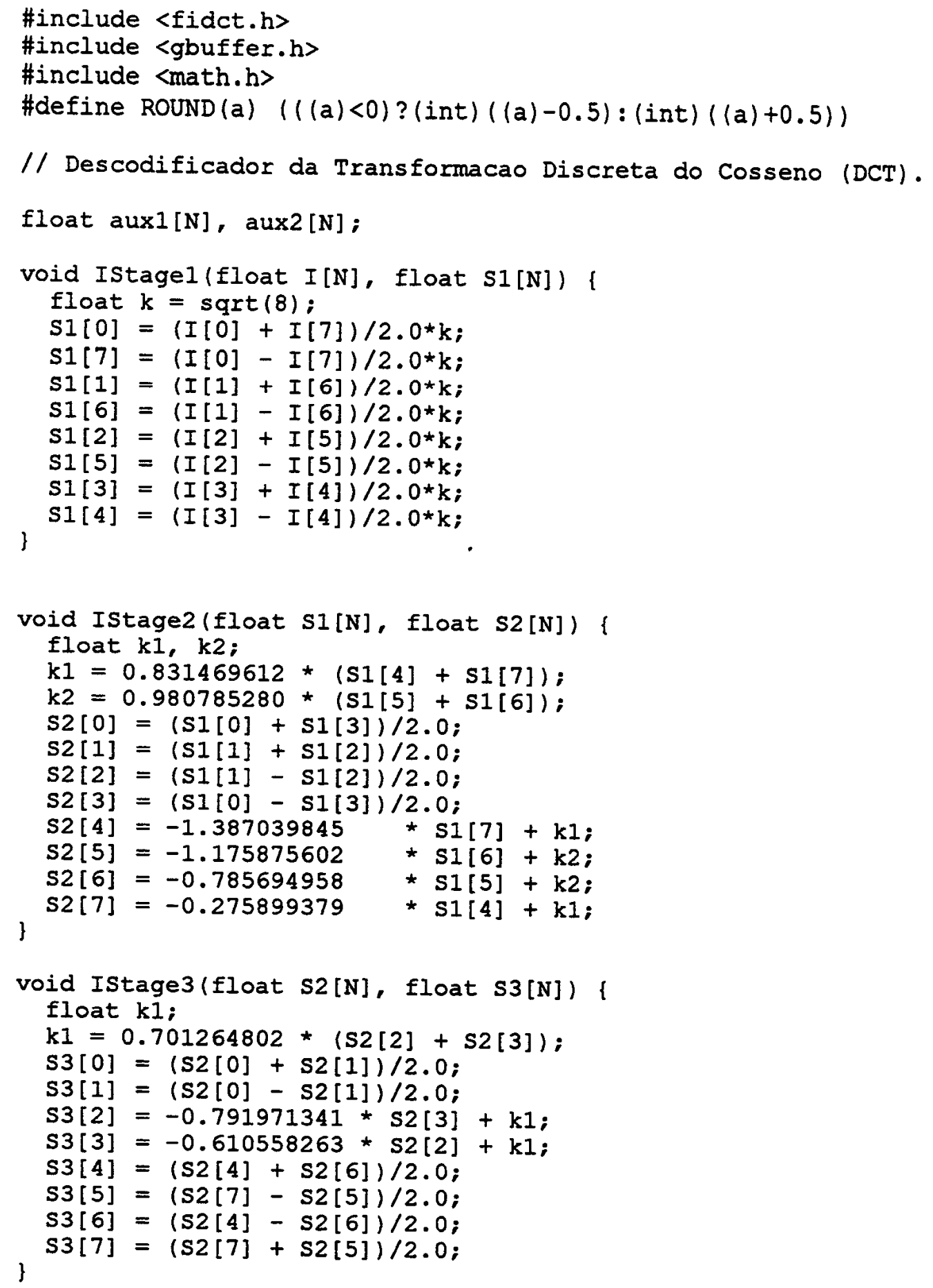


xxiv

\section{// BITIO.H}

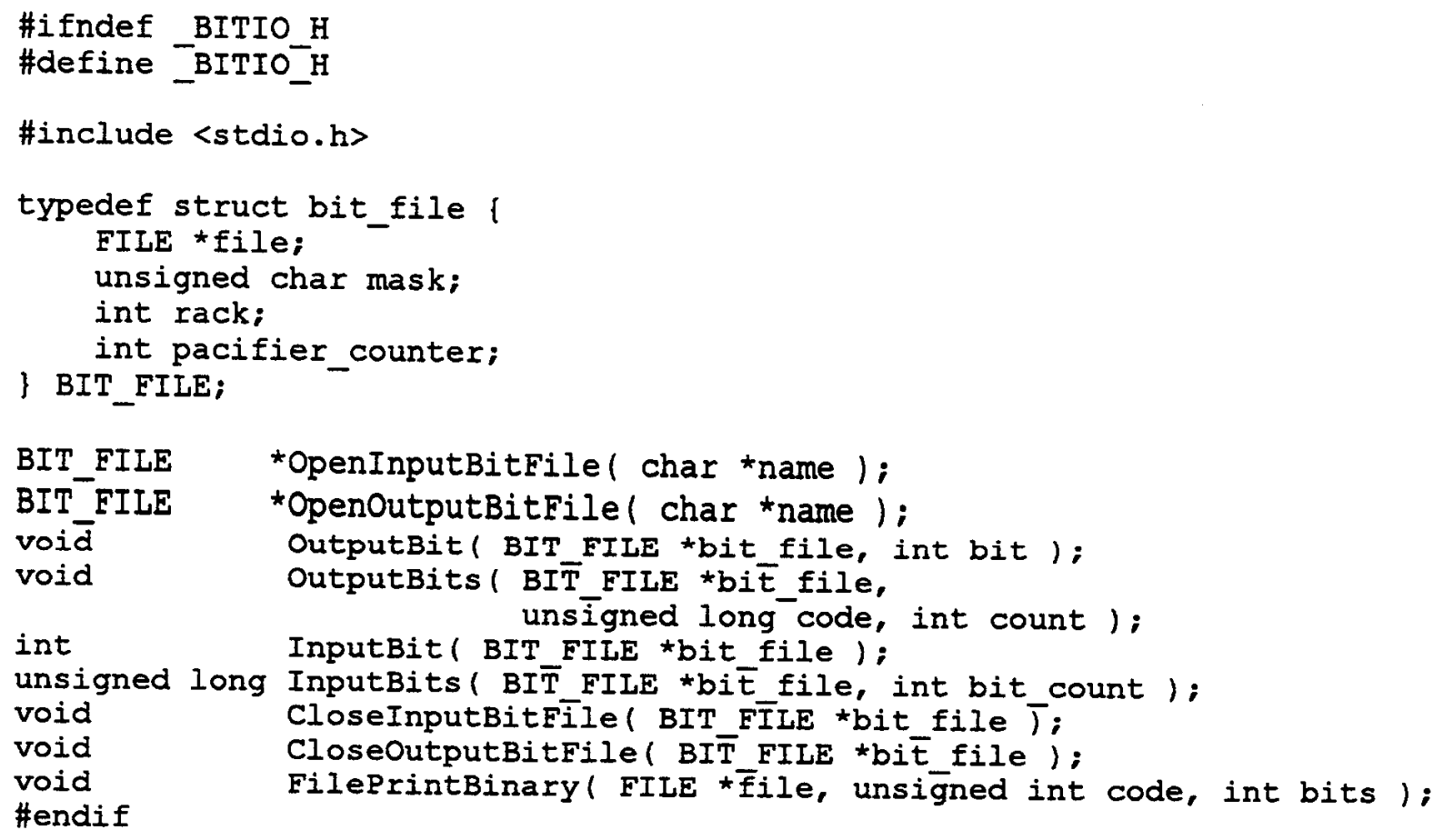




\section{// CONTFREQ.H}

\#ifndef CONTFREQ

\#define CONTFREQ

void ContaFreq(int bloco);

void InicFreq(void);

\#endif

\section{// DPCM.H}

\#ifndef DPCM

\#define DPCM

void DPCM (int DC, unsigned int *addbits, int *sSSS); \#endif

\section{// ENCODE.H}

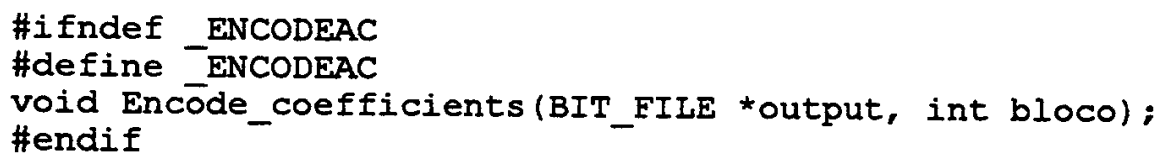

\section{// ERRHAND. H}

\#ifndef ERRHAND $\mathrm{H}$

\#define ERRHAND_H

void fatal_error ( char *fmt, ... ) ;

\#endif

\section{// FEDCT.H}

\#include <imagem. h>

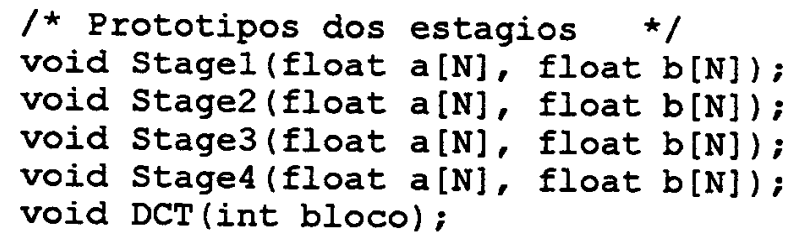




\section{// FIDCT.H}

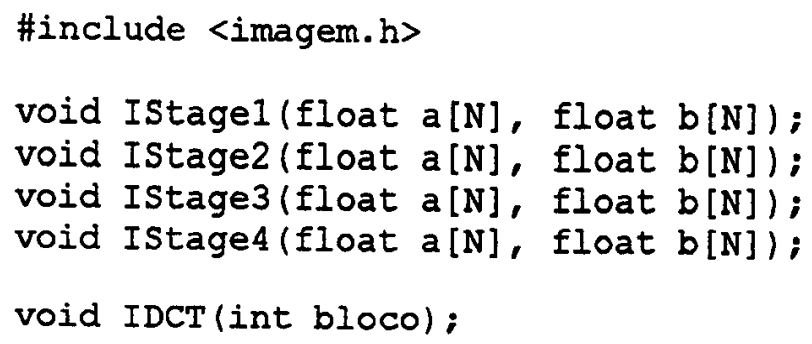

\section{// GBUFEER.H}

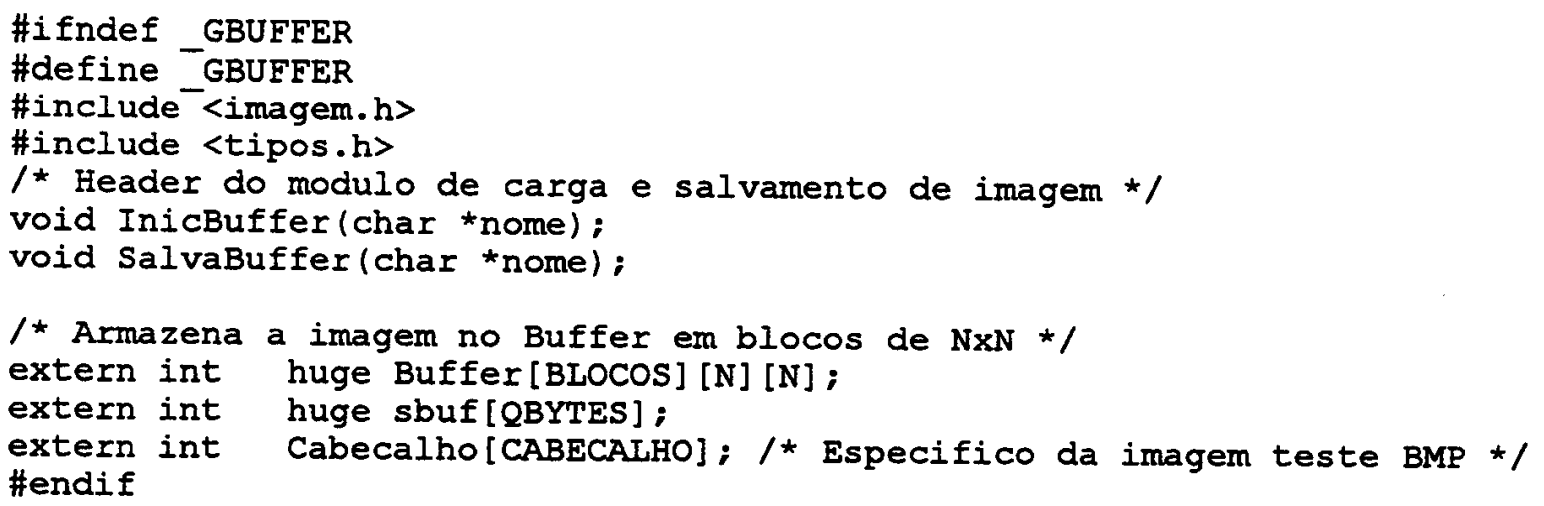

\section{// HUEEMAN. H}
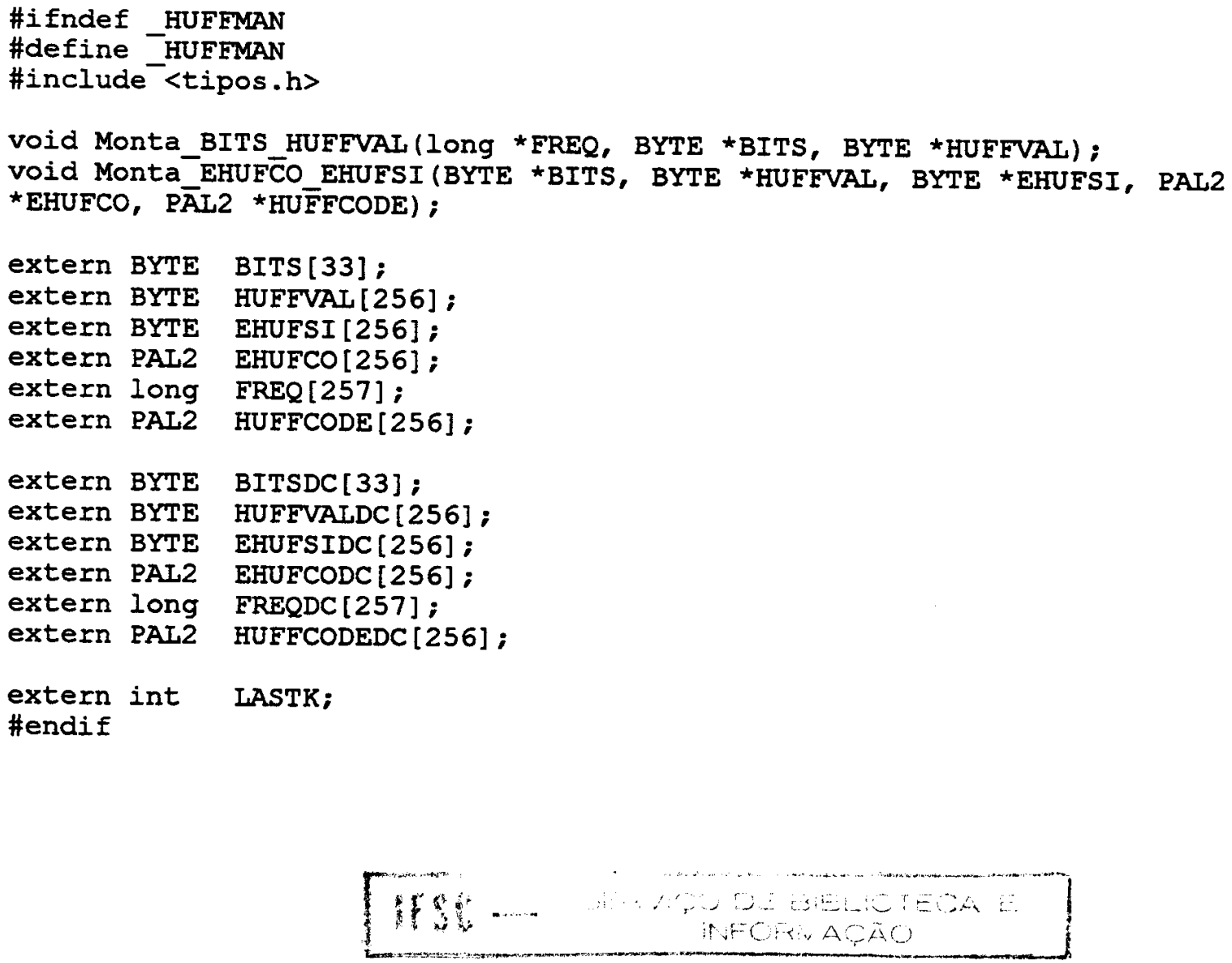
xxxvii

\section{// IMAGEM.H}

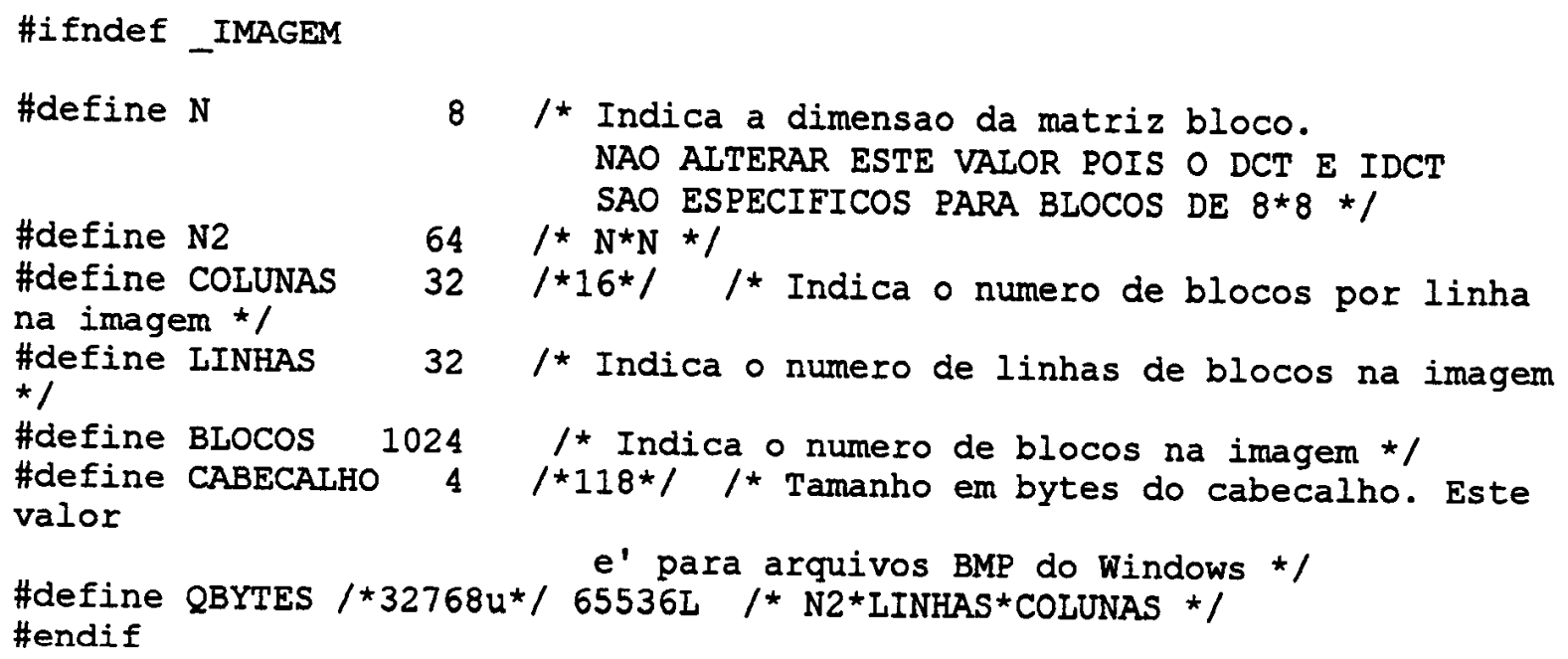

\section{// LECMP.H}

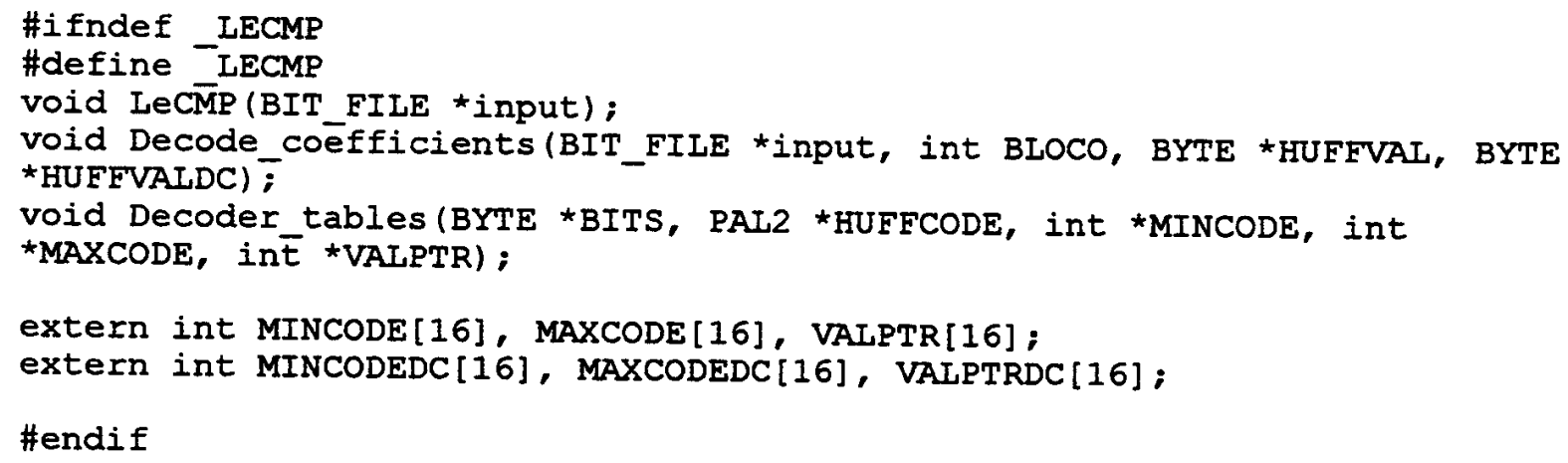

\section{// QUANTUM.H}

\#include <imagem.h>

// Heder do modulo de Quantizacao

void InicQuantum(int qualidade);

void Quantizar(int bloco);

void IQuantizar(int bloco); 


\title{
// TIPOS.H
}

\#ifndef_TIPOS

\#define TIPOS

\#define BYTE unsigned char

\#define PAL2 unsigned int

\#define PAL4 unsigned long

\#endif

\section{// ZIGZAG.H}

\author{
\#ifndef ZIGZAG \\ \#define ZIGZAG

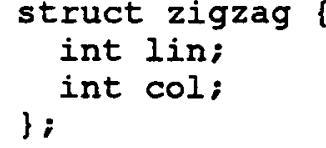

\#include $<$ imagem.h>

extern struct zigzag ZigZag[N2];

void Iniczigzag(void);

\#endif 